LOCKHEED MARTIN

ENVIRONMENTAL RESTORATION PROGRAM

\section{Multi-Point Injection Demonstration for Solidification of Shallow Buried Waste at Oak Ridge Reservation, Oak Ridge, Tennessee}

\section{RECEIVED NOV $O>1996$ \\ OSTI}

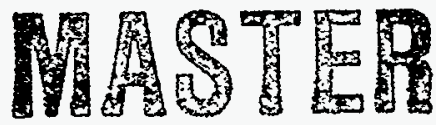

This document has been approved by the ORNL Technical Information Office for release to the public. Date: $8 / 12 / 96$

DISTRIBUTION OF THIS DOCUMENT IS UNLRATED ENERGYSYSTEMS

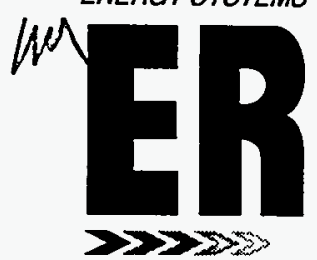


Ground Environmental Services, Inc. and

Gilbert Commonwealth Engineers and Consultants

contributed to the preparation of this document and should not be considered an eligible contractor for its review.

This report has been reproduced direotly from the best available copy.

Available to DOE and DOE contractors from the Office of Scientific and Technical Information, P.O. Box 62, Oak Ridge, TN 37831 ; prices available from 615-576-8401. Available to the public from the National Technical Information Service, U.S. Department of Commerce, 5285 Port Royal Rd., Springfield, VA 22161 . 
Energy Systems Environmental Restoration Program ORNL Environmental Restoration Program

Multi-Point Injection Demonstration for Solidification of Shallow Buried Waste at Oak Ridge Reservation, Oak Ridge, Tennessee

Date Issued-October 1996

Prepared by Ground Environmental Services, Inc. 200 Berry Glen Court Alpharetta, Georgia 30202

\section{Prepared for} U.S. Department of Energy

Office of Environmental Restoration and Waste Management under budget and reporting code EW 20

Environmental Restoration Program OAK RIDGE NATIONAI LABORATORY

Oak Ridge, Tennessee 37831-6285 managed by

LOCKHEED MARTIN ENERGY SYSTEMS, INC.

for the

U.S. DEPARTMENT OF ENERGY under contract DE-AC05-84OR21400 


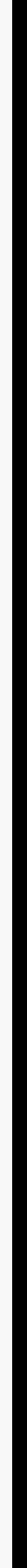




\section{DISCLAIMER}

Portions of this document may be illegible in electronic image products. Images are produced from the best available original document. 
The information presented in this report discloses the basic elements of the multipoint injection (MPI) process. This technology was invented by Dr. Joseph L. Kauschinger and is considered proprietary and trade secrets. The MPI process is currently undergoing patent application review. The information presented in this document is for the exclusive use of Gilbert Commonwealth, Jacobs Engineering, Lockheed Martin Energy Systems, and The Department of Energy for evaluating the MPI process for the particular application of solidifying the trenches at operable unit 1 at the Lockheed Martin Energy Systems Y-12 Plant. Prior to Jacobs Engineering request of Ground Environmental Services, Inc. (GES) to demonstrate the MPI technology, GES secured private funding for reducing the MPI technology to practice. The essential features of MPI as a general purpose delivery system were successfully proven at work conducted in Duncan, Oklahoma. The submission of this report SHALL NOT BE construed to provide a LICENSE FOR USE OF THE MPI TECHNOLOGY.

This notice MUST accompany any use or publication of this report.

ALL RIGHTS RESERVED

PATENT PENDING

MPI IS A TRADEMARK OF GES 


\section{PREFACE}

As part of the Comprehensive Environmental Response, Compensation, and Liability Act process for remediation of Waste Area Grouping (WAG) 6 at Oak Ridge National Laboratory, a public meeting was held on the proposed plan. It was recognized that contaminant releases from WAG 6 posed minimal potential risk to the public and environment. The U.S. Department of Energy (DOE) in conjunction with the U.S. Environmental Protection Agency and the Tennessee Department of Environment and Conservation agreed to defer remedial action at WAG 6 until higher risk release sites were first remediated.

DOE and the regulators also recognized the need for technology development for final remediation of WAG 6. Consequently, the record of agreement for the WAG 6 deferred action established the WAG 6 Remedial Technology Research, Development, and Demonstration Program for the Environmental Restoration (ER) Program to develop and demonstrate innovative technologies for the final remediation of WAG 6 and other ER contaminated sites.

This report presents the results of a study to evaluate the feasibility of various injection techniques and types of grout for the in situ stabilization of simulated buried heterogenous waste trenches. Additional funding was contributed by the Lockheed Martin Y-12 site ER Program to include the demonstration of multi-point injection (MPI), a promising proprietary high-pressure in situ delivery/mixing system developed by Ground Environmental Services (GES). The ER-sponsored MPI study included participation from GES, Christensen Boyles Corporation (CBC), and Scientific Ecology Group (SEG). The scope of the MPI study included the development and full-scale testing of injection equipment at the CBC Salt Lake City, Utah, facility and a full-scale demonstration at the SEG cold test site in Oak Ridge, Tennessee. This report documents the results of the MPI study. A separate report will be issued to document the results of the overall in situ grouting study. 


\section{CONTENTS}

Page

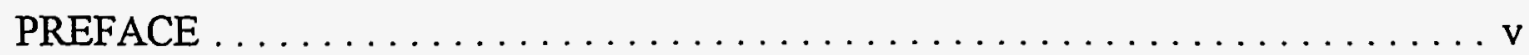

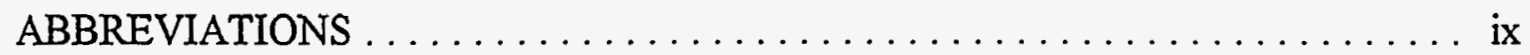

EXECUTIVE SUMMARY $\ldots \ldots \ldots \ldots \ldots \ldots \ldots \ldots \ldots \ldots \ldots \ldots \ldots \ldots \ldots \ldots$

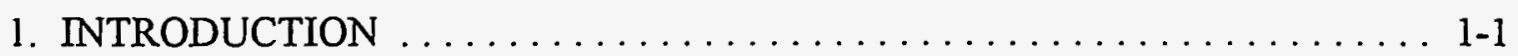

1.1 GENERAL FEATURES OF THE MPI TECHNOLOGY . . . . . . . $1-1$

1.2 PROPRIETARY NATURE OF MPI TECHNOLOGY $\ldots \ldots \ldots \ldots \ldots .1-2$

1.2.1 Duncan, Oklahoma: MPI Reduction to Practice ........... 1-3

1.2.2 Conductivity Tests: Monolith No. 3 ................ 1-4

1.2.3 Dissection of Duncan, Oklahoma, Solidified Waste ......... 1-6

1.3 GENERAL APPLICATIONS OF MPI TECHNOLOGY FOR

REMEDIATION ........................... 1-6

1.3.1 Cellular Encapsulated Waste $\ldots \ldots \ldots \ldots \ldots \ldots \ldots \ldots \ldots$ 1-6

1.3.2 Panel Cutoff Wall . . . . . . . . . . . . . . . . . . . .

1.3.3 Support of In Situ Vitrification ................. 1-7

1.3.4 Other Applications of MPI as a General Purpose Delivery System . . 1-8

2. IMPLEMENTATION OF MPI PROCESS $\ldots \ldots \ldots \ldots \ldots \ldots \ldots \ldots \ldots .2-1$

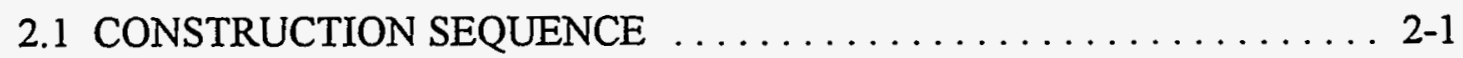

2.1.1 Percussion Installation of "Cuttable" Casing ............ 2-1

2.1.2 Lifting Frame Assembly/Load Special Jetting Tool . . . . . . . . 2-3

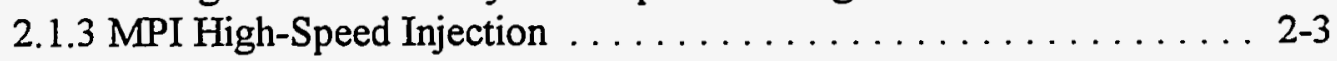

3. MPI DEMONSTRATION, SALT LAKE CITY, UTAH $\ldots \ldots \ldots \ldots \ldots \ldots$ 3-1

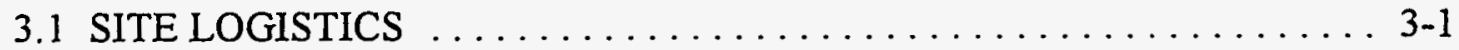

3.1.1 Equipment Verification Setup $\ldots \ldots \ldots \ldots \ldots \ldots \ldots \ldots \ldots \ldots \ldots, 2$

3.1.2 Barrel-Cutting Pit $\ldots \ldots \ldots \ldots \ldots \ldots \ldots \ldots \ldots \ldots \ldots \ldots \ldots \ldots \ldots .2$

3.1.3 Logistics of $P$ it 1 : Waste Interference . . . . . . . . . . . 3-3

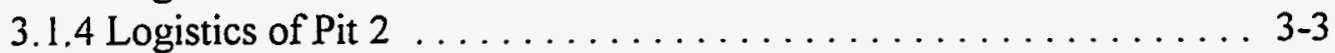

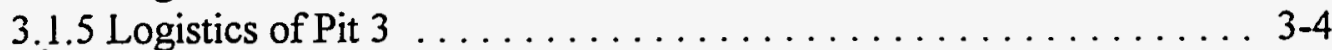

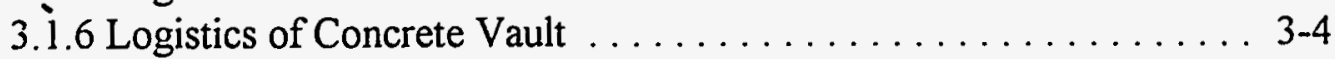

3.2 EQUIPMENT VERIFICATION $\ldots \ldots \ldots \ldots \ldots \ldots \ldots \ldots \ldots \ldots \ldots \ldots \ldots \ldots \ldots \ldots$

3.2.1 MPI Monitor . . . . . . . . . . . . . . . . . . . . . . .

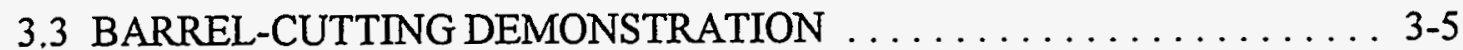

3.3.1 Jetting Inside Single-Steel Barrels $\ldots \ldots \ldots \ldots \ldots \ldots \ldots \ldots \ldots$ 3-6

3.3.2 Jetting Outside Twin Barrels $\ldots \ldots \ldots \ldots \ldots \ldots \ldots \ldots \ldots . . \ldots \ldots$ 
3.4 FORMATION OF A HOMOGENEOUS MONOLITH: PIT $2 \ldots \ldots \ldots .3-9$

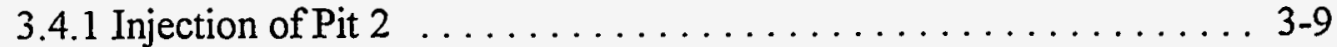

3.4.2 Conductivity Testing of Pit 2 Monolith $\ldots \ldots \ldots \ldots \ldots \ldots .3-10$

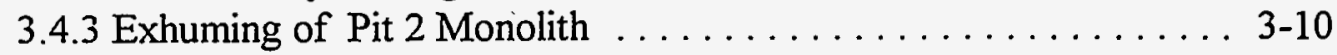

3.5 FORMATION OF A HOMOGENEOUS MONOLITH: PIT $3 \ldots \ldots \ldots$ 3-11

3.5.1 Injection of Pit $3 \ldots \ldots \ldots \ldots \ldots \ldots \ldots \ldots \ldots \ldots \ldots \ldots \ldots \ldots, 11$

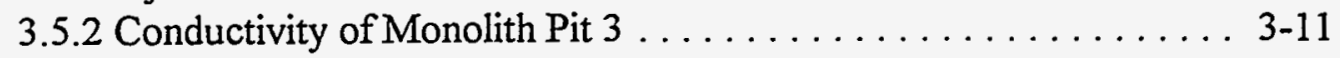

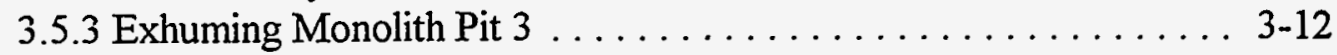

3.6 MPI INJECTION IN CONCRETE VAULT $\ldots \ldots \ldots \ldots \ldots \ldots \ldots \ldots . . \ldots \ldots$

3.6.1 MPI Injection of Concrete Vault . ................ 3-14

3.6.2 Conductivity of Monolith in Concrete Vault . . . . . . . . 3-14

3.6.3 Exhumation of Concrete Vault ............... 3-14

4. MPI DEMONSTRATION: OAK RIDGE, TENNESSEE . . . . . . . . . 4 4-1

4.1 MPI INJECTION . . . . . . . . . . . . . . . . . . . . . 4-1

4.2 INJECTION HOLE LAYOUT $\ldots \ldots \ldots \ldots \ldots \ldots \ldots \ldots \ldots \ldots \ldots, 4-2$

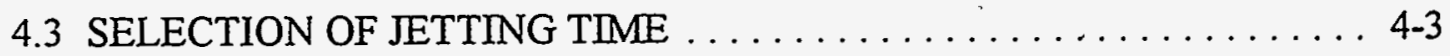

4.3.1 Use of Optical Casing and Borehole Cameras ............. 4-3

4.4 FILL/WASTE THICKNESS $\ldots \ldots \ldots \ldots \ldots \ldots \ldots \ldots \ldots \ldots, 4.4$

4.5 TREATMENT OF SAPPROLITE $\ldots \ldots \ldots \ldots \ldots \ldots \ldots \ldots \ldots, 4.4$

4.6 CONCLUSIONS SEG DEMONSTRATION $\ldots \ldots \ldots \ldots \ldots \ldots \ldots$. $4-5$

Appendix - Waste Formulation Basis $\ldots \ldots \ldots \ldots \ldots \ldots \ldots \ldots \ldots \ldots \ldots \ldots \ldots \ldots \ldots$

Table - Hydraulic Conductivity Values Measured on the Municipal Waste Solidified Using the Multi-Point Injection Process in Tank 3, Duncan, Oklahoma . . . 1-5 


\section{ABBREVIATIONS}

GES

HDPE

INEL

Jacobs

MPI

ORNL

SEG
Ground Environmental Servies, Inc.

high-density polyethylene

Idaho National Engineering Laboratory

Jacobs Engineering Group

multi-point injection

Oak Ridge National Laboratory

Scientific Ecology Group 


\section{EXECUTIVE SUMMARY}

A proprietary jet delivery system, termed: multi-point injection (MPI) was demonstrated for Lockheed Martin Energy Systems and Jacobs Engineering Group as part of a treatability study for Environmental Restoration Program activities at the Lockheed Martin Energy Systems Y-12 Plant (Y-12), in which in situ solidification of shallow buried waste is a preferred alternative for remediating the site. The MPI system is a remotely-installed, remotely-operated delivery system which has mostly low-cost, disposable equipment (plastic casing, rubber hoses, stub sections of steel pipe) which comes into direct contact with any contamination. Workers and major capital equipment are situated in the support zone.

The robustness of the MPI system which was quantified during this demonstration include:

1) Creation of several low-conductivity monoliths starting with randomly placed shallow buried waste placed into pits excavated in the ground. Conductivities on the order of 1.0 to $10.0 \times \mathrm{E}-07 \mathrm{~cm} / \mathrm{sec}$ were usually measured.

2) Injection hole spacing was large (usually 5 to 7 feet) when compared to other in situ solidification technologies, such as conventional grouting or jet grouting.

3) Capabilities of the MPI drive system to install high-density polyethylene plastic casing through at least 15 feet of miscellaneous shallow buried waste, with up to 75 percent by weight of metal.

4) In light of the in situ formation of homogeneous low-conductivity monoliths, the volume of construction-generated waste appears to be reasonable, and on the order of 25-30 percent of the total volume of waste to be treated. 


\section{INTRODUCTION}

The multi-point injection (MPI) technology is a precision, high-velocity jetting process for the in situ delivery of various agents to treat radiological and/or chemical wastes. A wide variety of waste forms can be treated, varying from heterogeneous waste dumped into shallow burial trenches to contaminated soils consisting of sands/gravels, silts/clays and soft rock. The robustness of the MPI system is linked to its broad range of applications which vary from in situ waste treatment to creation of both vertical and horizontal barriers, (see Section 1.3). The only major constraint on the type of in situ treatment which can be delivered by the MPI system is that agents must be in a slurry form.

One of the most important features of the MPI process for in situ treatment of radiological waste is associated with the safety aspects of the injection procedure. All construction activities associated with the MPI process can be conducted from a remote location using common construction equipment. There is no need for expensive robotics for remote implementation of the MPI method. Therefore, loss of expensive capital equipment due to contamination is highly unlikely since the major equipment is located in the support zone. Worker safety is assured since no workers are required to be in close proximity to the waste or point of treatment.

The flexibility and safety aspects of the MPI system led Jacobs Engineering Group (Jacobs) to select the MPI system for demonstration as part of a treatability study for the remediation of buried waste at the Bear Creek Valley, Operable Unit-1 (OU-1) on the Lockheed Martin Energy Systems Y-12 site. Jacobs had identified as part of the remedial investigation/feasibility study process that in situ solidification potentially offered a costeffective solution for remediating the trench waste in burial ground BG-C east and West. Jacobs requested Ground Environmental Services (GES) to demonstrate the in situ solidification capabilities of the MPI system on a surrogate shallow buried waste. This technology demonstration allowed Jacobs to witness the full deployment of the MPI process under non-radiological and controlled conditions. However, all the capital equipment, construction methods and activities which would be used for production work at the Y-12 site BG-C east and west burial grounds were used.

\subsection{GENERAL FEATURES OF THE MPI TECHNOLOGY}

The uniqueness of the MPI process is better understood if the technology is discussed in relationship to the sequence of construction activities used to deploy the technology. The following list of activities encompasses the basic features of the MPI process. A more detailed discussion is presented in Section 2.0. The MPI process involves the following general steps:

- A casing which can be cut via a jetstream is installed through the buried waste and/or contaminated soil. The casing is disposable and all elements of the casing are left in the ground. The "cuttable" casing is not destroyed during the high velocity injection stage. 
Thus multiple re-entries into the cased hole can be made as long as solidification agents have not hardened within the borehole. For instance, the MPI system can be used to perform multiple injections of peroxides to chemically oxidize organics.

- The remote installation of the "cuttable" casing allows additional site investigative work to be conducted to confirm the types of waste (chemical, radiological) to be treated. The MPI drive system resembles a cone penetrometer, which can be easily adapted to deploying field instrumentation. Rapid interpretation of the data may require the need for a laboratory to perform close field support activities. Since the MPI system is a generalpurpose delivery system, the actual remediation to be performed can be modified if the site-specific investigation uncovers widely changing conditions than were revealed during previous investigations. Furthermore, due to the injection staging of MPI, the type of injection can be changed at any location to treat local "hot" spots.

- The next activity associated with the MPI process requires placing a lifting device over each cuttable casing. The lifting device not only serves to remotely lift the MPI injectors but may also provide local containment over the area to be treated. The lifting frame is very low cost and can be abandoned in place; i.e,. no decontamination or disposal required.

- A hose-suspended jetting tool is attached to a lifting cable and the unit is placed inside of each "cuttable" casing. Jet nozzles are strategically placed around a jetting tool (monitor) such that waste can be treated over a 360-degree area without rotating the monitor. Nozzle orientations between 0 to 360 degrees have been successfully used for injection. The mono-directional injection allows the cutting energy of the jets to be concentrated upon a target and allows more effective cutting and mixing of miscellaneous waste when compared to a rotating jet or conventional low-pressure injection. The placement of multiple jets around the monitor is done to simulate rod rotation. Conventional drilling equipment must be computer controlled to inject material over varying angles of drill rod rotation. The hose-suspended monitor does NOT require drilling equipment (or personnel) to be at the surface over the point of injection to raise or lower the monitor.

- All multiple points are injected over a limited thickness to form a plate of treatment. Thereafter, the hose-suspended monitors are lifted to the next level which requires treatment. Each monitor is sequentially injected until the entire plan area has been done; i.e, a second plate of treatment. The process of lifting all the monitors and injecting is repeated until the entire thickness of the waste has been treated. The types of treatment

can be varied from elevation to elevation to reflect the local waste types detected during the installation of casing under step 2 above.

\subsection{PROPRIETARY NATURE OF MPI TECHNOLOGY}

The above discussion discloses the basic elements of the multi-point injection process. This technology was invented by Dr. Joseph L. Kauschinger and is considered proprietary and 
a trade secret. The MPI process is currently undergoing patent application review. GES secured private funding for reducing the MPI technology to practice. The essential features of MPI as a general purpose delivery system were successfully proven at work conducted in Duncan, Oklahoma. Some of the details of this work are presented in the next section.

\subsubsection{Duncan, Oklahoma: MPI Reduction to Practice}

The commercial work conducted in Duncan involved using the MPI process to inject a cement-based grout into heterogenous waste contained inside of steel B-25 boxes. The object of this project was to use the MPI process to solidify municipal waste to form a homogeneous monolith of low conductivity for possible landfill disposal. The highly- containerized waste form and disposal units solidified at Duncan are shown in the series of photographs contained in Figures 1(a) to 1(d). Three B-25 boxes, each being $5 \mathrm{ft}$. wide $x 10 \mathrm{ft}$. long $\times 3 \mathrm{ft}$. deep, contained miscellaneous solid waste to a depth of about 2.5 feet. Six inches of soil was placed over the waste to enhance the strength of the solidified waste. The soil caused the waste to settle by about 4 inches. The thickness of the various layers of soil and waste deposited inside of the B-25 box are illustrated in the profile drawn in Figure 2. Two- to fourinch diameter PVC (cuttable casing) were installed within the waste with about five feet of spacing along the center line of the waste, shown in the plan view of Figure 2. Each MPI injector was used to solidify about $3 \mathrm{cu}$. yds. of waste and soil.

The first two steel boxes were solidified using a cement-based grout under about 7,000 psi. Each MPI jetting monitor was operated for approximately 60 seconds. After injecting a single stage, the two monitors were lifted to the next level. Several levels of treatment were performed. Operational problems were encountered with clumps of cement clogging the injectors. This was probably caused by the poor quality of the bulk-delivered cement. It was decided to use other nozzles and pressures to overcome the operational problems which were occurring.

The extremes of jetting pressures $(3,000$ to $11,000 \mathrm{psi})$ and nozzle configurations were successful in cutting small diameter holes ( 1 in. to 4 in. ) through the walls of 55-gallon steel drums in a reasonable time ( 5 to 90 seconds). The standoff distance from the jet to the steel drum varied between 2 to 20 inches, with the shorter distance producing a hole in the least amount of time. The photograph in Figure 3 illustrates the barrel cutting ability of a hosesuspended MPI monitor.

The ability of the MPI system to puncture robust containers is an important characteristic if the delivery system is to function in an efficient manner. The efficiency is linked to the spacing between injection points. Robust containers (such as steel barrels) would tend to deflect a jet stream at slow speed, which could create shadows of untreated waste at the backside of the container. The ability of the MPI process to cut or not cut a steel barrel are scrutinized in greater detail under Section 3.0, which discusses the Salt Lake City, Utah, demonstration performed for the Y-12 site at Oak Ridge, Tennessee. 
During the Duncan project, conventional jetting technology was also used to examine the capabilities of a rotating jet to cut through a steel drum at a standoff distance of 10 inches; i.e, jet at the center of a conventional 55-gallon steel drum. Even through a jetting pressure of 11,000 psi was utilized, the rotating jet (25 rpms) could not focus its cutting energy to produce a hole in the wall of the steel drum. The maximum jetting time was about 60 seconds. The implication of this result is related to the maximum injection hole spacing which is possible using conventional jetting technology. If there are a significant number of "robust" containers within the shallow buried waste, then a narrow injection hole pattern ( 2 feet) must be used for conventional jetting. If the robust containers are NOT intact (releasing their contents) then the current jet grouting technology cannot be efficiently used to overcome the shadowing effects which arise due to metal containers blocking the delivery of the stabilizing agents. This is not a limitation of the MPI system, wherein injection hole spacing between five to eight feet is possible for effective delivery of various agents within miscellaneous buried waste. Larger spacing of injection holes are possible under other applications.

Once the MPI process was completed at Duncan, the solidified blocks of municipal waste were allowed to hardened for approximately one month. Thereafter, coreholes were bored into the waste for obtaining preliminary information on the continuity of the solidification. The corehole location drilled into Tank 3 is shown in Figure 2. The waste solidified in Tank 3 was treated the most uniformly. It was decided to conduct detailed conductivity tests of Monolith No. 3.

\subsubsection{Conductivity Tests: Monolith No. 3}

The MPI process is conducted using mono-directional jets which are spaced at discrete intervals along the jetting monitor. The jetting monitor is also lifted in discrete intervals. It was of interest during the MPI reduction to practice to verify that the MPI process caused enough turbulent action to create a "jet-washing machining" effect. This mechanism is the key to homogeneously mixing and cutting the waste for intimate contact with the solidification agents. Quantification of the homogeneity of monolith No. 3 was conducted to detect any minor defects in the treatment, since the process involves discrete increments of injection. The conductivity testing would validate the current practice of the MPI technology to form homogeneous monoliths of low conductivity.

After an extensive examination of hydraulic conductivity testing procedures and theories used to evaluate conductivity, the methodology developed at the University of Guelph, Toronto, Canada, was selected for use. The interested reader is referred to the literature cited in the reference section for understanding the procedure and data reduction required for calculating the hydraulic conductivities measured using the Guelph permeameter. The testing procedure utilizes a constant head versus flow measurement. Two sets of head-flow measurements were taken for calculating a single value of conductivity. This procedure corresponds to the more rigorous form of the theory developed at Guelph University. The two heads selected for the tests corresponded to 10 and $15 \mathrm{~cm}$. (4-6 inches). This water depth would adequately cover the sidewalls of the borehole and allow detection of any minor 
defects. The photograph in Figure 4 illustrates the experimental setup used for measuring the hydraulic conductivity of waste solidified inside of Monolith No. 3 .

Three coreholes (designated as 31,32, and 33) were drilled into the waste for conducting conductivity tests (see plan view of B-25 box illustrated previously in Figure 2). The testing procedure for each hole involved coring a limited distance into the waste, perform a conductivity test (typically two days per conductivity measurement), and then core a deeper hole into the waste, and perform other conductivity tests. Although this incremental procedure is very time-consuming, it allows a specific zone of solidified waste to be tested. Three conductivity tests, with three levels each, were performed inside each borehole. Level A corresponds to the uppermost level, Level B is intermediate in depth, and Level C is near the bottom of the monolith. The numerical depths at which the nine conductivity tests were conducted are listed in the table below along with the compiled values for conductivity. The first tests were typically done at about a 19-inch depth (below the top of the monolith). This location is near the original contact of the soil cover/waste. The data in the table indicate that at two locations $(32 \mathrm{a}, 33 \mathrm{a})$ the conductivity was around $1.0 \times \mathrm{E}-06 \mathrm{~cm} / \mathrm{sec}$. The conductivity measured at borehole location 31 a was greater (more pervious). The reason for this higher measurement is related to stopping the MPI injection below waste/soil contact. It was of interest to examine the influence which stopping the injection "short" of completion had upon the conductivity. The other conductivity data listed in table indicate that the monolith was of relatively low conductivity with eight of the nine conductivity values being between 1.0 to $10.0 \times \mathrm{E}-07 \mathrm{~cm} / \mathrm{sec}$.

Table. Hydraulic Conductivity Values Measured on the Municipal Waste Solidified Using the Multi-Point Injection Process in Tank 3, Duncan, Oklahoma

\begin{tabular}{|c|c|c|}
\hline Hole ID & $\begin{array}{c}\text { Test Depth } \\
\text { (in) }\end{array}$ & $\begin{array}{c}\text { Hydraulic Conductivity } \\
\text { (cm/sec) }\end{array}$ \\
\hline $31 \mathrm{a}$ & 19 & $1.9 \times$ E-04 \\
\hline $31 \mathrm{~b}$ & 26 & $1.0 \times$ E-06 \\
\hline $31 \mathrm{c}$ & 32 & $4.2 \times \mathrm{X}$-07 \\
\hline & & $1.7 \times$ E-06 \\
\hline $32 \mathrm{a}$ & 19 & $1.3 \times$ E-06 \\
\hline $32 \mathrm{~b}$ & 27 & $6.2 \times$ E-07 \\
\hline $32 \mathrm{c}$ & 31 & $1.4 \times$ E-06 \\
\hline & & $1.2 \times$ E-07 \\
\hline $33 \mathrm{a}$ & 16 & $2.7 \times$ E-06 \\
\hline $33 \mathrm{~b}$ & 23 & \\
\hline $33 \mathrm{c}$ & 30 & \\
\hline
\end{tabular}




\subsubsection{Dissection of Duncan, Oklahoma, Solidified Waste}

After the conductivity tests were performed on the cemented waste formed in Monolith No. 3, a borehole camera survey was performed in all corehole holes. The camera survey indicated that the waste along the sidewalls of the borehole was well cemented. The.interior of each borehole resembled the inside of a concrete pipe.

The final examination of the solidified waste required complete dissection of all three blocks. The photographs in Figures 5(a) and 5(b) were taken of the waste treated in Tank 2. Obviously, the treatment illustrated in the photograph is very poor and the injection should be considered inadequate for forming a monolith of low-conductivity waste.

In contrast, the solidification of Block No. 3 required a concrete saw to cut the block in the transverse direction at about the one-third point. The photograph of the dissected block, shown in Figure 6 reveals two well-cemented blocks of waste, which represents the interior of the Monolith No. 3. The overall appearance of the inside and outside of the block is similar to cast concrete.

It is obvious from the above discussion that the MPI process is much more than a solidification process. The technology demonstration performed for Jacobs was only interested in examining a limited application of MPI for remediation of the burial grounds at the $\mathrm{Y}-12$ site. A brief review of the possible applications of the MPI process are presented in the next subsection.

\subsection{GENERAL APPLICATIONS OF MPI TECHNOLOGY FOR REMEDIATION}

The types of treatment which can be delivered in situ with the MPI process can vary from surfactants for in situ washing of waste, delivery of biological material and nutrients, stabilizing agents for in situ solidification of the waste, or formation of barriers (vertical, inclined, and bottom seals). The following list of MPI application varies from barrier formation to overcoming the limitations of in situ vitrification (ISV) for shallow buried waste, to formation of an in situ battery. In brief, these applications involve:

\subsubsection{Cellular Encapsulated Waste}

Cellular encapsulated waste is formed by using the MPI system to form well-defined packets or solidified cells. The hole layout and MPI injection pattern to form "cellular encapsulated waste" is schematically illustrated in Figure 7, for a typical shallow burial trench which may be about 15 feet wide. The three-row injection pattern shown on this drawing has a primary row placed along the center line of the trench with the upper and lower rows installed adjacent to the trench sidewalls. The waste cell formation is accomplished by directing the jetstreams along orthogonal lines which are parallel and transverse to the trench 
sidewalls and endwalls. The maximum distance which a jet has to project its energy to make a cell wall is half the distance from the centerline row to the outer row ( 3.75 feet for a typical trench). There are six cellular encapsulated waste forms illustrated in Figure 7. The waste internal to the cell is cut and mixed by all the jetstreams; i.e., same jetstreams used for cell formation and solidification.

Separation of the waste into individual cells leads to a very redundant system for controlling the flow of water through the buried waste. A single poorly treated cell does not cause the adjacent cells to lose their function of encapsulation and solidification. This is an essential feature of the MPI solidification since the variety and distribution of waste is very heterogeneous. It is believed that the MPI system is the only delivery system capable of forming this cellular encapsulated waste form in situ for shallow buried waste with a high level of confidence.

\subsubsection{Panel Cutoff Wall}

Panel cutoff walls can be formed using the MPI process. Based upon current knowledge, it is believed that the panel cutoff wall illustrated in Figure 8 can be formed without generating any waste to the surface. However, there may be significant ground heave, which is usually not problematic for placing barriers in a landfill.

\subsubsection{Support of In Situ Vitrification}

The MPI system can overcome the limitations of in situ vitrification for treatment of shallow buried waste. The shortfalls of ISV include: not enough "ISVable" material in waste to promote lower temperature ISV, steam generation in humid regions with possible recharge from groundwater table; i.e., permanently inundated trenches, overpressurization, and explosion of containers. The MPI solidification of shallow buried waste at a large waste area group can be done more economically than many other in situ treatments, such as in situ vitrification. Therefore, the MPI process can economically treat a large amount of trench waste. This will allow identification of a select few trenches which may be candidates for other technologies such as ISV, (which may be more appropriate for treating transuranic acid waste). The MPI process can be used as a pre-treatment for ISV, wherein the MPI process can be used to rupture containers (steel drums), fill void spaces, and produce a solidified waste form with low hydraulic conductivity. These waste form improvements will overcome the drawbacks of ISV for shallow buried waste. The MPI pre-treatment of submerged waste can eliminate the problems associated with steam generation by creating a solidified waste with lower water content and elimination of groundwater recharge into the trench during ISV. 


\subsubsection{Other Application of MPI As a General Purpose Delivery System}

The broad application of the MPI technology is reflected in the other applications cited below:

- Solidification using multi-component chemical grouts

- In situ washing of the waste

- B-25 Box Solidification

- In situ Battery Technology

- Injection of Caustic to immobilize uranium

- Chemical burning of organics using peroxides and other chemicals

- Combined Treatments (example: MPI and ISV)

- Reinjectable MPI bottom seal 


\section{IMPLEMENTATION OF MPI PROCESS}

The techniques developed for implementing the MPI technology were devised to protect capital equipment and workers from becoming contaminated; i.e., in an "As Low As Reasonably Achievable" manner. Once this requirement was satisfied, emphasis was redirected at making the delivery system as robust and broadly applicable as possible. The constraints of safety and robustness naturally drove the delivery system to be based upon jetting technology. The major capital investment for jetting is related to the cost of the highpressure pumps, piping, and associated mixing equipment. During the MPI process this expensive equipment is located in the support zone, and the power generated by the pumps is brought to bear upon treating contamination via very inexpensive and disposable equipment (hoses and pipes). The following subsections discuss the details of the construction steps and the types of equipment utilized for each activity. This detailed presentation will allow health and safety officers a more detailed knowledge of the process for better planning the safe execution of multi-point injection.

\subsection{CONSTRUCTION SEQUENCE}

The construction activities required for implementing the MPI process in situ are:

- Percussion installation of "cuttable" casing.

- Assemble lifting frame and load jetting tools into "cuttable" casing. These components are used for remote injection of treatment for waste remediation.

- Perform injection/treatment.

\subsubsection{Percussion Installation of "Cuttable" Casing}

A wide variety of materials are applicable for use as a cuttable casing. The exact type depends upon the application. For the specific application of treating shallow buried waste the most appropriate casing is currently high-density polyethylene (HDPE). This casing is tough and can withstand extreme driving conditions without fracturing. Yet the plastic material is easily cut by a high speed jet to create a sidewall port for performing waste treatment.

The installation of HDPE casing is accomplished via a specially designed drive system. The plastic casing is installed via percussion drilling, which is similar to the method currently used at Oak Ridge National Laboratory (ORNL) for installing observation wells. This drilling technique does not generate spoil material, and the percussion equipment can be easily adapted for remote control. 
HDPE casing has been successfully driven through miscellaneous solid waste down to depths of 15 feet, which is comparable to the depth of many shallow burial trenches at ORNL. Prior to performing the MPI injection in the Scientific Ecology Group (SEG) concrete vault, a post-hole digger was used to dig a hole to locate the contact between the soil overburden and waste. The depth to waste was measured at about five feet. This was the depth which was used to define the uppermost level for terminating the MPI injection. However, after exhumation of the soil overburden and waste, the actual contact of soil/waste was measured at a depth of about eight feet. It should be noted that the post hole was installed after all the HDPE plastic casing had been hammered into the soil and waste. Therefore, the six inches of ground subsidence measured after installing all the HDPE plastic casing would not account for the three-foot difference in the measured depths. All the depth measurements are correct since they were visual observations of the soil/waste contact. Since the post hole was installed in a corner of the concrete box, it is believed that the soil overburden did not consolidate in the same manner as the soil deposited in the center portion of the box. The soil in the center of the box was not affected by the soil/concrete frictional forces which would be imposed upon the soil deposited in the corner of the box. The following stratigraphy represents the actual layering of the soil and waste deposited into the SEG vault and represents the material which was driven through with the HDPE casing:

- surface - 5 feet: medium dense sapprolite (fill soil)

- $8-13$ feet:

heterogeously placed bags, cardboard, wooden pallets, steel drums, and miscellaneous metal, as illustrated in the photographs contained in Figure 9.

The photograph in Figure 10 depicts the arrangement of the HDPE casing used during the injection at the SEG test site. The driller in the photograph is holding a piece of HDPE casing which illustrates the type of drive point attached to the plastic pipe. Of the eight HDPE plastic casings installed through the above-referenced soil/waste form, four were driven totally through the waste to a depth of 14.5 feet. The other four plastic casings were driven to about 11.5 feet, which is 1.5 feet above the bottom of the waste. Typically, all HDPE casing required around 1000 blows per foot to penetrate through the waste material. A 140-pound standard penetration hammer was dropped 30 inches under gravity to drive the 4.5 -inch diameter plastic pipe. After 500 blows, if the casing had not advanced more than 0.5 inches, the driving was terminated. Even after such a severe pounding (over 5000 blows per five feet), all the HDPE plastic casings were intact and could withstand additional pounding. Since the field demonstration was scheduled for only a few days at SEG, there was no opportunity to change over to a heavier drive hammer with capabilities of driving the four HDPE casings to full depth. The impact of not advancing all the injection points through the 13 feet of waste is discussed more fully in Section 4.0, which presents the results from the SEG demonstration. 


\subsubsection{Lifting Frame Assembly/ Load Special Jetting Tool}

The second stage of the MPI technology is related to assembling the disposable lifting frame over the area to be injected. The lifting frame serves the purpose of allowing the jetting tools to be lifted from a remote location. Also, the lifting frame provides local containment over the area injected. The photograph in Figure 11 shows the lifting frame used during the $Y-12 / O R N L$ demonstration.

Once the lifting frame is assembled and placed over the treatment area, the jetting monitor and high-pressure hoses are attached to steel cables and lowered into each of the HDPE plastic casings. This activity is illustrated in the photograph in Figure 12. The jetting monitor, nozzle arrangement, and remote lifting aspects of MPI are proprietary and the intellectual property of GES. The jetting tools used for the Salt Lake City and the Y-12 site demonstrations were identical to those used at the Duncan project.

\subsubsection{MPI High-Speed Injection}

The final stage of the MPI process is associated with the actual injection of the chemical agents. For purposes of this discussion we shall limit the agents to Portland Type I cement; however, the MPI system can be used to deliver other material for a broad range of applications (see section 1.3). The pumping services for the MPI demonstration at Salt Lake City and Oak Ridge were provided by Haliburton Energy Services. The major equipment provided by Haliburton included: four HT- 400 high-pressure pumps, a recirculating cement mix, bulk storage containers, and data acquisition system for monitoring the injection in real time. This equipment is standard oil field equipment and is available locally throughout the world. This has obvious implications with respect to the pricing structure of MPI since the mobilization costs of the equipment are based upon local transport; i.e., do not have to send an ISV hood from one DOE complex to another.

The bulk batching plant used in the MPI demonstrations had the capacity to inject at least 1,000 pounds of cement per minute. The HT-400 pumps provided enough energy $(2,000$ hydraulic horsepower) to drive the MPI jetting monitor. The MPI injection sequence is similar to an upstage grouting process. Each hole is sequentially injected for about 20 to 90 seconds. Thereafter, the hose/jet monitor assembly is lifted remotely using the winching and steel cable system previously shown in Figures 10 and 11 . The sequence of injecting a discrete layer of waste at a time allows precise control over the type of treatment a particular zone of waste receives. All injection is conducted under real time data acquisition and analysis. The photograph in Figure 13 displays the lifting frame located in the exclusion zone.

Once the entire column of waste has been treated, a short portion of the jetting hose can be cut from the lifting cable and the monitor, hose and steel cable segments allowed to freefall into the open borehole. If retreatment is required over time, the hoses and jetting tools can remain suspended within the confines of the enclosed lifting frame. Therefore, the equipment 
used to perform the actual injection can be reused and/or become disposable components; i.e., steel pipe, jets, rubber hose, HDPE casing.

The simplicity of the equipment used to implement the MPI system allows the technology to be adapted to widely varying site conditions. The MPI system was conceived for application at sites with widely varying terrain; example, hillocks with moderately sloping ground surface. 


\section{MPI DEMONSTRATION, SALT LAKE CITY, UTAH}

There were two major phases to the MPI technology demonstration. The most comprehensive phase was performed in Salt Lake City at the construction yard of Christensen Boyles Corporation. The major emphasis of the Salt Lake City demonstration was to show Jacobs and The Department of Energy (Y-12 site) how well the MPI process homogenized shallow buried waste to form a low-conductivity monolith. Several shallow pits excavated in natural ground were used during the demonstration. A goal of the demonstration was to generate as little surface waste as possible, yet form a low-conductivity monolith. Core samples and constant head conductivity tests (Guelp Permeameter) were performed for quantifying the tightness of the monolith. Most of the data collected indicated that the MPI system can form a monolith of low conductivity $(1.0$ to $10.0 \mathrm{E}-07 \mathrm{~cm} / \mathrm{sec})$ using ordinary cement grout, with about 25 percent waste volume to the surface. Once the Salt Lake City demonstration was completed (early August 1995), the MPI process was demonstrated inside of a large concrete vault ( $14 \mathrm{ft}$. $\times 14 \mathrm{ft} . \times 15 \mathrm{ft}$. deep), which was constructed at the SEG site in Oak Ridge. The concrete vault demonstration showed the robustness of the MPI system to drive plastic casing through several layers of densely-packed steel (see previous Section 2.1.1).

There were three phases executed during the MPI demonstration in Salt Lake City. These phases correspond to:

- Equipment Verification.

This phase allowed verified equipment performance and demonstration of safety plan related to performing injection under high pressure.

- Barrel-Cutting Demonstration.

Demonstrate the ability of a high-speed cement jet to cut free-standing steel barrels, and barrels buried within waste which had varying degrees of cutting difficulty, paper, metal shavings, and stacked computer paper.

- MPI Injection.

Form homogenous, low-conductivity monolith of solidified waste using remotelycontrolled MPI process.

\subsection{SITE LOGISTICS}

The execution of the above activities required the construction of five major trenches/pits. The layout of the pits with respect to the injection equipment is shown in the site location map attached to Figure 14. The major pumping equipment was located about 145 feet away from any of the pits. The high-pressure grout slurry was delivered to the injection points using a manifold and valving system. In Figure 14 there are five valves and hoses leading to the barrel cutting pit. East of the barrel cutting pit are three other pits and a concrete vault. Pit 1 was 
cutting pit. East of the barrel cutting pit are three other pits and a concrete vault. Pit 1 was used to demonstrate the interference which solid waste has upon a high-speed jet to cut through steel drums. Pits 2 and 3 and the concrete vault were used to make modifications in the injection hole spacing and injection time in an attempt to minimize surface waste generation.

The details of the pit construction, types and location of solid waste are given below. The overall site setup is shown in the photograph in Figure 15. The specific locations of each portion of the MPI demonstration are discussed below.

\subsubsection{Equipment Verification Setup}

The activities conducted during the equipment verification phase was to determine if the high-pressure pumping equipment, data-acquisition system, and jetting tools were functioning correctly. Furthermore, the equipment verification phase allowed implementation and close scrutiny of the safety plan. The safety aspects of the demonstration were extremely important since very high pressures and flow rates were being used.

Transducers were placed into the pipeline to measure the density, flow rate and pressure of the grout supplied under high pressure. The three transducers were located immediately after the high pressure strainer used to filter hardened particles of grout. This would prevent the ports on the transducers from being clogged with cement clumps. Calibration certificates were supplied for each transducer. The calibration factors were incorporated into the data acquisition which was used to measure the pressure, density, and flow rate in real time. The output from the data acquisition system was written onto floppy disks in ASCII format.

The equipment verification was performed in a thick wall steel tank (see Figure 16). The top of the tank was open so that the cuttable casing and jetting tool could be securely placed inside while full-pressure flow was pumped through the jetting tool.

\subsubsection{Barrel-Cutting Pit}

The photograph in Figure 17 is a close-up of the pit used to cut free-standing 55-gallon steel drums. The pit is about 8 feet wide by 31 feet long. The lightweight tubular steel framing, which spans across the pit, was used as the lifting frame to support the hosesuspended jetting tool, shown in the background of the photograph. The tool was suspended from a steel wire which was attached to an overhead I-beam. The I-beam allowed the jetting tool to be moved along the length of the barrel cutting pit. Plastic sheets were attached to the tubular framing to prevent airborne particles from spreading across the site. The photograph in Figure 17 was taken from the east end of the barrel pit shown in the site location map.

The steel 55-gallon drums placed into this pit were new and had been approved by the Utah Department of Transportation for transporting hazardous chemicals. Obviously, these 
drums would be in much better condition than steel drums buried in waste for extended periods of time. Two different configurations of steel drums were placed into this pit. The barrels placed in the foreground of the picture were individual barrels, which had "cuttable" casing located at three different locations across the barrel diameter. The spacing allowed examining the amount of time required for a jet to cut steel placed at different standoff distances. These barrels would simulate a jet cutting out of a steel barrel. The other situation which could be encountered would be a jet located outside of a steel barrel. This situation was simulated by attaching twin sets of barrels together via a holding frame, see photograph in Figure 18. The jetting tool was placed inside of the cuttable casing, which was usually located at different distances to the drums. Each of the twin barrels were loaded with red-colored sawdust, which is a substitute chemical absorbent.

\subsubsection{Logistics of Pit 1: Waste Interference}

The injection conducted in Pit 1 was used to demonstrate the capabilities of the MPI system to cut 55 -gallon steel drums surrounded by waste. A typical burial trench at ORNL is about 10 feet wide. A ten-foot-wide pit was built to accommodate three steel drums and five injection points. The pit geometry in plan view is shown in Figure 19(a). Grout injection work conducted at ORNL indicates that the poorest injection occurs in the shallowest portions of the trench. Therefore, the maximum depth of Pit 1 was also shallow. The elevation view of Pit 1 indicates that the total pit depth was about four feet, with about 2.5 feet of waste and 1.5 feet of soil cover. The elevation view is shown in Figure 19(b).

Miscellaneous waste placed into Pit 1 consisted of three major waste types: easily cuttable, moderately difficult, and very hard to cut. The plan view of the waste placed into the bottom one foot of Pit 1 is shown in Figure 20. The easily cuttable waste was placed in the western one-third of the pit. This waste consisted of paper, sawdust, brush containerized within plastic bags. The central section of Pit 1 consisted of moderately difficult waste to cut, mostly cardboard boxes filled with metal shavings which are analogous to machine cuttings from milling uranium. The hardest material for a jet to cut was stacked reams of computer paper, as illustrated in the eastern one-third of the plan view of Pit 1 in Figure 20. The southern section of Pit 1 was filled with 55-gallon corrugated cardboard drums filled with red sawdust. This waste form was added to the pit since it appears to be a primary type of waste form used at the Idaho National Engineering Laboratory (INEL) site.

Each of the five injection holes installed into Pit 1 had an MPI jetting tool installed to the bottom of each of the five injection holes.

\subsubsection{Logistics of Pit 2}

Pit 2 was used to demonstrate the ability of the MPI process to form a homogeneous monolith of low conductivity without critical concern to minimizing generation of surface waste. The waste placed within Pit 2 was done in a random manner to try to simulate the 
disposal practice at ORNL. The waste forms used in Pit 2 varied from 55-gallon steel drums, corrugated paper drums filled with sawdust, stacked computer paper, paper, and brush. The basis for the waste formulation is presented in the Appendix. All material was highly containerized. The disposition of the waste is shown in the sketch contained in Figure 21 .

The location and type of waste placed within Pit 2 was kept confidential until the MPI injection pattern was selected. Therefore, there was no prejudice in selecting the injectionhole pattern; i.e., select a pattern which would be most effective in treating the waste. Obviously, there is little information about the logistics of the waste in the actual radiological trenches.

The injection performed in Pit 2 used the largest flow and closest spacing of injection holes for forming a low conductivity monolith.

\subsubsection{Logistics of Pit 3}

The waste deposited into Pit 3 was also used to examine the ability of the MPI process to form a low conductivity, homogeneous monolith, but with care taken to minimize surfacewaste generation. The waste inventory placed into Pit 3 was similar to Pit 2 . The only major difference being that some of the waste was placed in different locations. The types and disposition of the waste within the central elevation (two-foot level) is shown in the drawings contained in Figure 22. The major item to note in the waste is that a 55-gallon steel drum (filled with red sawdust) is placed centrally within the waste. The injection hole pattern used

$\therefore$, for Pit 3 represented the least amount of holes used for solidifying the waste.

The photograph in Figure 23 shows the arrangement of the waste inside of Pit 3 . The reader should especially note the location and orientation of the 55-gallon steel drums. As will be discussed in subsequent sections (see Section 3.5), an MPI injection hole was driven directly through the steel drum lying on its side in the photograph.

\subsubsection{Logistics of Concrete Vault}

The final MPI demonstration performed at Salt Lake City was done inside of a $10 \mathrm{ft} . \times 10 \mathrm{ft} \times 8 \mathrm{ft}$.-wide concrete vault. This was done as a preliminary test for maximizing the hole spacing prior to performing the injection in the concrete vault at Oak Ridge. The waste types are similar to the inventory deposited inside of Pits 2 and 3.

\subsection{EQUIPMENT VERIFICATION}

The work plan developed for the MPI demonstration required certain activities to be performed prior to starting any other phase of the work. The following activities were conducted to verify that the equipment was working correctly. 


\subsubsection{MPI Monitor}

An MPI monitor was placed inside of the steel test tank, previously shown in Figure 16. A nominal pressure of 11,000 psi was imposed and water was jetted for a period of about one to two minutes. The data acquisition system recorded the pressure-density-flow output. The density of water is approximately 8.3 pounds per gallon, which is nearly the value recorded by the data acquisition system. The 11,000 psi was maintained very well over the one-to-two minute duration. For each rise in pressure, it took approximately five seconds to fully pressurize the grouting system from 0 to 11,000 psi. During the injection work the Haliburton equipment was able to continually repeat the pressure rise/flow rates required to implement the MPI process.

\subsection{BARREL-CUTTING DEMONSTRATION}

Obviously, if effective solidification can be obtained with a few holes, then the risk to equipment, workers and the environment is greatly reduced. Furthermore, fewer injection points translates into lower cost. The difficulty with achieving large-hole spacing (greater than four feet) is related to containers deflecting the jet and keeping the jet from mixing the waste with the stabilizing agents. Furthermore, buried steel containers do not offer reliable longterm containment of waste deposited inside the barrel. If a barrel is breached, the contents are released and the barrel can still act as an obstruction to a jet-injecting treatment (or lowpressure treatment). It was shown in the Duncan project that a rotating high-velocity jet (operating at $11,000 \mathrm{psi}$ ) does not have the concentrated energy to cut through a steel drum. Therefore, utilization of this approach may require closely-spaced injection holes to overcome the "shadowing" effects of the containers. It is, therefore, important that the jetting technology have the potential for cutting through a steel barrel and exit outside so that the treatment can be successfully injected throughout the waste.

There are two scenarios under which a jet may encounter a steel barrel. They are:

- If a barrel is drilled into, then the jet will have to cut itself out from the barrel. A typical 55-gallon steel drum is about 20 inches in diameter. Therefore, at the extreme, the jet would have to possess enough energy to cut a hole in the drum at a standoff distance of about 10 inches. This situation is not deemed critical for solidification of the waste using the MPI process. During installation of the cuttable casing, samples of the contaminants will be taken. The "correct" type of solidification agent will be selected. Therefore, the hole cut into the barrel will be sealed by the hardening of the solidification agent. These statements are supported by the results from the twin-barrel setup in which cemented sawdust was found to plug the hole created by the jets.

- The other configuration of a jet impacting a barrel occurs when the jet is outside of the barrel. The twin-barrel setup demonstrated the jet cutting of free-standing barrels. However, this is somewhat academic since the real case will have the barrels surrounded 
by waste. The difficulty with determining the ability of the jet to cut barrels is related to the position of the barrel and also the waste between the barrel and the jet. The jetting conducted in Pit 1 with easy, moderate, and hard-to-cut waste obstructing the jet path shed light on this situation.

The jet cutting of barrels was conducted in an 8-ft.-wide trench. Due to the narrowness of the trench, it was difficult to visually observe when the jets cut a hole into the drum. In Duncan, a wide pit was used, and it was relatively straightforward to observe when a jet cut the drum. Therefore, the barrel-cutting experiments were conducted for a set amount of time, typically from 15 to 90 seconds. The jetting was stopped and visual observations as to hole sizes, location, etc. were made. In some instances, visual observations could be made as to when the drums were initially cut by the jetstream.

\subsubsection{Jetting Inside Single-Steel Barrels}

A total of four barrels was used to examine the cutting capability of a high-speed jet $(11,000 \mathrm{psi})$ when the jet starts from the inside of a barrel. The general finding from this portion of the demonstration was that 11,000 psi of pump pressure can develop enough jet speed to cut one-half to one-inch diameter holes in the sidewalls of steel drums. The MPI monitor was hung freely and only the design of the jetting monitor provided force balance. This was similar to the work conducted previously in Duncan:

At a standoff distance of 10 inches (half of a 55-gallon drum diameter), the jetting time required was about 20 to 30 seconds. When the jetting distance was reduced to about four inches, the time decreased to 15 seconds. When the jets are closer to the surface of a steel drum, the size of the hole dramatically decreases. At a standoff distance of one-fourth inch, the jetting time to cut a hole is less than 10 seconds, but the hole is only about one-half inch in diameter. The hole does not enlarge even if the jetting time extends to 90 seconds. These findings were consistent with the work conducted in Duncan (see Section 1.2).

The importance of these observations is related to the minimum jetting time required for a jet to exit out of a steel drum. If the maximum distance of any drum is about 10 inches, then a minimum jetting time of about 20 to. 30 seconds should be used to minimize shadowing effects. This is only valid for the MPI process (mono-directional jets), since a rotating jet at 11,000 psi will never be able to cut the sidewalls of a steel drum (standoff distance 10 inches).

The photograph in Figure 24 is illustrative of the types of holes which the MPI process is capable of producing when jetting from inside a steel drum. The major portion of the steel drum is intact and only relatively small-sized holes (about one inch) are cut into the sidewalls of the drum. If waste were inside of the drum then this solidified waste would form a solid plug over the hole and reclose the drum. 


\subsubsection{Jetting Outside Twin Barrels}

A total of six pairs of barrels were subjected to jets cutting through the outer sidewalls of two steel drums interconnected using a holding frame (see previously-presented Figure 18 for twin-barrel setup). Each barrel had only one jet pointing at it, with the other jets spraying against the sidewalls of the trench. Therefore, a maximum of one hole per barrel could be produced during a particular stage of cutting. The initial demonstration indicated that it took about 75 to 90 seconds to cut a hole in a steel barrel at a distance of 20.5 inches. This is about twice as long as the work at Duncan and may be due to the differences in the quality of the barrels. Usually, the jets were pointed directly at the drum, and in many instances only dimples were formed in the surface of the drum. The increased difficulty to cut a drum from the outside is due to jet energy being expended to deform the steel and form a dimple. Furthermore, a film of grout develops within the dimple which tends to disperse the size of the jet and, thus, reduce the jet's cutting ability. A freely-suspended MPI monitor requires about three times as long to cut the outside of a steel drum when compared to a jet cutting the drum from the inside (jetting against a convex surface produces a faster cut).

The last series of twin-barrel cutting demonstrated that a hose-suspended monitor can be aimed at a particular point on the steel drum. All previous twin-barrel work had been done with the jet directly hitting the barrel. This direct impact caused the steel drum to form dimples. When the jet monitor was rotated by about two to four inches off the center line of the drum, the jets were able to cause sideshear forces against the steel surface and cause the steel to erode. Slashes on the order of two inches were made in the drum surface at jetting distances of up to 36 inches. The total jetting time was approximately 60 to 75 seconds at 36 inches.

The twin-barrel cutting demonstration produced the following observations:

- It is more difficult to cut a steel drum when the jets are hitting against a concave surface. It appears that a water film builds up, which tends to create a dimple in the drum and prevents erosion of the steel.

- A free-hanging MPI monitor can be aimed at a particular point on the steel drums. This is an important consideration since there is little torsional resistance in the rubber jetting hoses. The design of the MPI monitors produce stable jetting such that the jets can be aimed at a target without being clamped onto a drill rod and surface drill.

The final demonstration related to the MPI system's ability to cut steel drums is related to the interference which the waste has upon the cutting jet; i.e., waste disperses jet and lessens cutting ability of jet. The waste and drum configuration previously described under Pit 1 (see Section 3.1.3) was used to examine the influence which easily-cuttable, moderate, and difficult-to-cut waste has upon a jet ability to puncture a steel drum at a fixed standoff distance of about 20 inches. 


\subsubsection{Pit 1: Waste Interference With Jet Cutting Ability}

The injection conducted for Pit 1 quantified the effect which different types of waste have upon the cutting ability of a high speed jet. The waste arrangement, hole spacing, etc. have previously been described in Section 3.1.3. The steel barrel was always located at about 20 inches from the cuttable casing. The following observations were extracted from the Pit 1 demonstration:

- Easily Cuttable Waste: Paper, Cardboard, Plastic Drums.

The jets were able to cut two holes into the steel drum. The first hole was formed during the very first injection, (monitor at bottom of trench, no previous jetting performed). The jet time was 90 seconds. The second hole was cut at a distance of 18 to 24 inches from the bottom of the pit. The hole was cut within 70 seconds of injection. Therefore, of the five possible holes, only two holes were formed.

- Moderately Difficult Waste: Metal Shavings.Inside Wrapped Cardboard Boxes.

The jets were never able to cut a hole into the steel drum even when 90 seconds of jetting were conducted. The metal shavings disperse the jetstream and do not allow the jet to concentrate its energy.

- Hard-to-Cut Waste: Stacked Computer Paper.

One hole was cut into the steel barrel when the jet was located at about 12 to 18 inches from the bottom of the barrel. The time required was 90 seconds. It is believed that the jet did not penetrate through 20 inches of computer paper, but rather the jet sliced its way between the seam between two boxes stacked on top of each other.

Other observations during Pit 1 demonstration related to operational activites:

- The first three injections resulted in a total grout flow of 630 gallons. The grout level tube indicated that the grout was at about 16 inches. The total volume of the pit at a depth of 16 inches was $=8 \mathrm{ft} . \times 10 \mathrm{ft}$. 16/12=107 cubic feet ( 803 gallons). The average porosity of the waste after the first level of injection was approximately 78 percent or $(630 / 803=$ $78 \%$ ). At the end of the first level of injection (5 injection holes), the total grout volume injected was about equal to 68 percent. This would indicate a high level of intermixing between the grout and the in situ waste. It should be re-emphasized that all waste in Pit 1 was highly containerized and the void space was not accesssible to grout flow under gravity.

The 78 percent and 68 percent measured from Pit 1 at Salt Lake City is comparable to the value reported by INEL from their jet grouting demonstration. Grout volume was 67 percent of the total pit volume.

- Although waste was injected to an excessive degree, the HDPE did not exhibit any flotation charateristics; i.e., elevation of monitors was not influenced by buoyancy or adjacent jetting to cause cuttable casing to displace. 
- Since the prime interest for jetting in Pit 1 was to examine the interference different waste has upon interferring with a cutting jet, the amount of grout injected was not of prime concern. The total volume of grout injected was about 2650 gallons. The total volume of Pit 1 (waste + soil) was $8 \mathrm{ft}$. $10 \mathrm{ft}$. $4 \mathrm{ft}=320$ cubic feet ( 2400 gallons). Therefore, the grout injection was about equal to the total volume of the original pit. During the last stages of injection, (conducted within 12 inches of the surface) some waste material had floated to the surface (computer paper and wooden blocks). Furthermore, the surveying monuments and soil overburden was sucked into the waste and incorporated into the solidified mass.

- As a collary to item 3, there was a total loss of ground support within Pit 1 during the final stages of injection. If a drill or crew were located at the surface, then the drill would have collapsed into the pit. However, there was no distress to the remote lifting frame at this stage. The injection could have continued without any risk to capital equipment or worker exposure to contamination.

\subsection{FORMATION OF A HOMOGENEOUS MONOLITH: PIT 2}

There were two pits to demonstrate the MPI process for forming a homogeneous monolith of low conductivity. The injection performed in Pit 2 represented the upper bound for the number of holes, jetting time and volume of injection. Pit 3 attempted to utilize the minimum number of holes and lowest injection volumes.

\subsubsection{Injection of Pit 2}

The inventory dumped into Pit 2 has been presented previously under Section 3.1.4. There were seven injection holes driven into Pit 2 , and were arranged according to the layout shown in Figure 25. The hole spacing varies from 51 to 62.5 inches, with most holes being about 56 inches apart. MPI monitors were placed within each borehole and the injection was performed using the procedure specified under Section 2.0. Each of the seven injection holes had six stages of injection, with about one minute per stage in each hole. Two different types of MPI monitors were used to try to keep all the injection energy within the confines of the $8 \times 10 \mathrm{ft}$. pit; i.e, full array of nozzles to perform MPI process would have been too much injection for Pit 2. MPI injection holes 1, 2, 3, 5, 6, and 7 (shown in Figure 25), had five nozzles attached to the jetting monitor. The five jets were arranged to cover a plan area of 180 degrees. The centrally-located MPI monitor (No. 4 in Figure 25) had eight nozzles symmetrically placed around the monitor. A total of six levels of injection were performed to solidify the three feet of waste. The total volume injected was equal to about 4000 gallons of grout containing around 12.5 tons of cement. The volume of injection represents about two times the total volume of the waste deposited into Pit 2 . The overinjection resulted in ground flow of material breaking through at the surface. This ground flow was contained within a sand bag moat constructed at the surface. There was never any airborne releases of grout 
observed during any phase of the injection work. About 100 percent of the volume of the waste was generated as ground flow to the surface.

\subsubsection{Conductivity Testing of Pit 2 Monolith}

Four coreholes ( $\mathrm{CH}-1, \mathrm{CH}-2, \mathrm{CH}-3$, and $\mathrm{CH}-4)$ were drilled into the monolith created in Pit 2. The location map of the four holes is presented in Figure 26. Typically the coreholes are about two feet away from any adjacent injection holes. Guelph permeameter tests were conducted on the block using the setup shown in the photograph in Figure 27. Typically, one hydraulic head was used to calculate the conductivity of the solidified waste. The material property relating the type of fabric (parameters required in theory developed at Guelph University) was obtained from the data extracted from monolith No.3. formed in the Duncan project. The conductivity value measured from corehole number $\mathrm{CH}-1$ was obtained by testing the waste over the interval of 27.4 to 46 inches from the top of the solidified monolith. The depth of borehole used to calculate the conductivity are contained in the sketch in Figure 28. The photograph of the core along with the essential data for calculating the conductivity of $3.7 \times \mathrm{E}-07 \mathrm{~cm} / \mathrm{sec}$ are attached in Figure 29. There was about 83 percent of the core recovered from the borehole. Visual inspection of the core photograph confirms the low conductivity.

Similar calculations were performed for coreholes $\mathrm{CH}-2, \mathrm{CH}-3$, and $\mathrm{CH}-4$. The data for coreholes $\mathrm{CH}-2$ and $\mathrm{CH}-4$ resulted in very low values of conductivity: $7.3 \times \mathrm{E}-07$ and $6.2 \mathrm{x}$ $\mathrm{E}-07 \mathrm{~cm} / \mathrm{sec}$, respectively. Although the corehole recovery from hole $\mathrm{CH}-3$ was about 63 percent, the conductivity tests were inconclusive; i.e., very good core recovery, but a minor defect within the hole prevented calculation of conductivity. It appears that there was a 55-gallon steel drum on its side in the location of CH-3, (see Figure 26). It appears that the inside of the steel drum was not grouted (not penetrated by jetstream), and, therefore, there is uncemented sawdust within the corehole CH-3. While drilling for the core, the sawdust was blown out of the hole. The steel barrel could be encased within cement grout, yet the interior penetrated by the corehole may not be treated since the steel drum was not penetrated by the jet.

\subsubsection{Exhuming of Pit 2 Monolith}

The conductivity data tends to indicate that the heterogeneous waste in Pit 2 was transformed into a low conductivity material. The concept that the waste pit was turned into a monolith is confirmed by the excavation performed on the pit. It is obvious from the visual inspection of the photograph in Figure 30 that a monolith was formed. It should also be noted that the injection sequence and types of monitors used for the injection caused the treatment to extend about one foot outside the sidewalls of the excavated pit. For instance, observe the extent the treatment which lies outside the black HDPE pictured in Figure 30. 


\subsection{FORMATION OF A HOMOGENEOUS MONOLITH: PIT 3}

The purpose of the injection performed within Pit 3 was to demonstrate the formation of a low-conductivity monolith using a small amount of injection. The injection pattern, volume of injection, and results from conductivity tests and exhumation of the Pit 3 monolith are presented in the following sections.

\subsubsection{Injection of Pit 3}

The inventory dumped into Pit 3 has been presented previously under Section 3.1.5. There were five injection holes selected for Pit 3 and were arranged according to the layout shown in Figure 31. The holes spacing varies from 58.5 to 112.51 " inches, with most holes being about 60 to 72 inches apart. Each of the five injection holes had six stages of injection, with about 30 seconds per stage in each hole. Injection pressures were typically 11,000 psi. Two different types of MPI monitors were used to try and keep all the injection energy within the confines of the $8 \mathrm{ft}$. $\times 10 \mathrm{ft}$. pit; i.e., full array of nozzles to perform the MPI process would have been too much injection for Pit 3 . Most of the monitors were high-eccentricity monitors which are equipped for jetting within a corner of a trench; i.e., only 90 degrees of coverage.

Injection holes numbered 1,2,3, and 4, shown in Figure 31, had five nozzles attached to the jetting monitor. The five jets were arranged to cover a plan area of 90 degrees. The centrally located MPI monitor (No. 5 in Figure 31). and eight nozzles symmetrically placed around the monitor. A total of six levels of injection were performed to solidify the three feet of waste. The total volume injected was equal to about 1500 gallons of grout containing around 4.7 tons of cement. The volume of injection represents about 0.8 times the total volume of the waste deposited into Pit 3 . The overinjection resulted in ground flow of material breaking through at the surface. There was nine inches of ground flow, which was contained within a sandbag moat constructed at the surface. The ground flow represents about 25 percent of the total volume of waste deposited into Pit 3 . The ground flow density was measured as $1.76 \mathrm{~g} / \mathrm{ml}$. Since the grout break was so heavy, there was never any airborne releases of grout observed during any phase of the injection work.

\subsubsection{Conductivity of Monolith Pit 3}

Four coreholes ( $\mathrm{CH}-1, \mathrm{CH}-2, \mathrm{CH}-3$, and $\mathrm{CH}-4)$ were drilled into the monolith created in Pit 3. The location map of the four holes has been previously presented in Figure 31. Typically the coreholes are about two feet away from any adjacent injection holes. Guelph permeameter tests were conducted on the block. Typically, one hydraulic head was used to calculate the conductivity of the solidified waste.

The conductivity value measured from corehole number $\mathrm{CH}-1$ was obtained by testing the waste over the interval of 32.1 to 50.5 inches from the top of the solidified monolith. These depths were measured from the top of the hardened cement overflow, which was about nine 
inches. The conductivity measured for $\mathrm{CH}-1$ was about $3.2 \times \mathrm{E}-05 \mathrm{~cm} / \mathrm{sec}$. This value is comparable to the conductivity of the natural ground which surrounds the waste trenches at ORNL; however, when compared to the data reported from Pit 2, it is about 70 times more pervious. During the injection performed using injection holes 1 and 2 (see Figure 31), the jetstreams broke to the surface break along the west and south sides of the pit, as illustrated by the vectors emanating from injection holes 1 and 2 . Upon close examination of the video tapes of the work it was evident that the hoses for these injection points had rotated counterclockwise as the pressure was built-up in the lines. The hose rotation caused the monitors to rotate in the borehole and the jets projected their energy outside the pit area into the zones designated in the sketch at the top of Figure 31. The hoses for injection holes 3 and 4 did not rotate. The work plan for the Salt Lake City demonstration suggested the use of a T-preventer/packer at the collar of each injection hole. This appliance should provide the torsional restraint needed to assure that the hoses never rotate during the injection. Furthermore, the hoses should be suspended over the top of the lifting frame to remove any loops in the hoses. As the pump pressure increases, these loops tend to wiggle a little and if unrestrained, rotate in the wrap direction of the hose (which is counterclockwise). Therefore, with a few operational changes (which were known prior to the demonstration) the MPI monitors can be aimed in the correct direction for performing the solidification. See Section 3.3.2 Jetting Outside Twin Barrels, in which the MPI monitor was aimed, as various points to cut holes into steel drums.

Obviously, if there are fewer nozzles to perform the MPI process then the waste will not be homogenized as much as when more jets impact the waste. This observation is supported by the data measured for $\mathrm{CH}-1$ versus $\mathrm{CH}-4$. The monitors located at holes 3 and 4 did not rotate and provided more mixing of the waste with cement grout. Therefore, the zone of waste in the vicinity of $\mathrm{CH}-3$ and $\mathrm{CH}-4$ produced conductivities on the order of $7.2 \times \mathrm{E}-07$ and $6 \times \mathrm{E}-07 \mathrm{~cm} / \mathrm{sec}$, respectively. Indeed for the northern portion of Pit 3, there was excellent solidification performed with injection holes spaced at about 5 to 7 feet.

As a final note on the conductivity measurements, it is noted that the value of conductivity at $\mathrm{CH}-4$ is indeed low $(6.0 \mathrm{E}-07 \mathrm{~cm} / \mathrm{sec})$. This point is located outside of the steel drum illustrated in Figure 32. Injection holes 3 and 4 are each about five feet away, with injection hole 3 being located behind a steel barrel. Injection hole 5 was located inside of a steel drum, yet the core extracted from corehole $\mathrm{CH}-4$ reveals well cemented waste for the entire core length recovered, which was 70.5 inches of 90 inches sampled. The situation of placing an MPl monitor into a steel drum and cutting through and solidifying the waste around the drum, illustrates the robustness of the MPI system to overcome the shadowing effect of metal containers such as steel barrels.

\subsubsection{Exhuming Monolith Pit 3}

The cemented monolith of waste created during the injection for Pit 3 is shown in the photograph in Figure 33. The block was exposed on the east southwest side, with the east and south sides shown in Figure 33. In general, the outer surface of the monolith was well 
cemented as evidenced by the scratch marks of the backhoe teeth on the surface of the south side of the block. The mass of cement outside the confines of the pit (see slab of cement grout in lower portion on south side of block in Figure 33) represents the cement injection, which was due to the monitor rotating in a counterclockwise fashion. The excavation on the west side of the block uncovered a pocket of uncemented soil and waste, as shown in the photograph in Figure 34 . The open pocket is approximately 24 in. high $x 18$ in. wide $x 18$ in. deep. The interior surface of the pocket is well cemented. The waste within the pocket was shredded paper and plastic bags with some soil intermixed. This waste combination has always been well cemented using the MPI system. The cause of the pocket is believed to be due to two situations:

- The injection performed from hole 1 was not effective in projecting its mixing energy since the monitor had rotated and at least one or two jets were not cutting and mixing the waste within the zone where the pocket was formed. It should be noted that the waste between injection hole 1 and the south side of the pocket represents about 54 inches of well-cemented soil and waste; i.e., this would represent an interaxis spacing between injection holes of about five feet. The injection-hole spacing along the west side of Pit 3 was approximately seven feet.

- The injection hole 3, shown in Figure 33, is about one foot away from where the pocket was uncovered. It is believed that the jets emanating from injection hole 3 were still very coherent; i.e., narrow in width and did not cause much turbulent mixing of the soil and waste. The concept of multi-point injection for solidifying waste requires one jetting monitor to cut apart waste within a zone of about 18 to 24 inches from the point of injection, and the surrounding jetting monitors to cause turbulent mixing of the waste at other injection points; i.e., jetstreams are coherent near the point of injection and diverge as the jetstream travels farther away from the point of injection. A coherent jetstream is more effective at cutting waste, whereas a divergent jetstream is more effective at turbulent mixing of waste.

It is unclear why no untreated pockets of waste were found along the south side of Pit 3. The monitors in holes 1 and 2 had both rotated and it would appear that there should have been some defects uncovered along the excavated southern face of Pit 3 . This is especially true since the hole spacing between holes 1 and 2 was about eight feet ( 96 inches). However, no untreated pockets were found along the southern face of Pit 3 . The well-treated waste could be due to the relatively easy cuttable waste placed along the south side of Pit 3 (see Figure 31).

Since the purpose of the MPI demonstration was to demonstrate the MPI system under extreme conditions, it appears that injection-hole spacing of seven feet and jetting time of 30 seconds do not provide enough redundancy in the system to assure well-treated homogenous waste throughout. Operational factors such as monitors rotating must be improved before using seven feet and 30 seconds as standards of injection. 
It should be noted that the total volume of the pocket of untreated waste is approximately 4.5 cubic feet which represents a total of about 1.5 percent of the total volume of soil and waste treated. The impact which this pocket has upon the transport of contaminants should be minimal. This is further supported by the observation that the conductivity measured in corehole $\mathrm{CH}-3$ is about $7.2 \times \mathrm{E}-07 \mathrm{~cm} / \mathrm{sec}$. This corehole is only about 6 to 12 inches from the perimeter of the untreated pocket (see plan view in Figure 31 ).

\subsection{MPI INJECTION IN CONCRETE VAULT}

The last phase of the injection work conducted at Salt Lake City was conducted inside of a $10 \mathrm{ft}$. $\times 10 \mathrm{ft}$. $88 \mathrm{ft}$. deep concrete vault. This was done as a preliminary test for maximizing the hole spacing prior to performing the injection in the concrete vault at Oak Ridge.

\subsubsection{MPI Injection of Concrete Vault}

There were four MPI injection points used to solidify the waste inside of the concrete vault. Each injection hole was equally spaced 2.5 feet from each of the four corners of the concrete vault (see sketch in Figure 35). The maximum distance between any injection point is 102 inches and is along the diagonal from injection holes 1 to 4 and 2 to 3 . Six-foot (72 in.) interaxis spacing is more typical for each of the four injection points. A total of 12 levels was injected with each of the four MPI monitors. The average jetting time was about 30 seconds. The total volume of grout injected was about 3,300 gallons, which is approximately one-half the total volume of the concrete vauit. The injection spacing, time, and total volume injected were the lowest used during the Salt Lake City demonstration.

\subsubsection{Conductivity of Monolith in Concrete Vault}

There was a total of four coreholes drilled through the waste solidified within the concrete vault. In general, there was about 40-70 percent core recovery of cemented waste. This was the lowest percent recovery of core for, any monolith formed at Salt Lake City. It is obviously due to the lack of sufficient cement injection. Approximately 15 gallons of water were poured into one of the corehole holes. The water level dropped from the ground surface to the bottom of the concrete vault within about three minutes. From the gurgling sounds of the flowing water it was obvious that there was open pathways within the cemented mass. No refinement of the conductivity measured was deemed necessary.

\subsubsection{Exhumation of Concrete Vault}

The solidified waste inside of the concrete vault was never exhumed for visual examination. 


\section{MULTI POINT INJECTION DEMONSTRATION: OAK RIDGE, TENNESSEE}

Once the MPI demonstration was completed in Salt Lake City all the equipment was mobilized and sent to the demonstration site in Oak Ridge. A $14 \mathrm{ft}$. $\times 14 \mathrm{ft}$. $\times 17 \mathrm{ft}$. concrete vault had been prepared with waste at the SEG site in Oak Ridge. The MPI injection was conducted in August 1995.

\subsection{MPI INJECTION}

There was a total of eight injection holes installed into the waste deposited inside the Oak Ridge concrete test bed. The plan location and elevation of each hole is illustrated on Figure 37. The waste inventory has been discussed in detail in Section 2.1.1, and, in summary, consisted mainly of eight feet of sapprolitic fill which was underlain by five feet of miscellaneous buried waste (wood, steel drums and plate, cardboard boxes, paper, and plastic). The basis for the waste formulation is presented in the Appendix. The eight-foot thickness of the fill was measured after the entire waste pits were exhumed. However, at the time of the demonstration, a single, hand-dug pilot hole in the corner of the box indicated a fill thickness of only five feet, which is three feet less than the actual fill placed. No data were collected during the loading of the concrete vaults to keep track of the consolidation of the waste and also the thickness of fill placed. For example, telltale settlement plates could have been used to monitor the settlement of the waste. If we had known that there was only a fivefoot thick layer of waste (instead of the estimated eight feet of waste), then a different injection strategy would have been used. Obviously, the injection performed from eight to 11 feet was conducted in fill soil and was not a productive exercise for solidifying the buried waste. The lack of information about the top (and bottom) of the waste points to the need for this information to be gathered for the actual burial trenches at $Y-12$. Obviously, it would be preferable to have this information gathered during the site characterization phase, since this data could have a marked effect upon the total amount of injection, and, thus, the final cost of the remediation. However, if this data is not available, then it could be obtained as part of the remediation activities. This issue will be addressed below when discussing the needs associated with performing quality control/quality assurance (QC/QA) during the MPI remediation.

All the eight plastic HDPE casings were hammered into the test beds using a 140-pound hammer dropped 30 inches. Four of the eight HDPE casings were driven to a depth of about 11.5 feet, which would have left about 1.5 feet of waste beneath each injection hole, as illustrated in the elevation view of the waste shown in Figure 37. The other four plastic casings shown in this figure were driven completely through the waste to a depth of 15 feet. Typically, it required about 5000 blows to penetrate through the five feet of waste. The driving of the HDPE plastic pipe was stopped after driving the casing to +500 blows per 0.5 inches of penetration. All eight plastic casings were completely intact (no broken joints or connections) after the severe pounding and could have been driven farther if a heavier hammer were available. However, there was not enough time scheduled in the demonstration 
to stop and obtain a heavier hammer to completely drive the four plastic casings the additional 1.5 feet. Furthermore, in an actual trench situation, which is dug into soil, plastic casing could have been driven at the contact of the waste and soil sidewalls of the trench to accommodate the need for additional injection holes that fully penetrated the waste. During the injection of the MPI jetting process, the cement jets would penetrate through the soil sidewalls and solidify the trench waste (see Section 1.3.1 for a discussion of using the MPI process for forming cellular encapsulated waste).

The impact of only driving 50 percent of the MPI injection holes to full depth, waste thickness being only five feet (instead of the estimated eight feet), and the goal to perform the injection without any grout breaking through to the surface (waste management issues) had significant impact upon the results from the MPI demonstration at SEG. Essentially, the injection produced unacceptable results with totally inadequate solidification of the waste, as shown in the photograph in Figure 38. The impact which each of the three items had upon the resulting injection is discussed in the next subsection. The major issue that will become prominent in the discussion is related to field quality control and ability to select the injection time on a more rational basis.

\subsection{INJECTION HOLE LAYOUT}

The elevation view and layout of the eight MPI injection holes was presented in Figure 37. The injection hole numbers $1,3,4$, and 8 fully penetrated the five feet of waste, while injection holes $2,5,6$, and 7 were 1.5 feet above the bottom of the waste. Therefore, only four MPI injectors were used to solidify the lower $1 / 3$ of the waste ( 1.5 feet of five feet total thickness). The spacing between holes $1,3,4$, and 8 varies between 4.5 to 12.5 feet, with most interaxis spacing being about 9.5 feet apart. If all eight injection holes were at full depth, the average spacing was planned to be about 4.5 to 5.0 feet. Therefore, the actual injection in the lower one-third of the waste was performed at about twice the hole spacing than planned or used during the Salt Lake portion of the demonstration.

The problem of penetrating the waste was discussed above, and is not related to the MPI system but rather the light hammer selected by the contractor to install the plastic casing. Furthermore, since the test was done in a concrete box, there was a limited configuration of injection holes that could be selected. The concept of the MPI process is that the jets cut apart waste close to the injection hole and mix the solidification agents with waste as the jets are propelled farther and farther away. In the lower one-third of the waste, there was not enough injectors used to homogeneously mix the waste and grout. However, eight injection holes were used to solidify the waste in the upper two-thirds of the waste. Yet, inadequate solidification was observed. This leads to the discussion of how the jetting time per injection hole was selected. 


\subsection{SELECTION OF JETTING TIME}

One of the most influential factors which controls the end product formed using the MPI process is the amount of time each MPI injector actively jets. At Salt Lake City this time varied from 30 seconds up to 60 seconds per injector. Since it was suggested that we attempt to perform the MPI process without generating any cuttings to the surface, it was decided to use the shortest practical jetting time possible. At the SEG site, this corresponded to 20 seconds per injector. There was no other rational basis for selecting this time since the waste form and its characteristics were unknown. The 20 seconds was merely selected based upon operational considerations of how fast the pumps could pressurize the system to $11,000 \mathrm{psi}$ and then shut down. Obviously, this is not an acceptable methodology for conducting the MPI injection. There are reasonable field tests which can be used for rationally selecting jetting times and involves the use of optical casing and borehole cameras; however, due to budget and time constraints, field QC/QA options could not be incorporated into the demonstration. The strategy to implement the optical casing quality control measures is discussed in the next section.

\subsubsection{Use of Optical Casing and Borehole Cameras}

Installation of plastic casing is an integral part of the MPI process. Therefore, strategic placement of clear plastic casing naturally fits into the MPI process. The concept would be to install clear plastic casing as part of the normal installation of the HDPI plastic casing, then load borehole cameras into the clear plastic holes (instead of MPI injection monitors). The borehole cameras would be attached to the lifting frame in the usual manner as the MPI monitors. The borehole cameras would be lifted in a synchronous manner as the MPI monitors are lifted. The borehole cameras would serve a multiplicity of purposes:

- They could be used to verify the exact location of the top and bottom of the waste in the actual trenches at the $\mathrm{Y}-12$ site. Therefore, knowledge of the waste thickness a priori is not totally required.

- The borehole cameras would allow visual examination of the waste over the entire waste thickness.

- The borehole cameras could be used as null indicators to visually observe if grout passes through the location of the plastic casing. The jetting time could be controlled such that the time would be varied based upon the observation of when grout appears in the camera image. Since the borehole cameras would be contained within a totally sealed casing, there would be no concern of damaging the cameras. Furthermore, since the cameras would be lifted incrementally along with the MPI injectors, the cameras would be viewing through clear casing; i.e., no grout has coated the clear casing since all injection is done at one elevation. Also, this strategy could be used to vary the injection time for the entire thickness of the waste. 
The current injection strategy is to select a single injection time and use this value for the entire waste thickness. This is somewhat of a guessing game; however, this is the only logical approach because there is currently no other information available. However, if the optical casing and camera approach were used, then the jetting time could be varied based upon the local condition of the waste. Since the waste would only receive the most appropriate level of treatment (as verified by visual confirmation), the jetting time can be varied along the trench and at different elevations. This would allow the borehole camera/optical casing concept to fit into management of waste generation.

\subsection{FUL/WASTE THICKNESS}

The last item to be discussed is related to the impact which the thinner waste had upon the injection, and why was the waste thinner than the other test cells. It appears that the waste deposited into the MPI concrete vault was very heterogeneous and produced a denser waste form after compaction by the overburden (when compared to the other cells at the SEG demonstration). The thickness of the fill in the MPI cell was the greatest (eight feet), which is indicative of the void reduction which the waste in the MPI cell experienced. This amount of overburden tended to create a more compact waste than that injected previously at Salt Lake City. The increased density of the waste, coupled with short injection times of 20 seconds and wide spacing of the injection holes made solidification of the waste even more difficult. Again, without any field monitoring device, the injection was done blindly, and the end result was unacceptable. However, a more rational basis for performing the injection with optical casing and borehole cameras appears to be a reasonable approach for overcoming the limitation of not knowing the waste thickness.

There was a total of 14 levels of injection performed over the eight feet of injection performed (five feet of waste and three feet of sapprolite fill). Within the waste, six levels of injection were done using all eight injection holes. The average jetting time of around 20 seconds caused a total volume of 2,400 gallons of grout to be injected into the 980 cubic feet of waste. This grout volume represents about 33 percent of the waste volume. This is an exceptionally low number when compared to the values used at Salt Lake City, which varied from 80 to 200 percent of the waste volume. These percent injection values produced very good results but presented waste management issues. Approximately 100 percent outflow of cuttings was generated when the 200 percent grout volume was injected, and 25 percent outflow was generated when the 80 percent grout volume was used.

\subsection{TREATMENT OF SAPPROLITE}

The injection performed in the sapprolite fill from a five- to eight-foot depth produced very good results in terms of the continuity of treatment; i.e., MPI process created a continuous wall in the remolded clayish soil (see the close-up photograph of the treatment of the sapprolite shown in Figure 39). Since there were no cuttings generated during any phase of the MPI injection in the fill overburden, it appears that the MPI process could be used in 
the sapprolite to form cutoff walls without generating soil to the surface. This is the second most significant observation extracted from the SEG demonstration. This first being related to the need for field quality control and a method for rationally selecting the injection time.

\subsection{CONCLUSIONS SEG DEMONSTRATION}

The work at the SEG site proves that anecdotal information is not sufficient for planning an injection strategy. Actual data must be the basis for rational selection of the jetting parameters. Data with respect to void space and waste density cannot be obtained in a practical manner and are not needed to execute the MPI system since its effectiveness is not dictated by void volume (as in the case of low-pressure permeation grouting). Rather, a visually-based method (optical casing and borehole camera) has been devised for selecting the jetting time used to treat a particular waste form. Because the jets cut through the waste, their arrival at the optical casing is merely a matter of how much time it takes (which can be measured by the first arrival of grout detected by the cameras). For low pressure permeation grouting, the grout may never pass through the region of the borehole cameras because the grout may find a flow path with a much lower resistance. Since the budget for the MPI demonstration was low cost and schedule tight, there was no time or money to implement a comprehensive quality control and assurance procedure. If additional work is conducted using the MPI system, the recommendations forwarded under Section 4.3.1 should be implemented. 
APPENDIX

Buried Waste Formulation Basis 
There should be sufficient miscellaneous waste to fill the pits and concrete vault. The waste placed within any trench/vault should have the following approximate percentages (based upon volume):

A.1 $35 \%$ scrap metal, such as metal filings from machining operations, steel blanks, metal pieces up to about 6 inches in diameter. Scrap metal to be placed within cardboard drums/boxes and shrunk wrapped with several layers of plastic.

A.2 $18 \%$ wood, whole pine pallets, pine core boxes, wooden shavings. Wooden shavings (inside cardboard box) and core boxes to have shrink wrap around them.

A.3 47\% plastic, rubber, paper, tyvek, HEPA filters, glassware, and other laboratory type of equipment. These items may include stacked computer paper, shredded paper inside of plastic bags, mason jars, cardboard boxes and drums. 


\section{FIGURES}




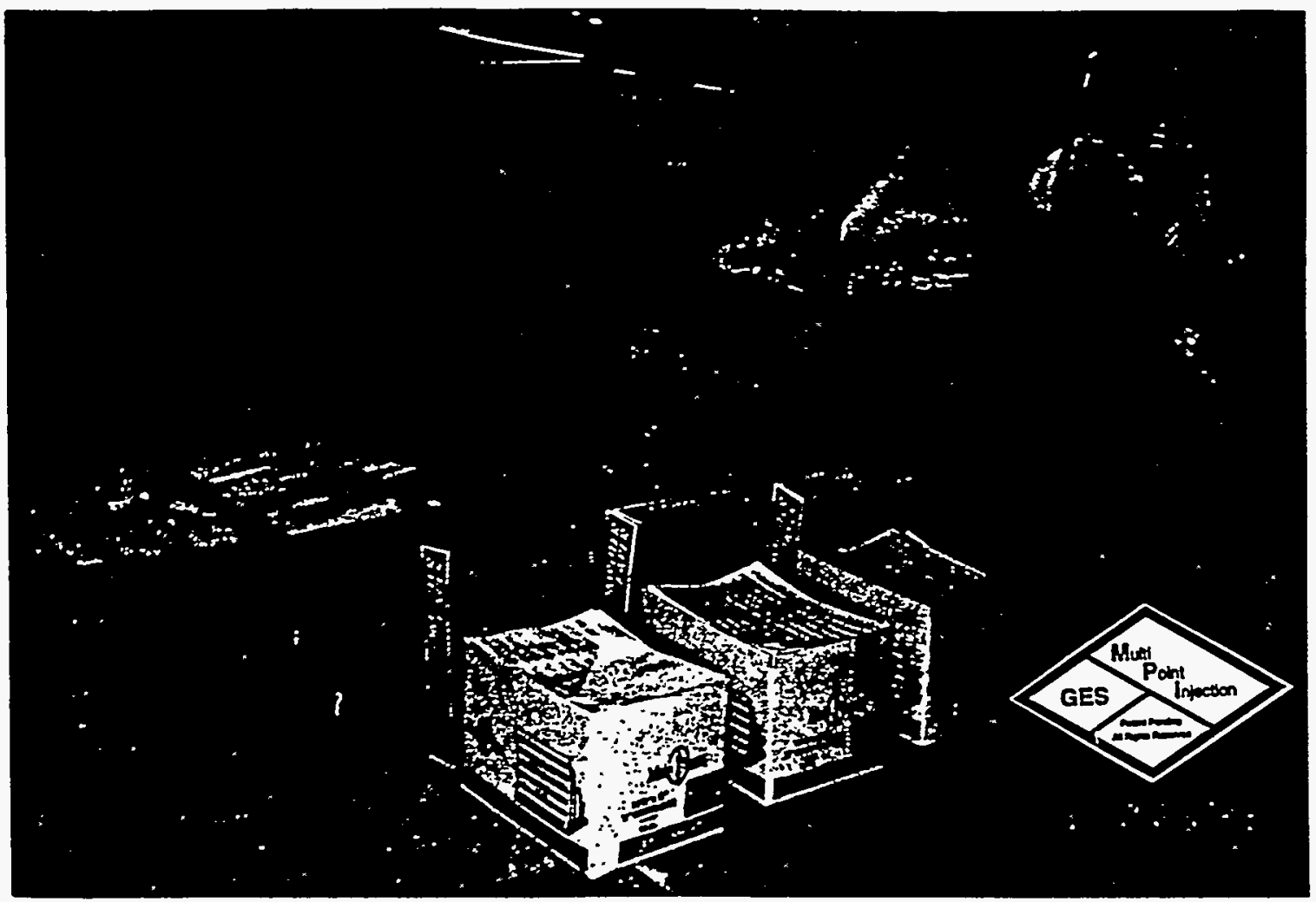

gure 1

Waste Form Used During Duncan, Ok. Solidification Project

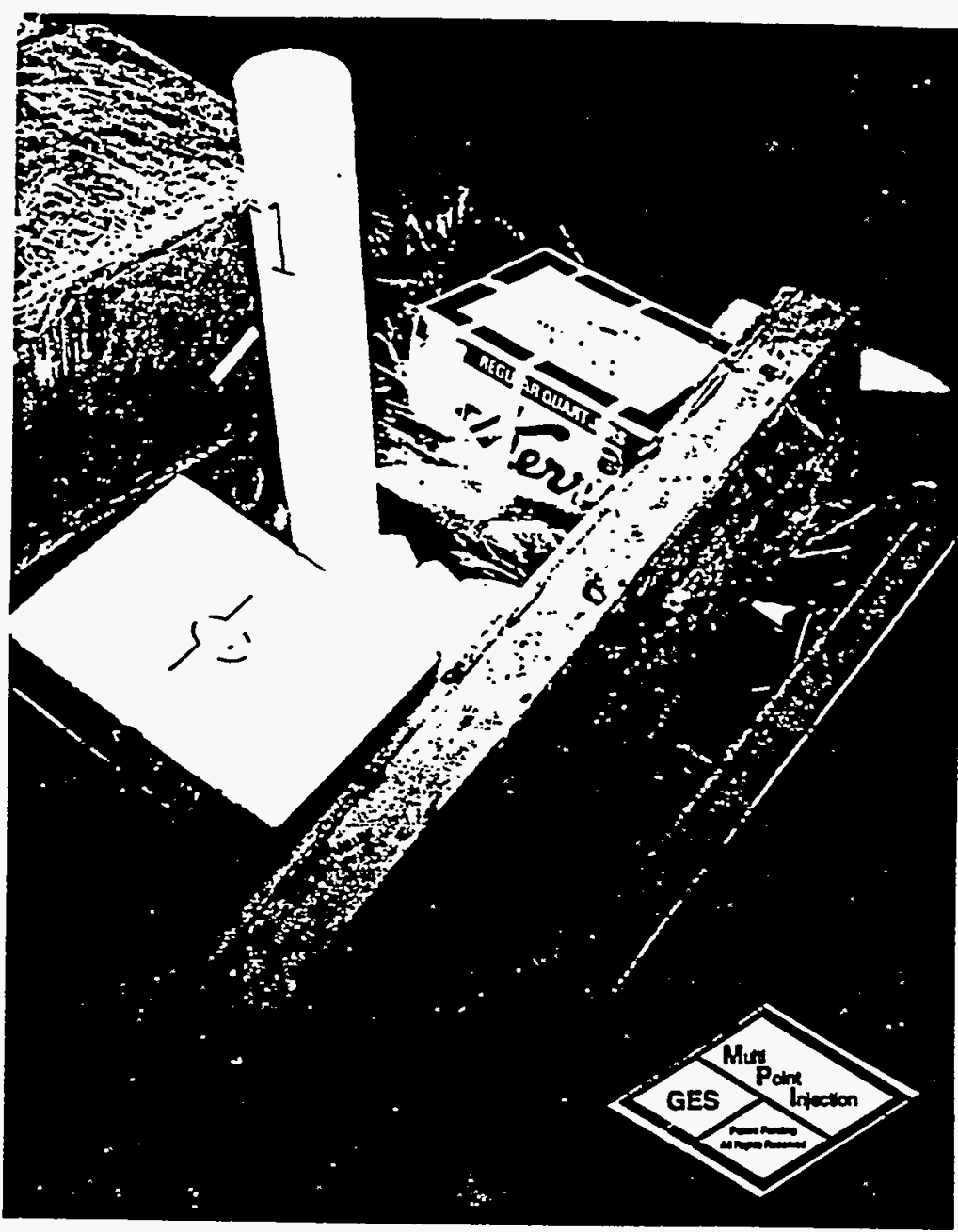




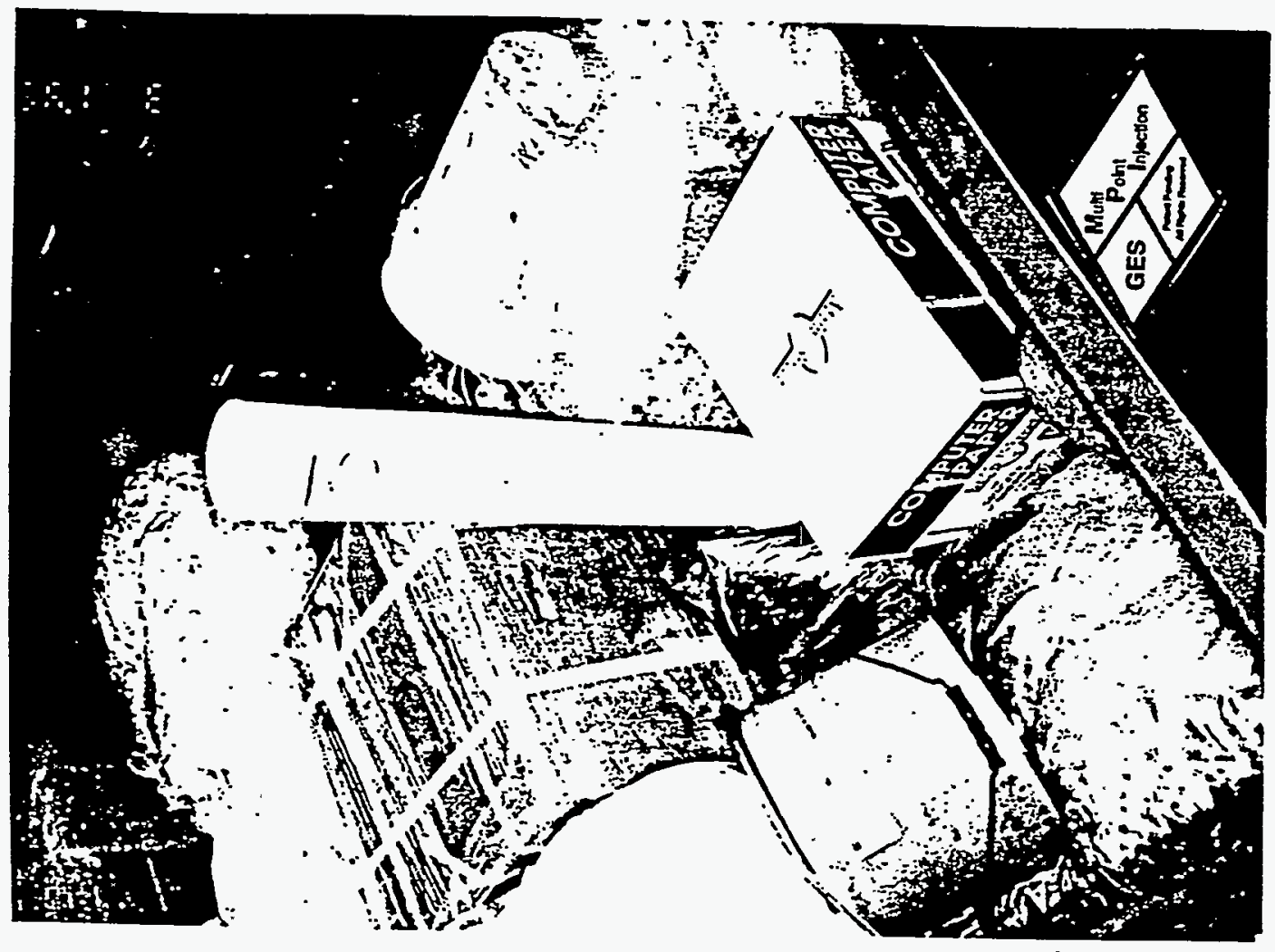

0
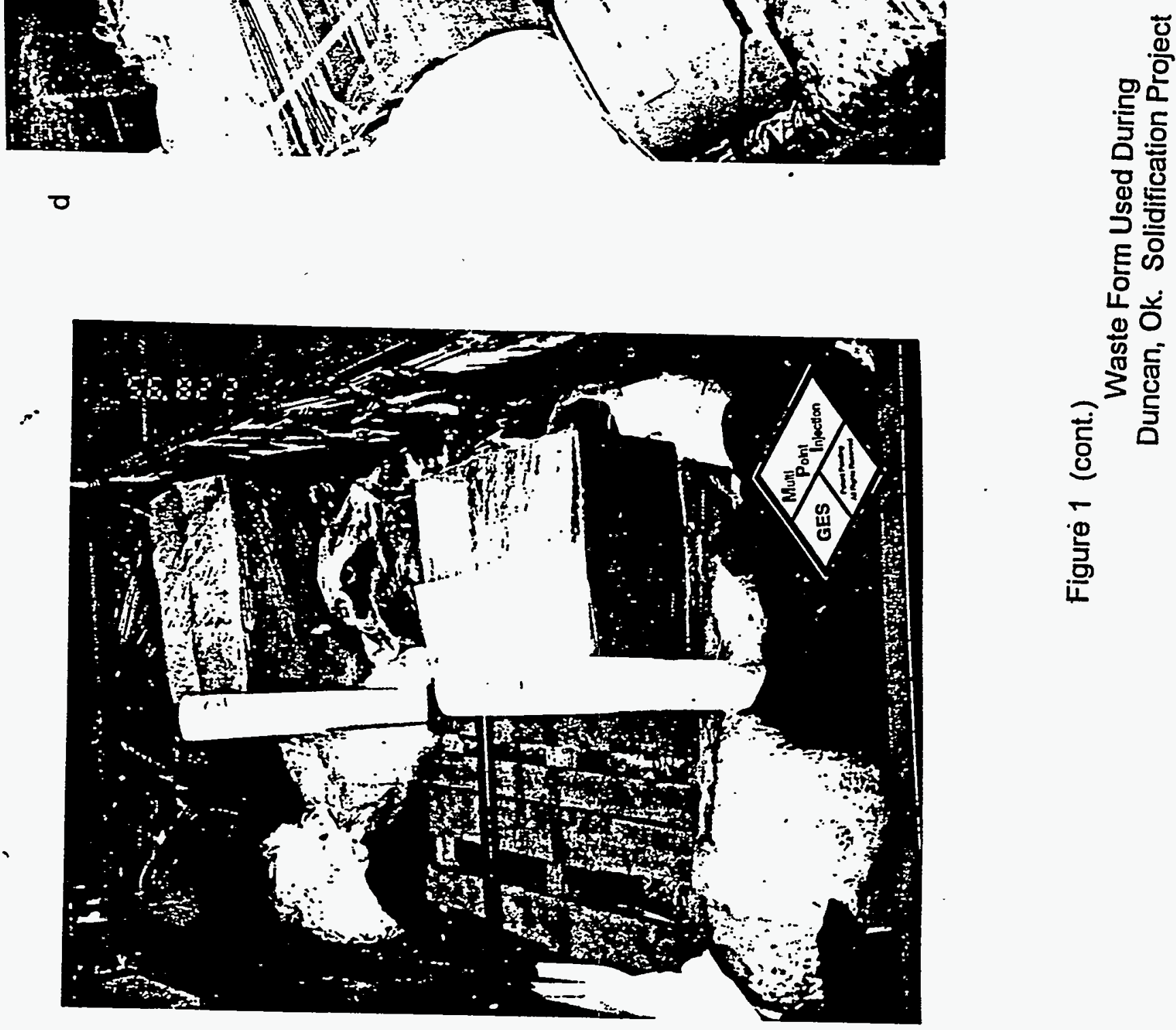


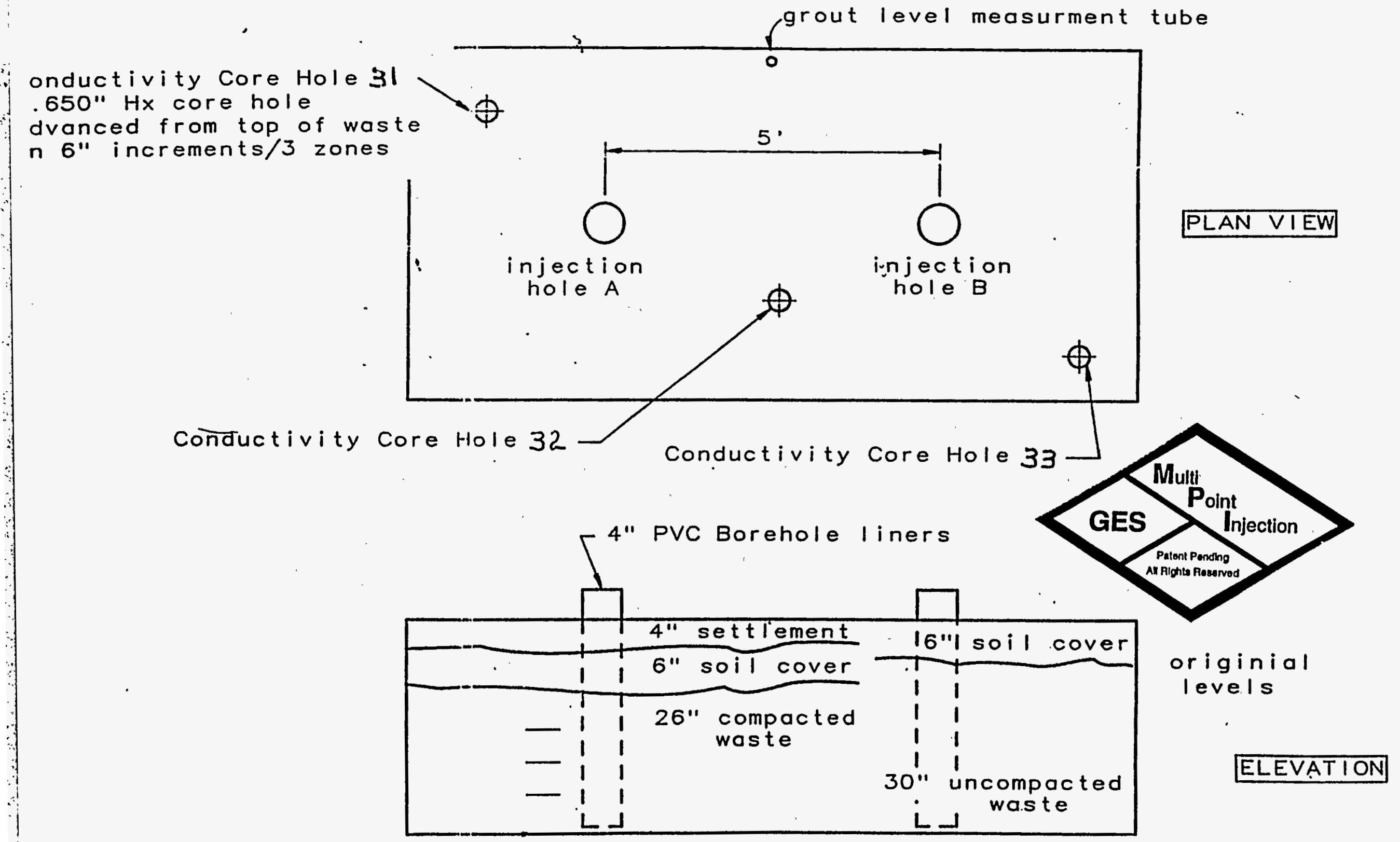

Figure 2 Arrangement of Municipal Waste Solidified at Duncan, Ok. Location Plan for MPI Injection Holes;

Corehole Pattern to Test Monolith 


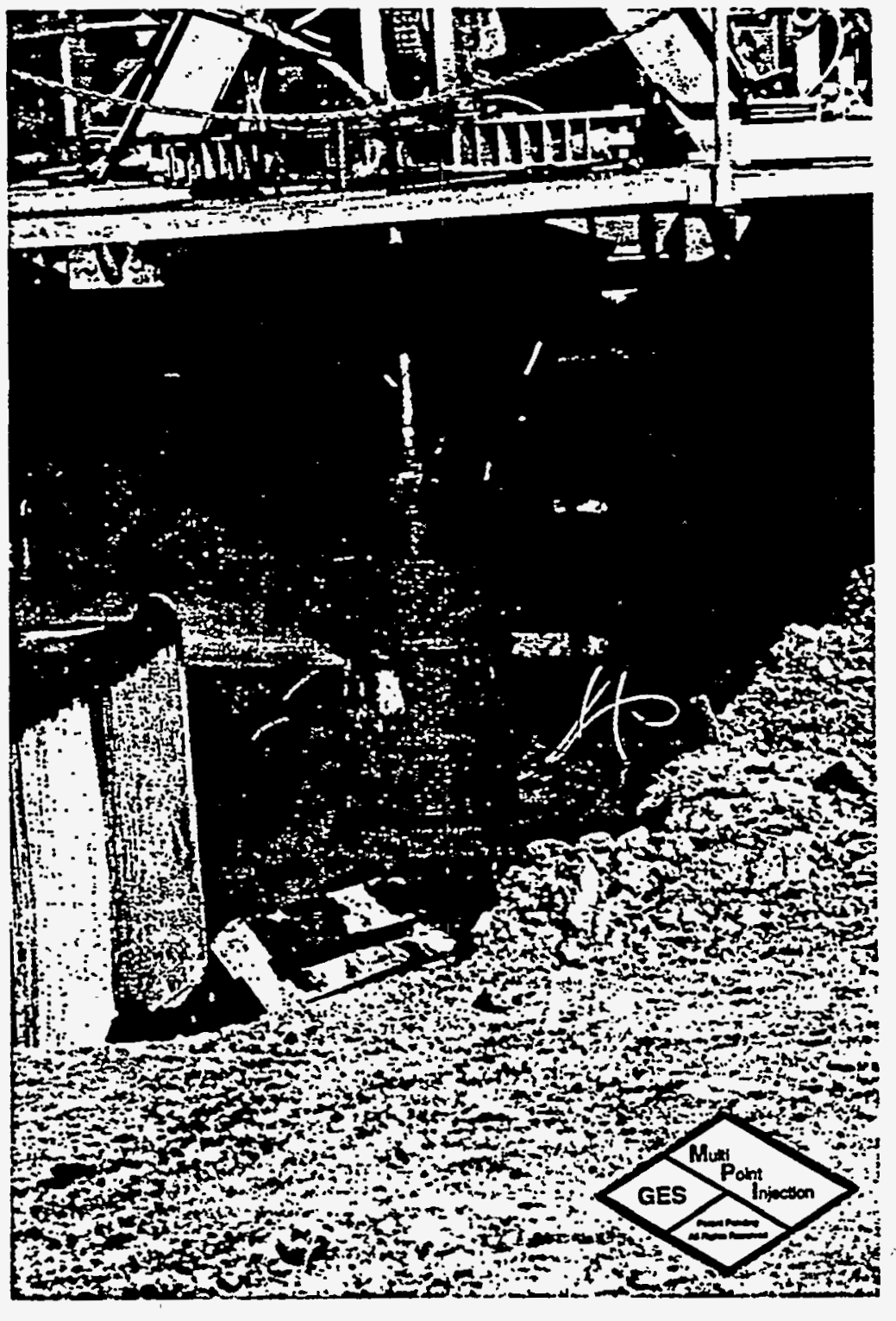

Figure 3 Barrel Cutting with Hose Suspended MPI Jetting Monitor Duncan, Ok. Project 


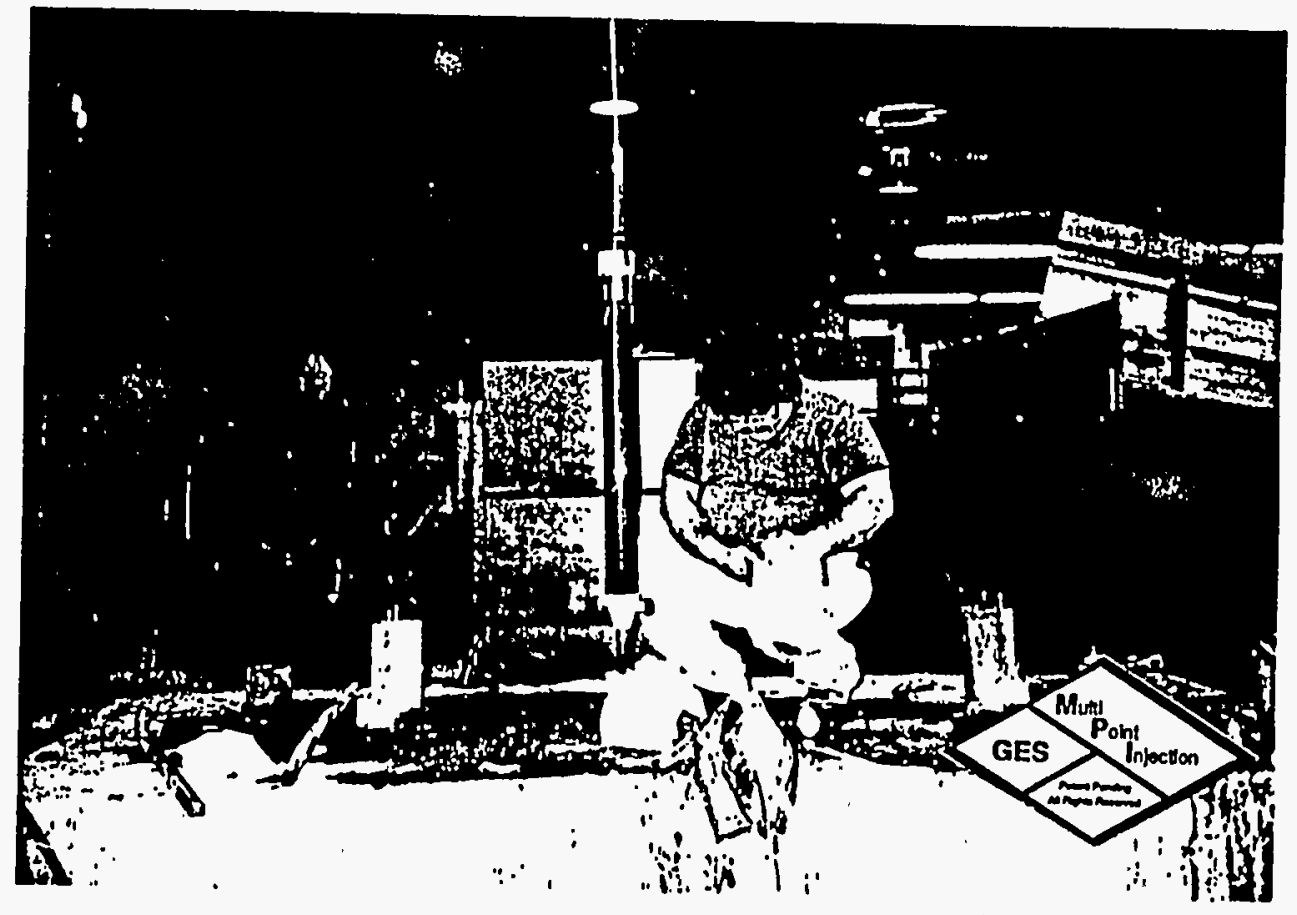

Figure 4 Guelph Permeameter Test Set-Up For Verifying Homogeneity of Monolithic Treatment of Waste Solidified Using MPI Process, Duncan, Ok. Project 

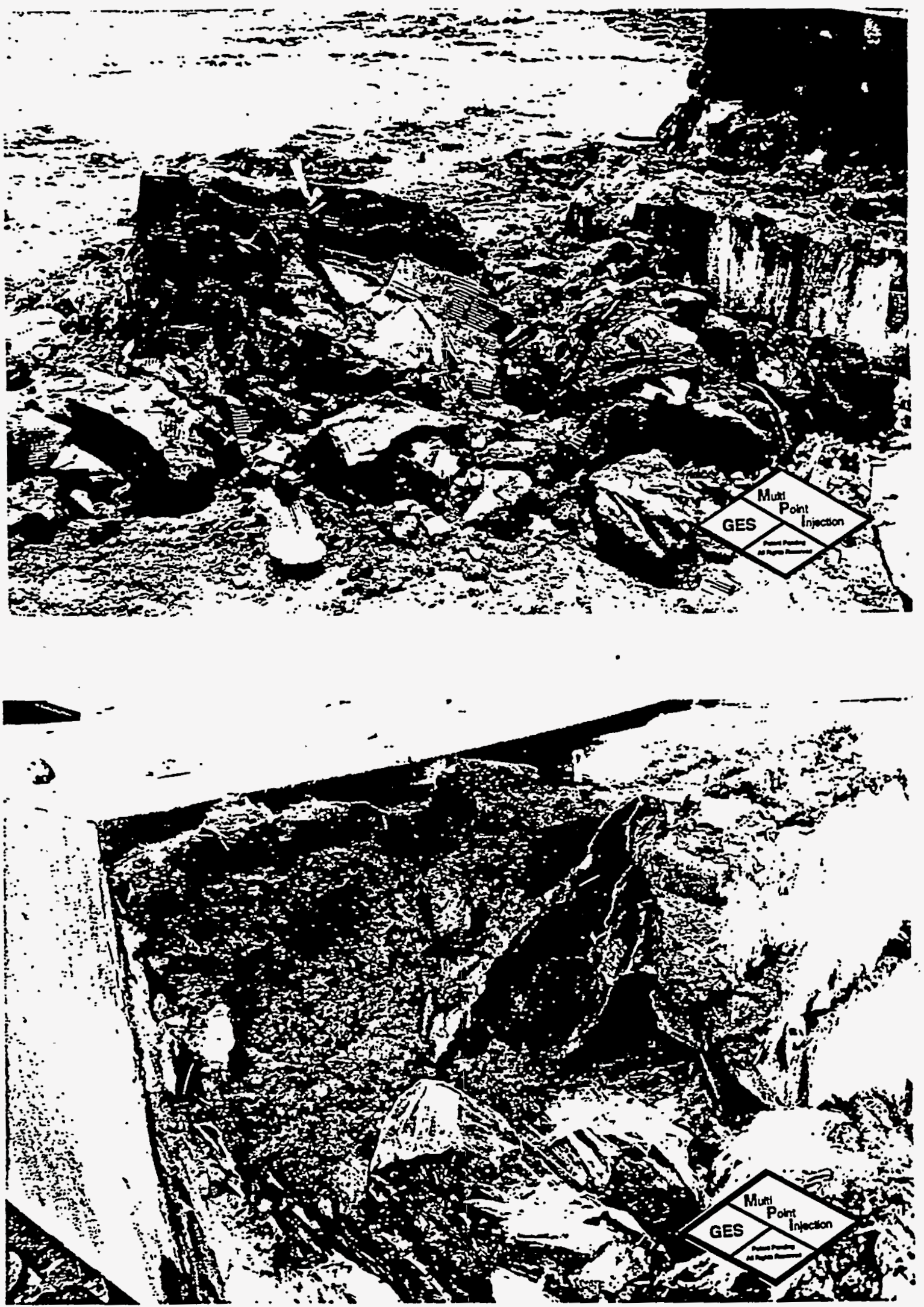

Figure 5 Poorly Treated Municipal Waste, MPI Reduction to Practice Duncan, OK. Project 


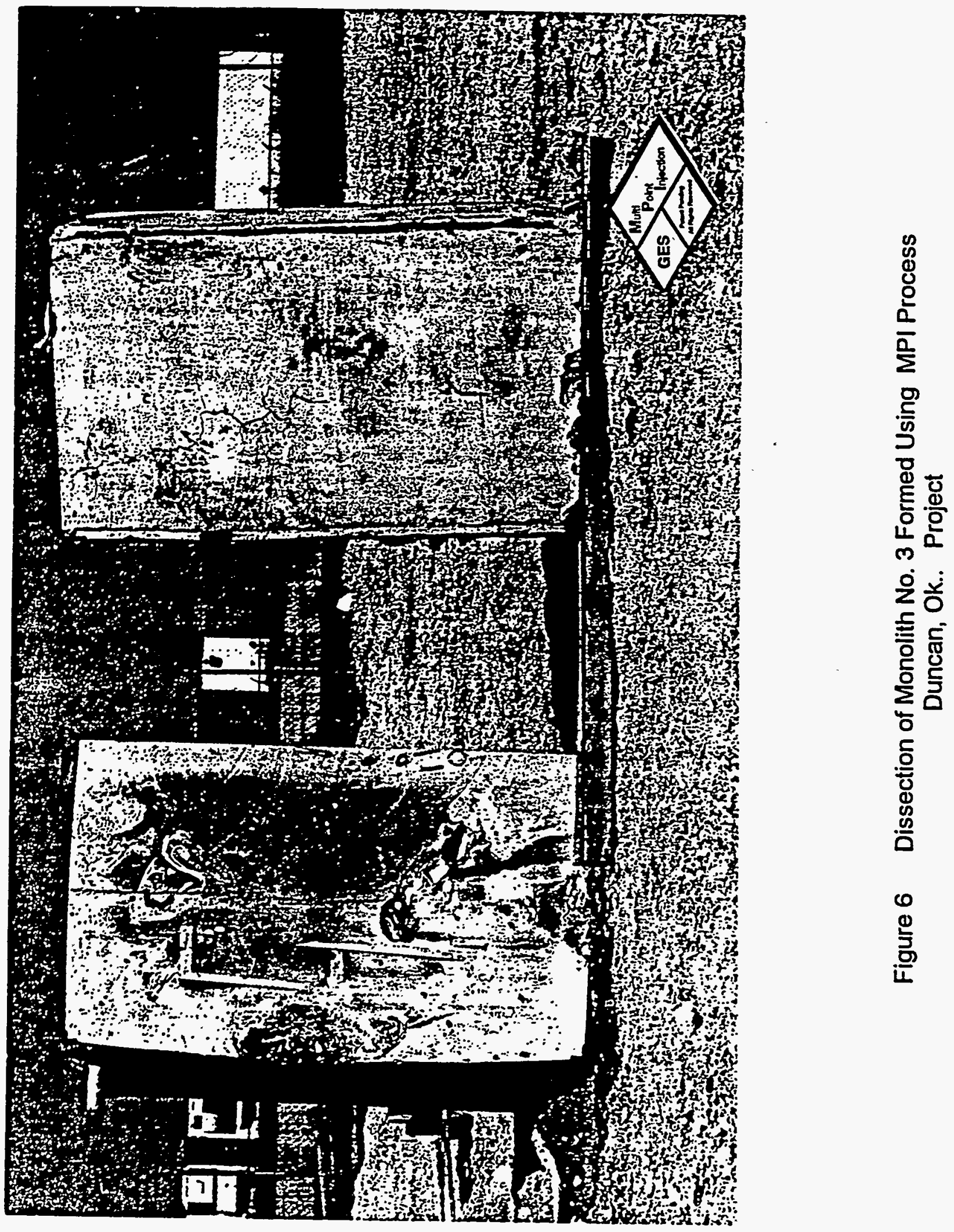




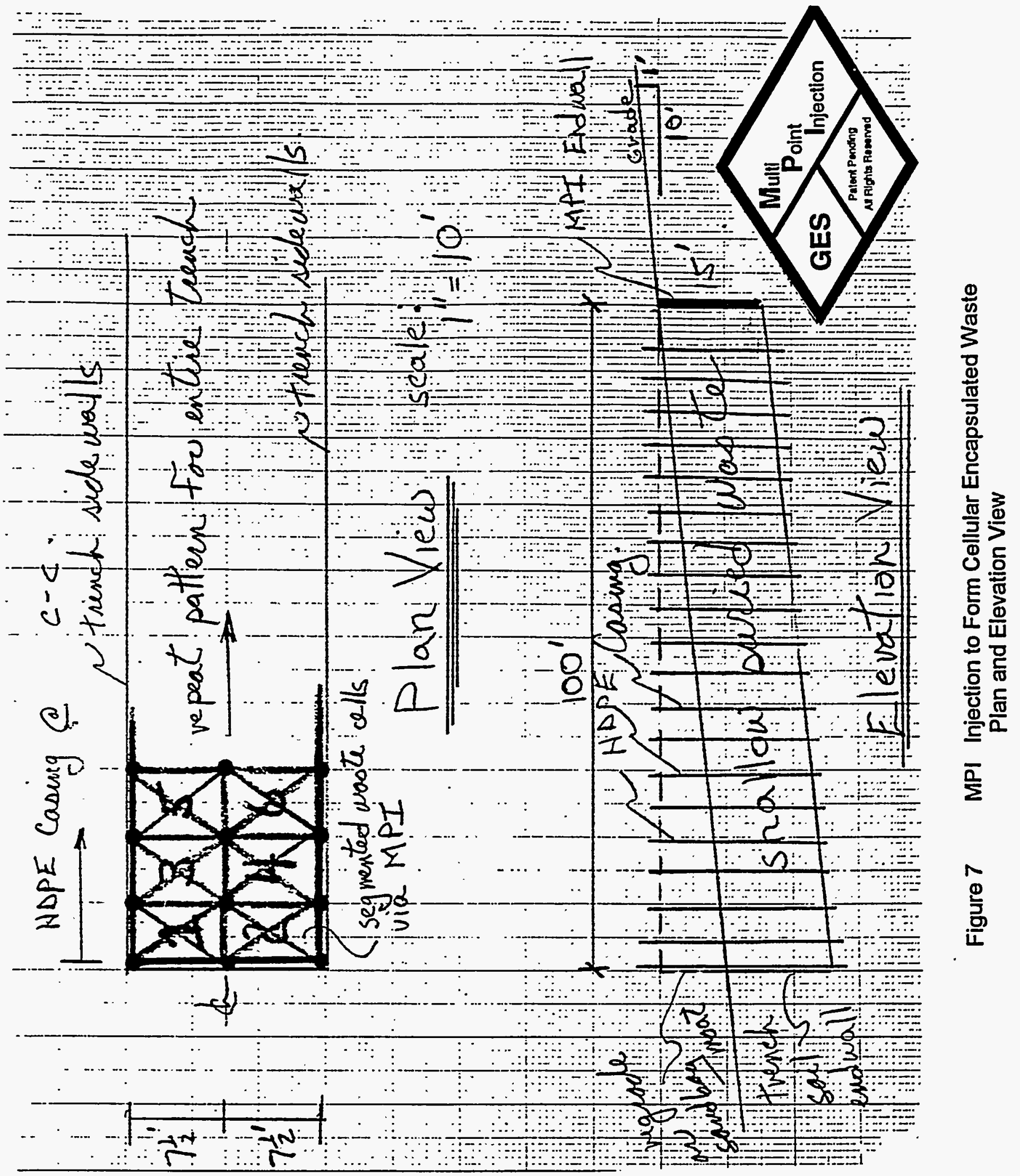




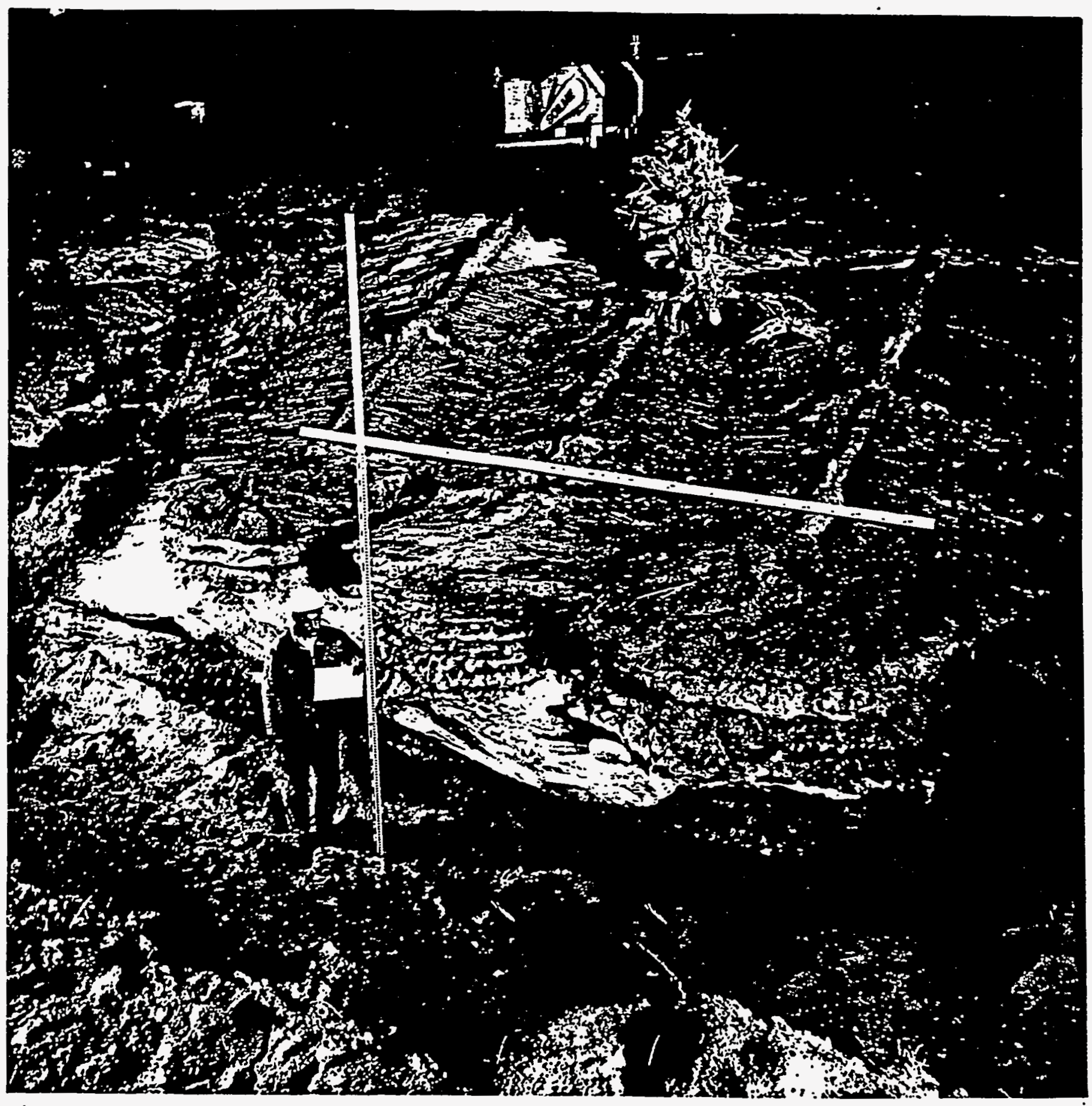

Figure 8 Photograph Illustrating Inclined Panel Wall Formed Using High Speed Jetting With Cement Grout (Fondazioni Speciali \& GES) 

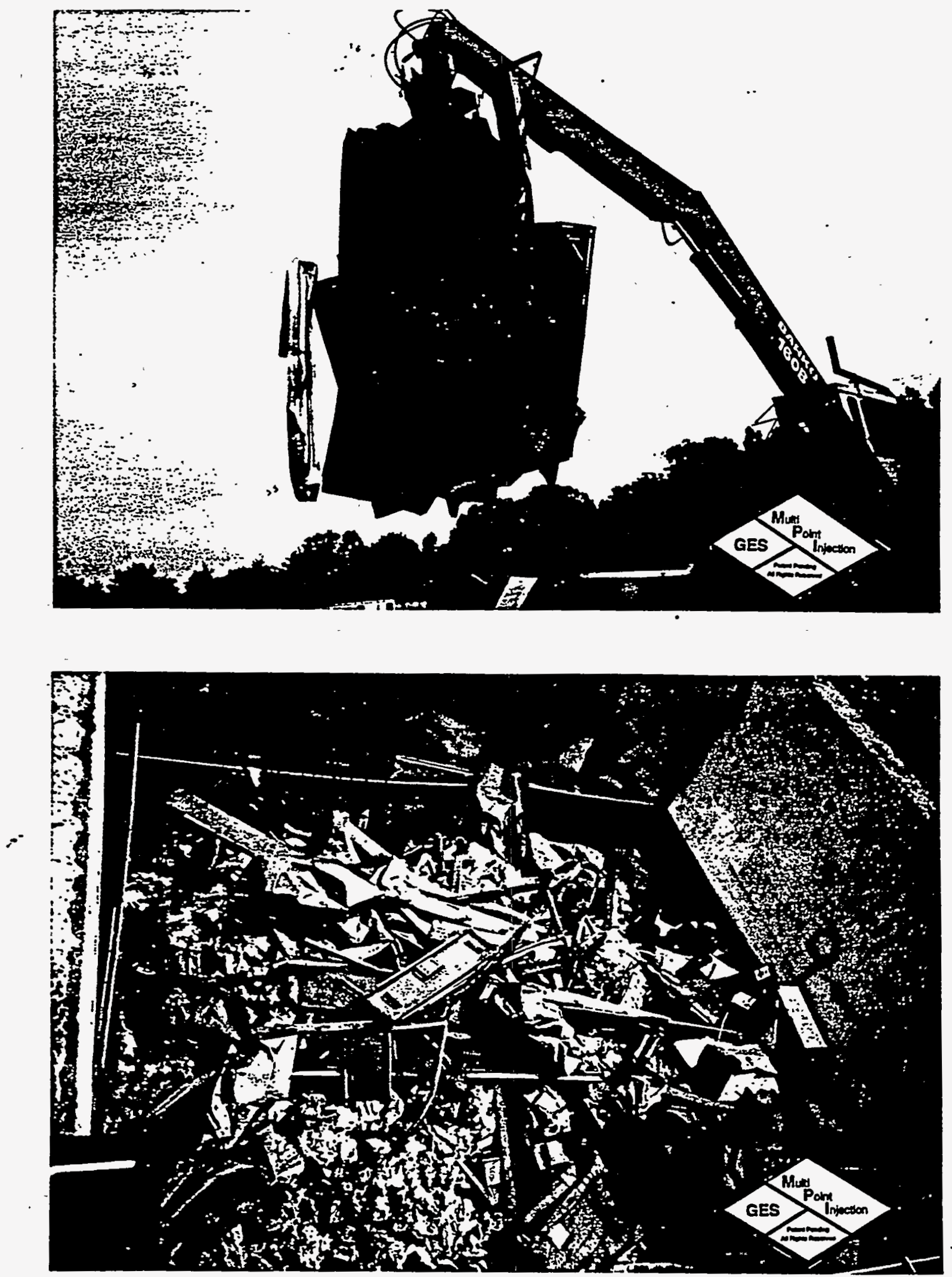

Figure 9 Waste Form Deposited into MPI Test Bed at Oak Ridge 


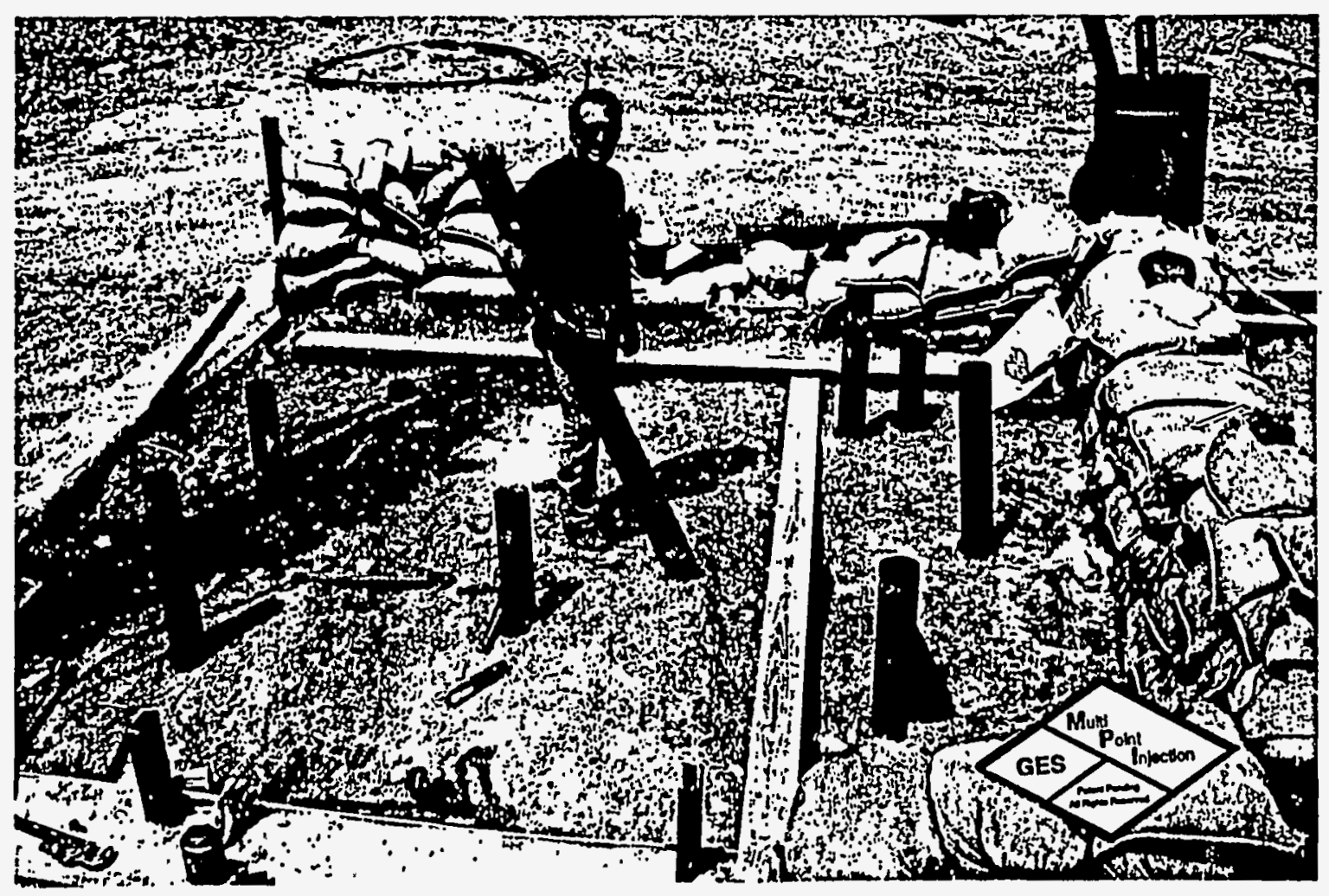

Figure 10 HDPE Casing Layout Used to Perform MPI Injection of Waste in Oak Ridge Test Bed 


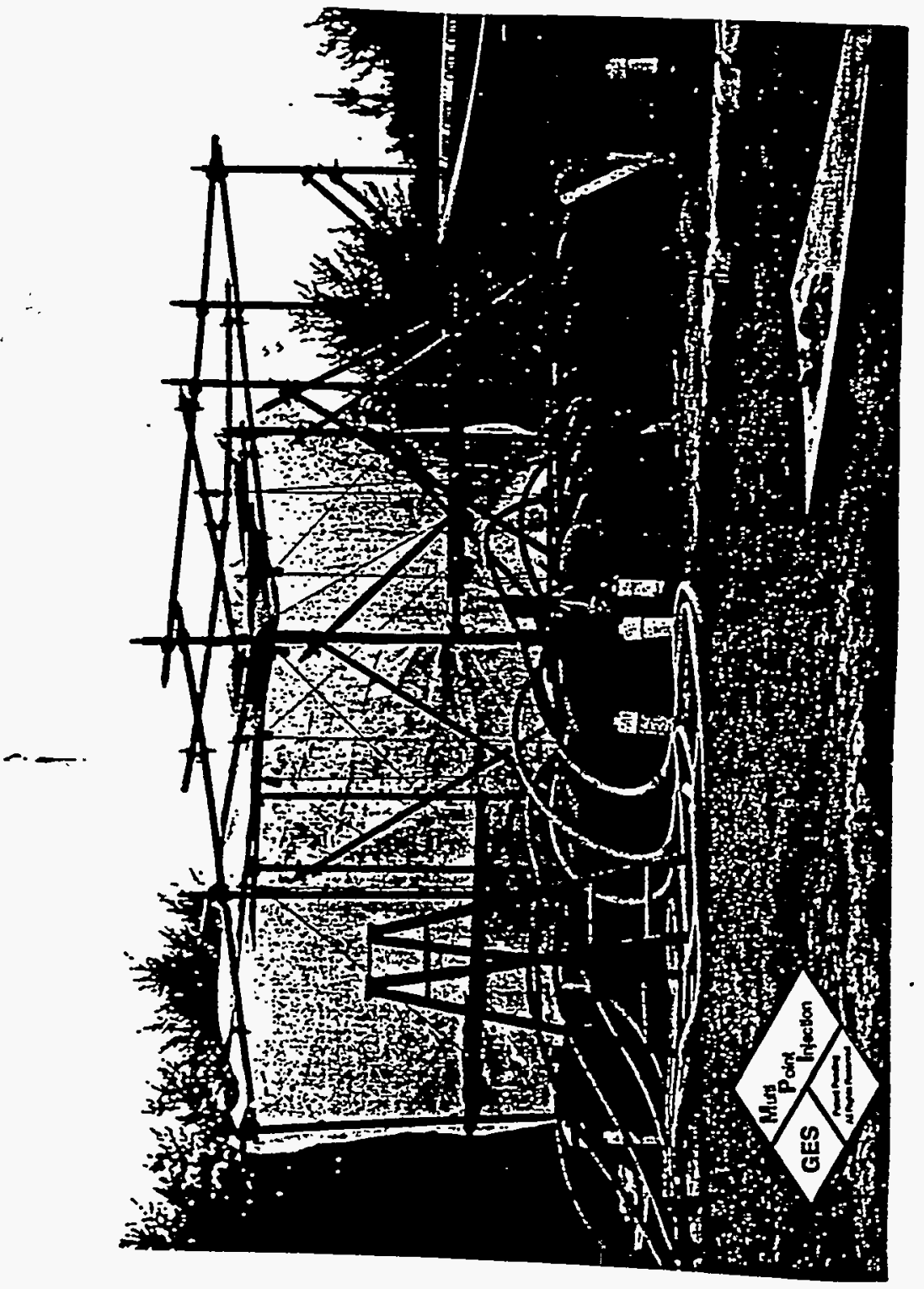

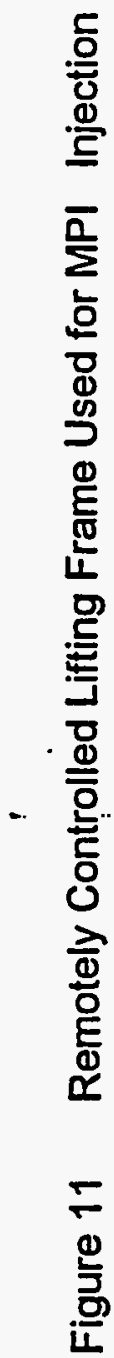





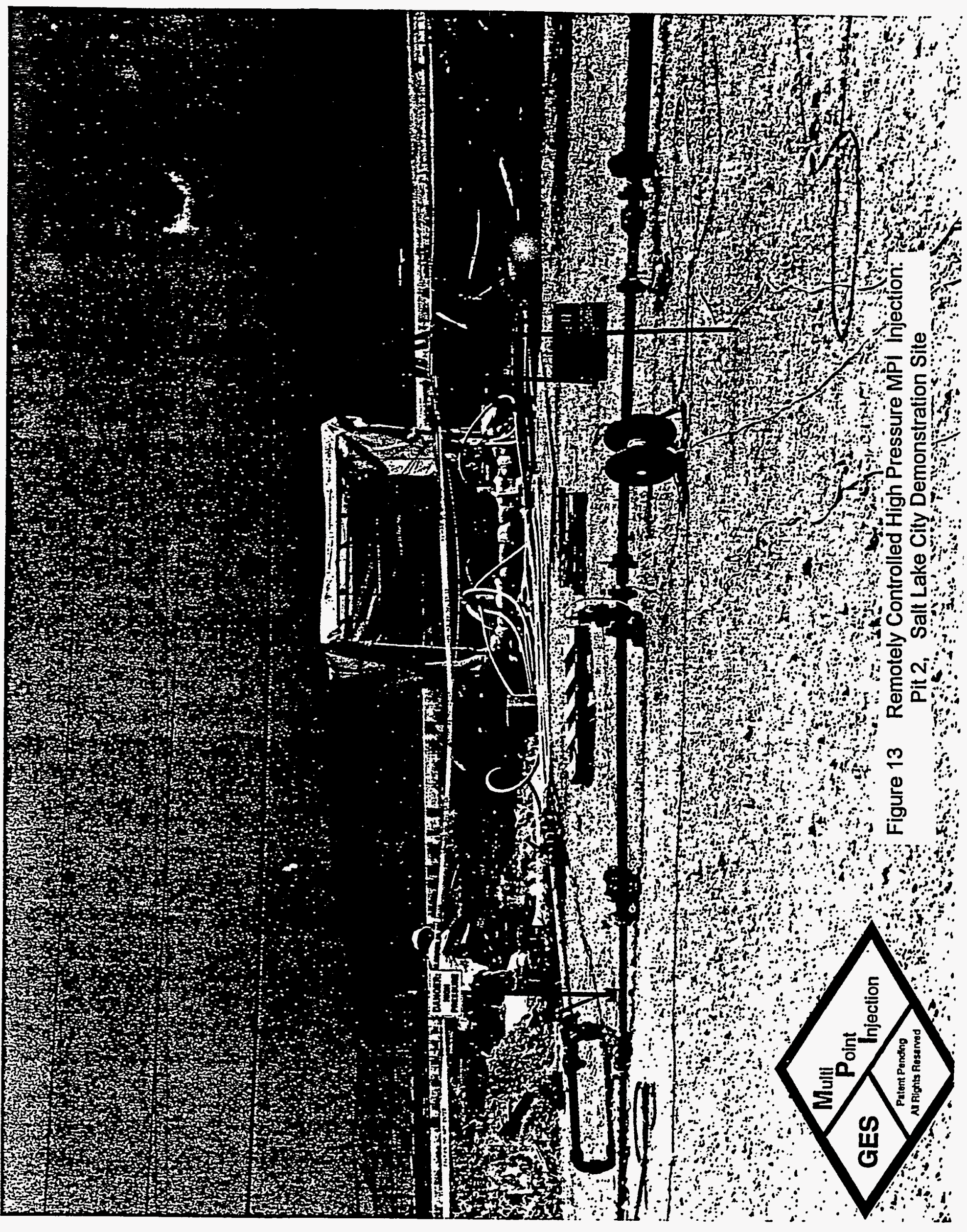




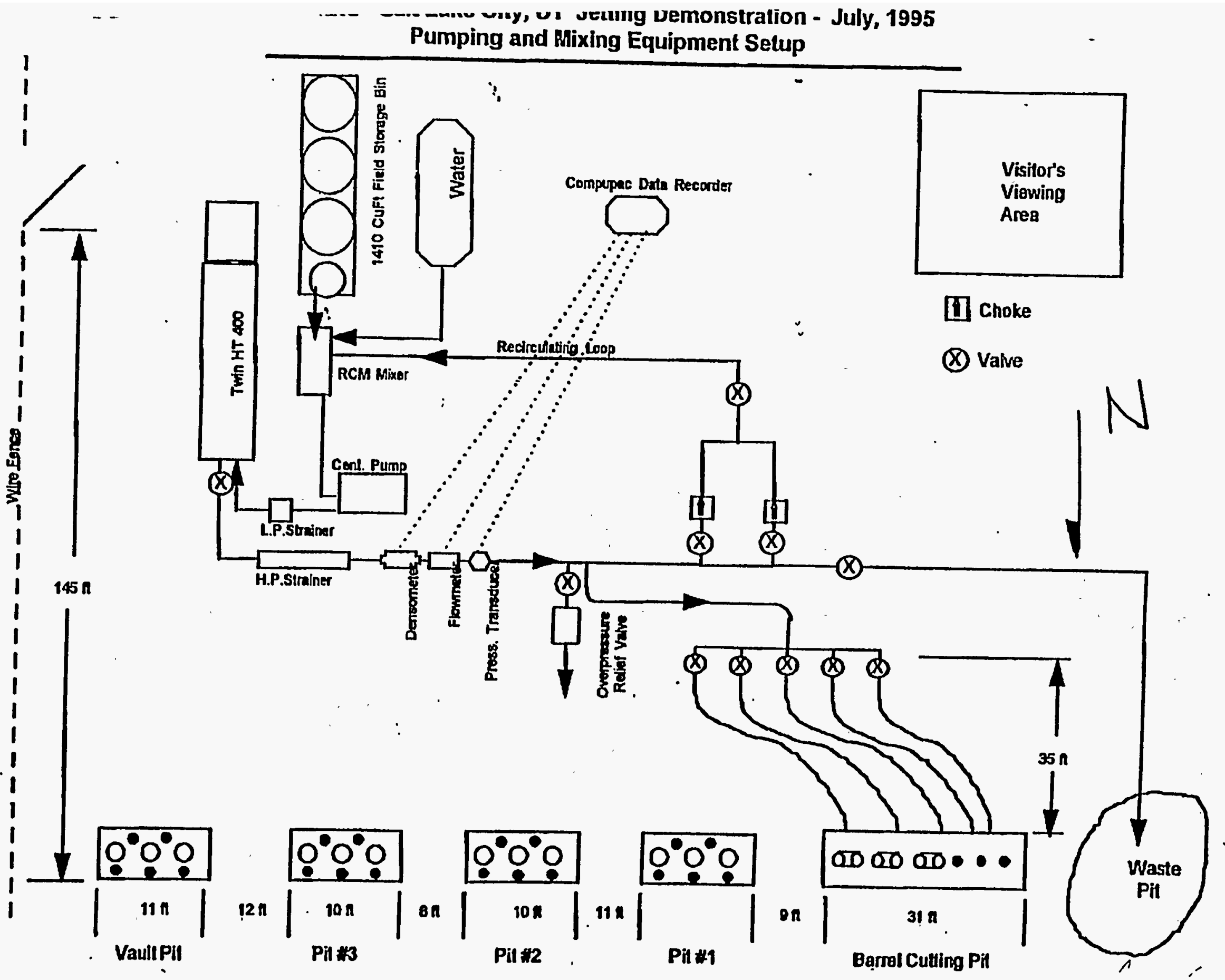

Figure 14 Schematic Illustrating the General View of Salt Lake City Test Site 


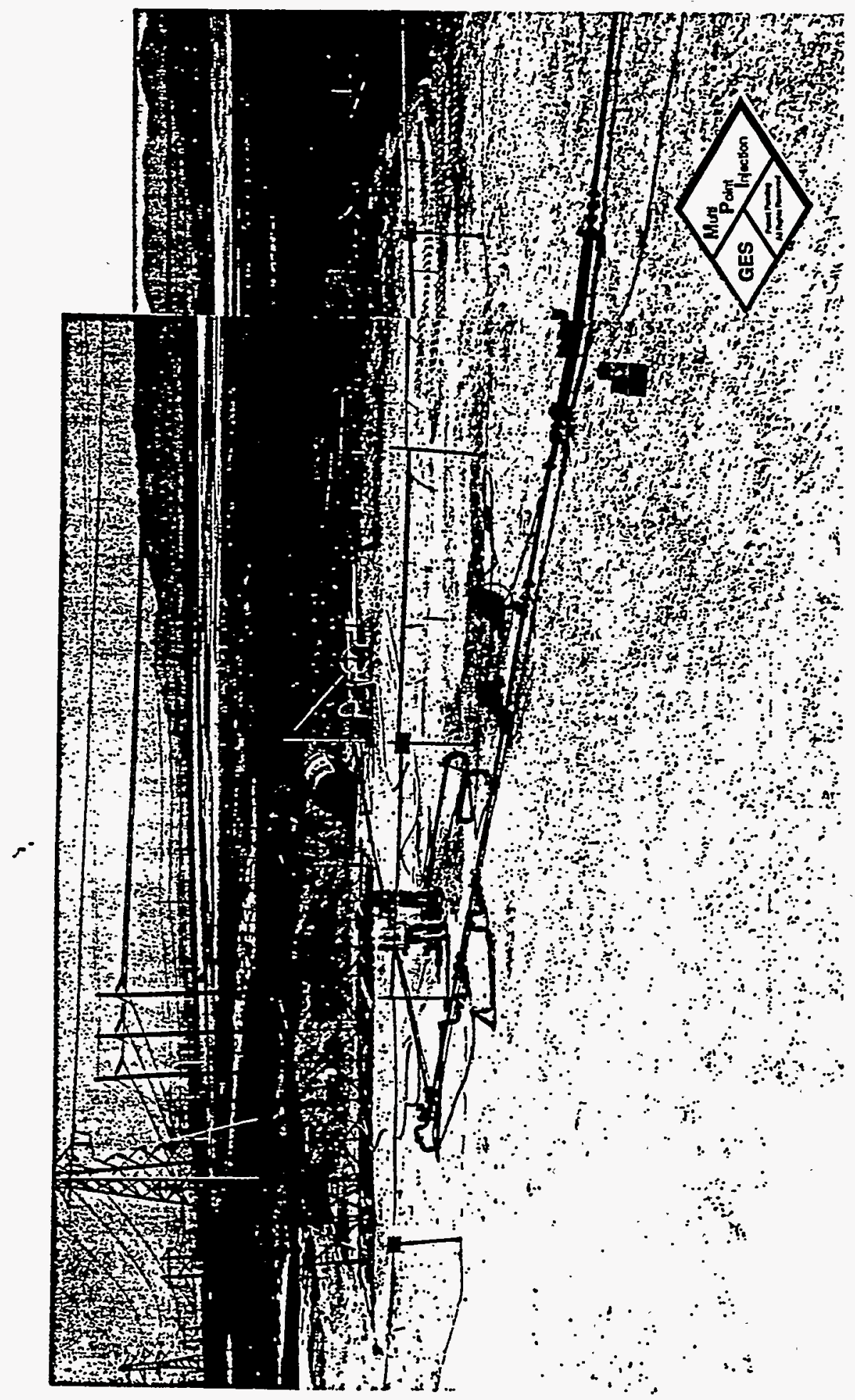

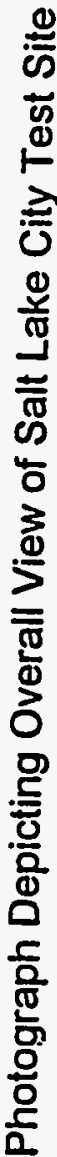

20

高 


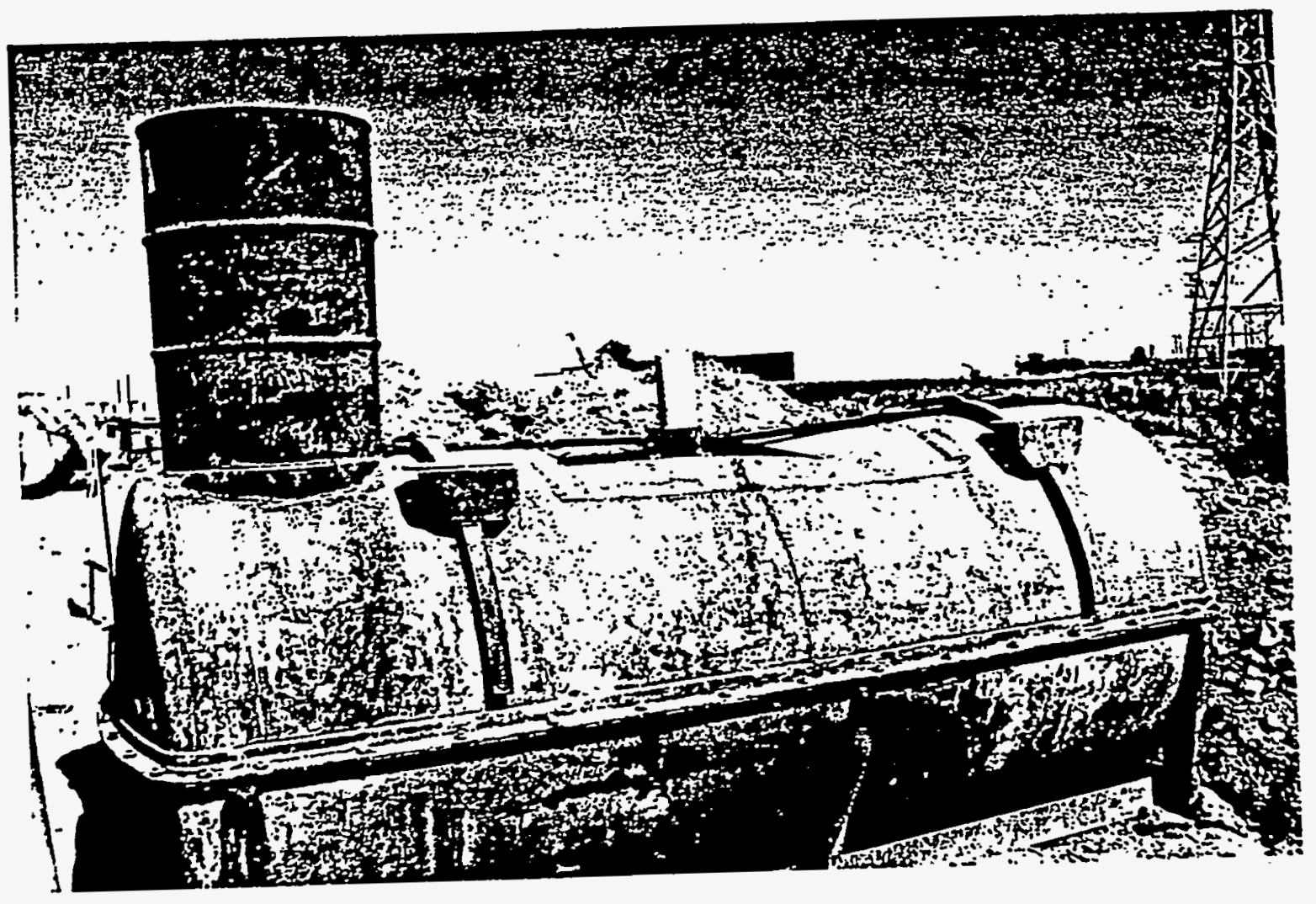

Figure 16 Photograph of Test Tank to Check MPI Jetting Tools and Verify Equipment Function 


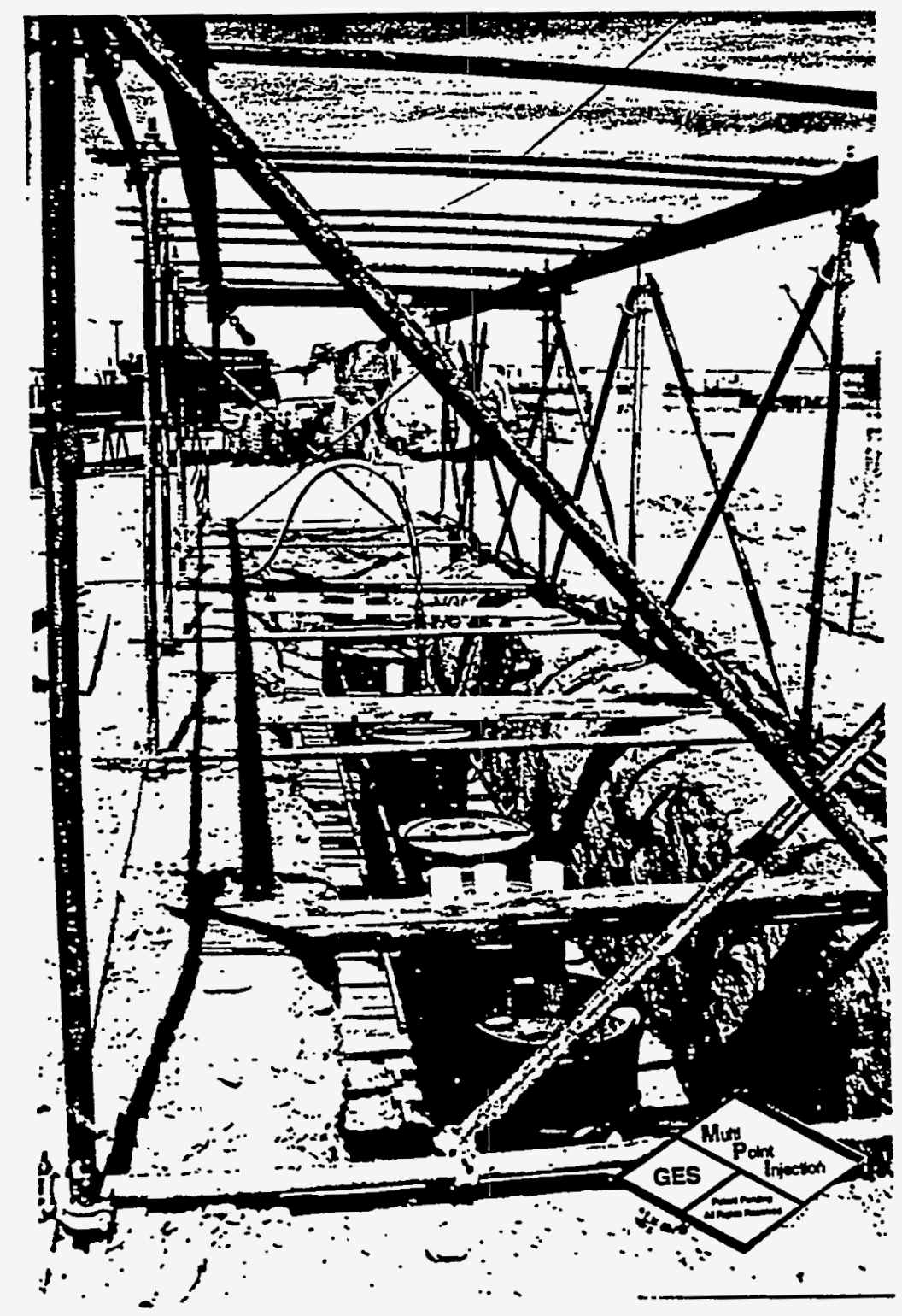

Figure 17 Close-up Photograph of Barrel Cutting Pit ; MPI Demonstration Salt Lake City 


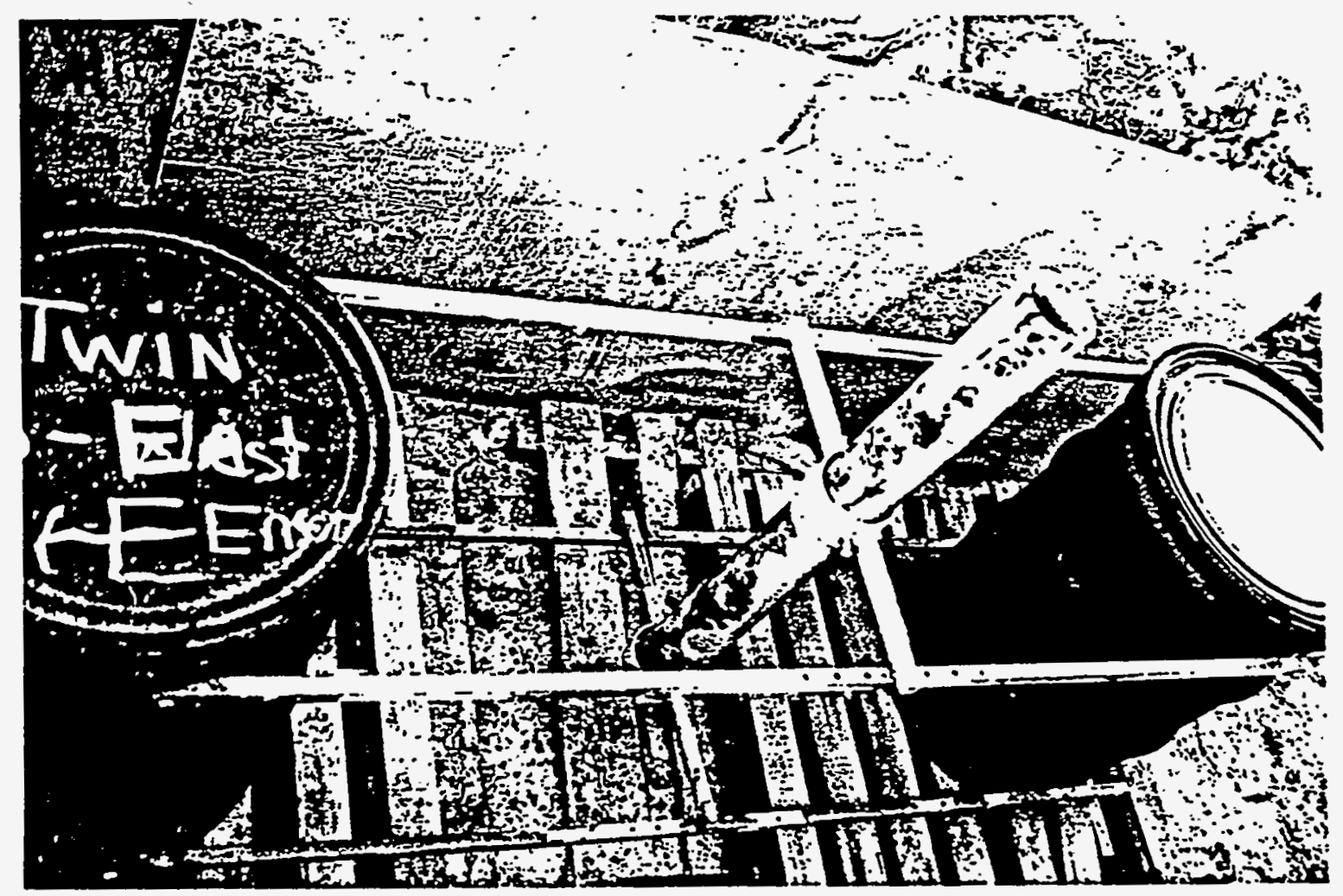

Figure 18 Close-up Phistograph of Twin Barrel Cutting Setup MPI Demonstration Salt Lake City 


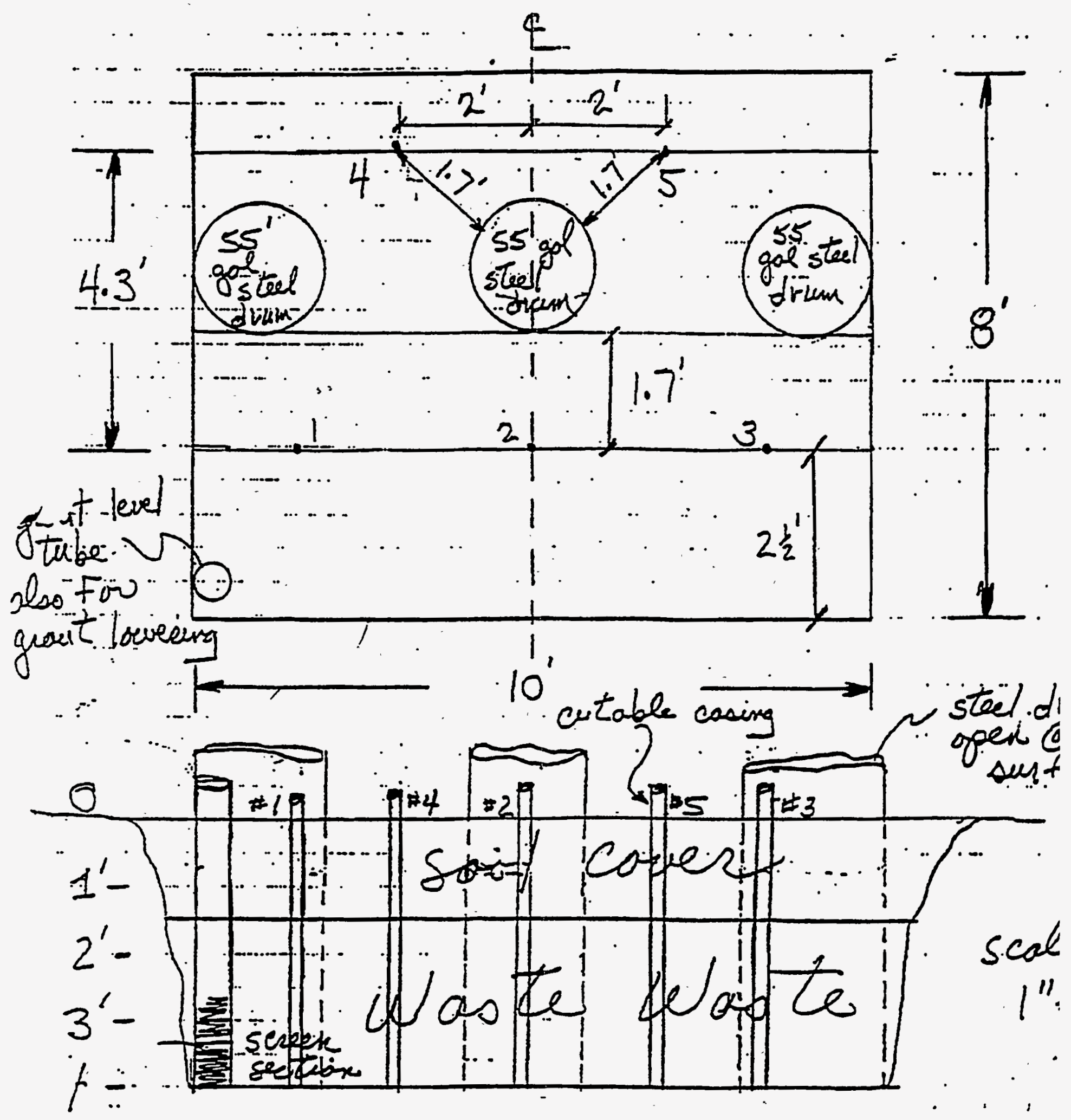

Figure 19 Arrangement of Waste to Demonstrate Influence of Various Waste Upon Cutting Ability of MPI Jetting Tools Salt Lake City Demonstration 


\section{BotTOM ELEVATION}

$$
\text { I'ELE. }
$$

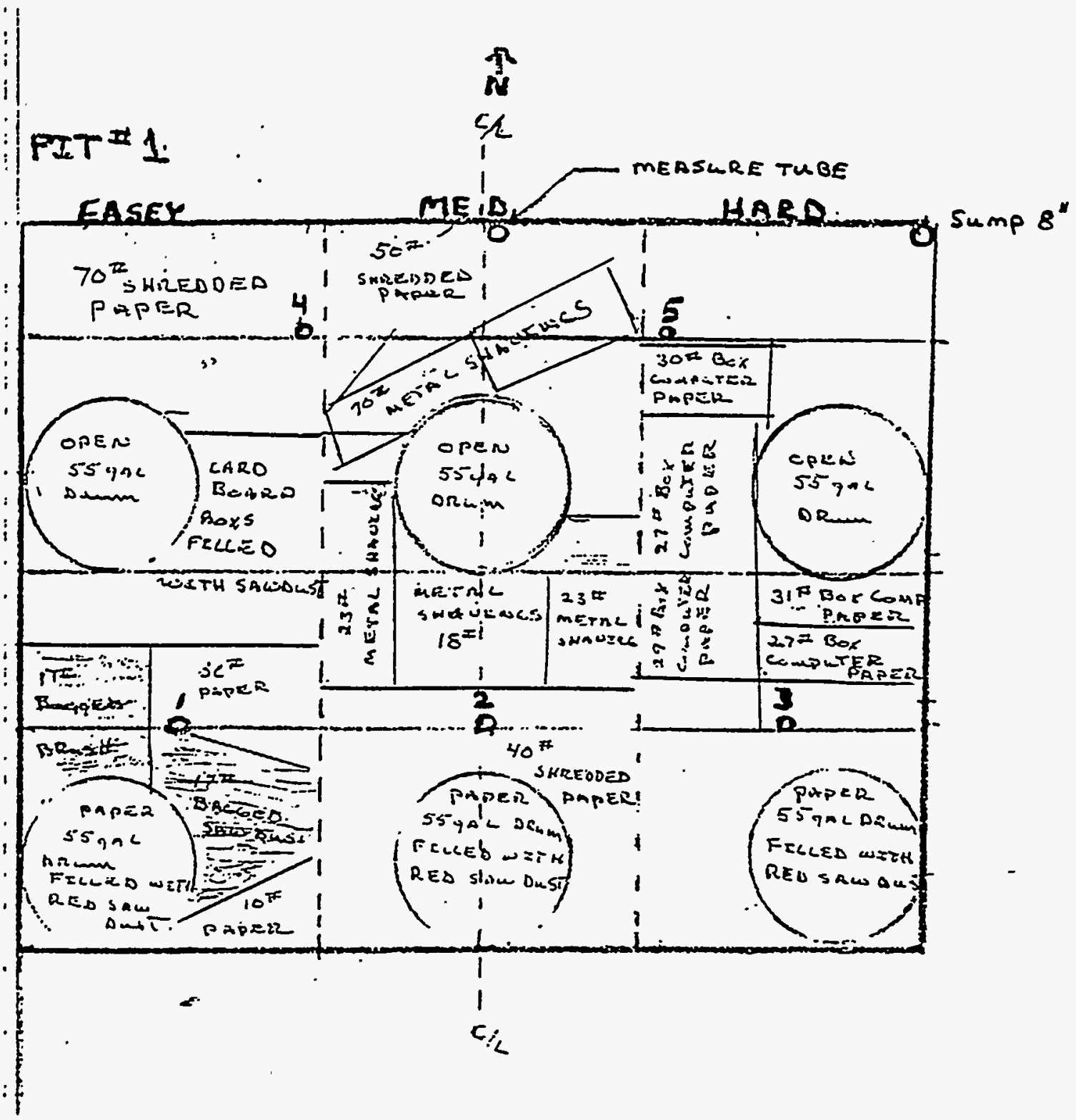

Figure 20 Sketch Illustrating Location of and Waste Inventory Placed Into Pit 1 MPI Demonstration Salt Lake City 


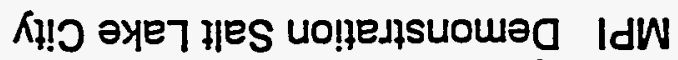

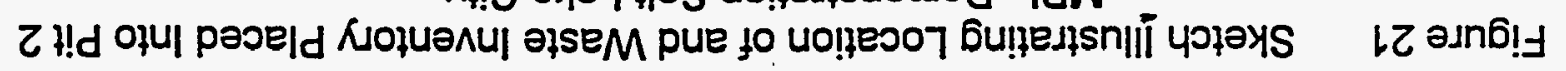

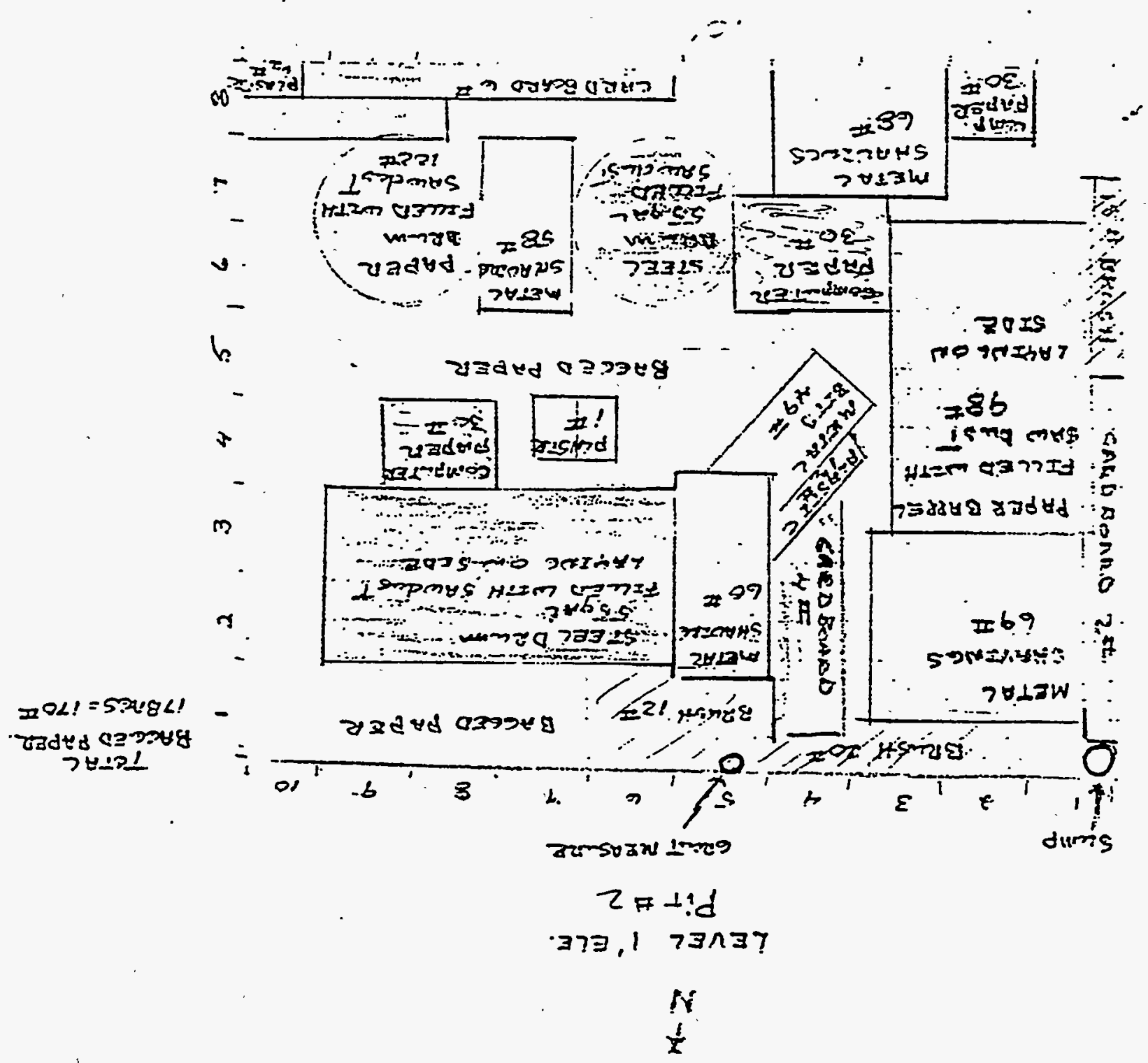


LEVEL $2^{\prime}$

PIT $=3$

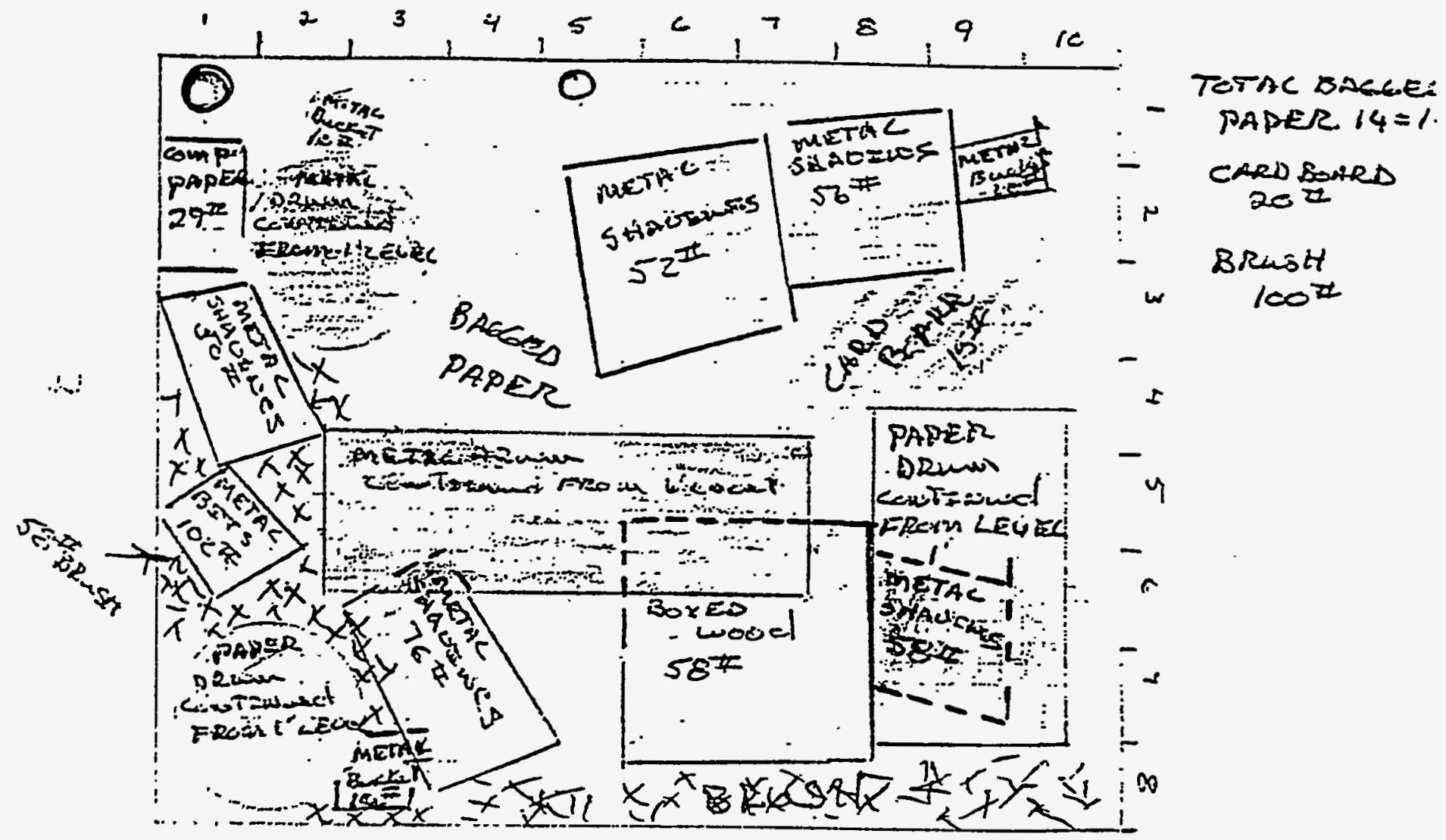

$\therefore$

Figure 22 Sketch Illustrating Location of and Waste Inventory Placed Into Pit 3 MPI Demonstration Salt Lake City 


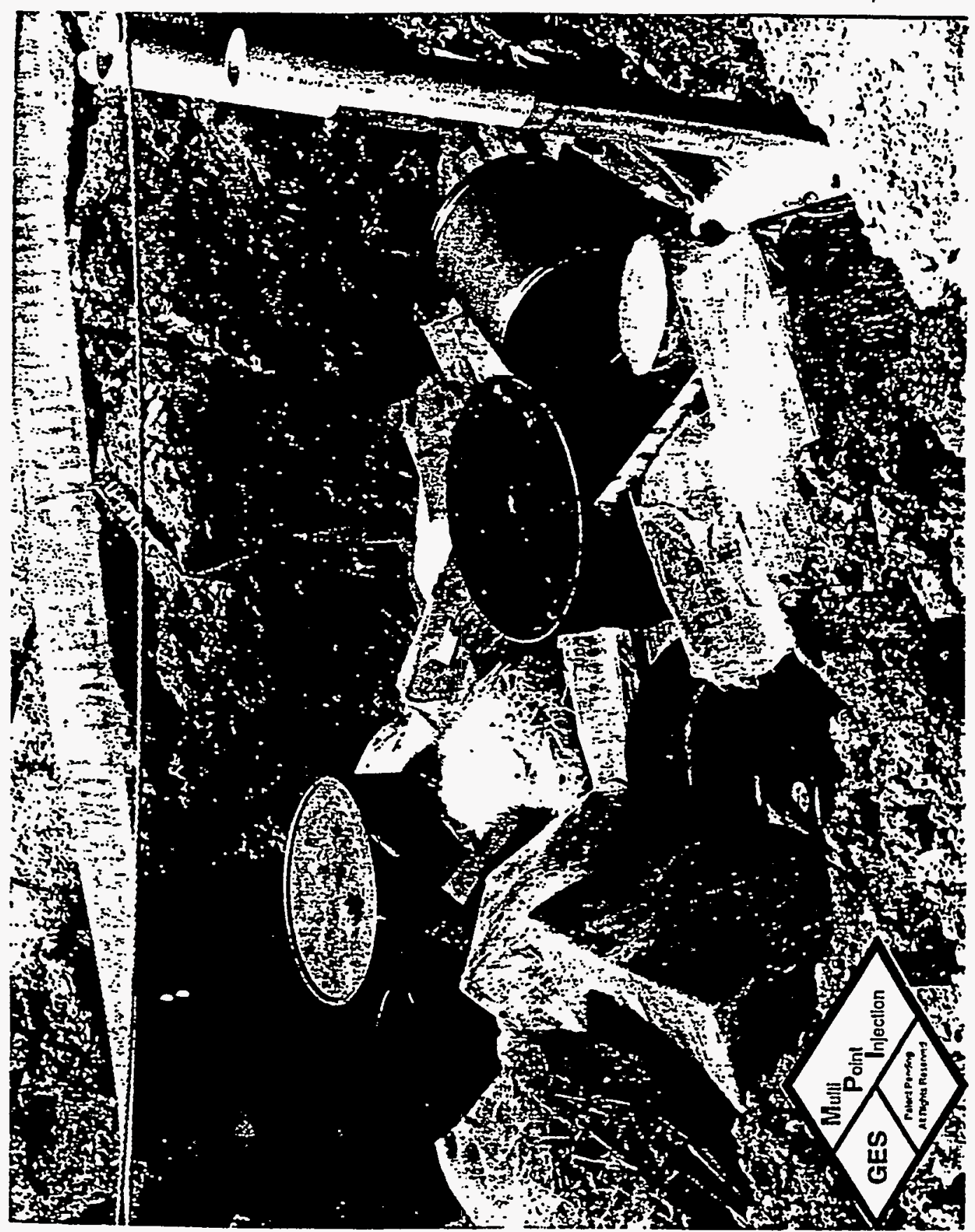

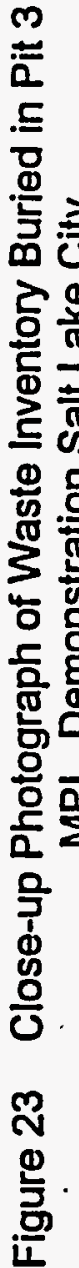




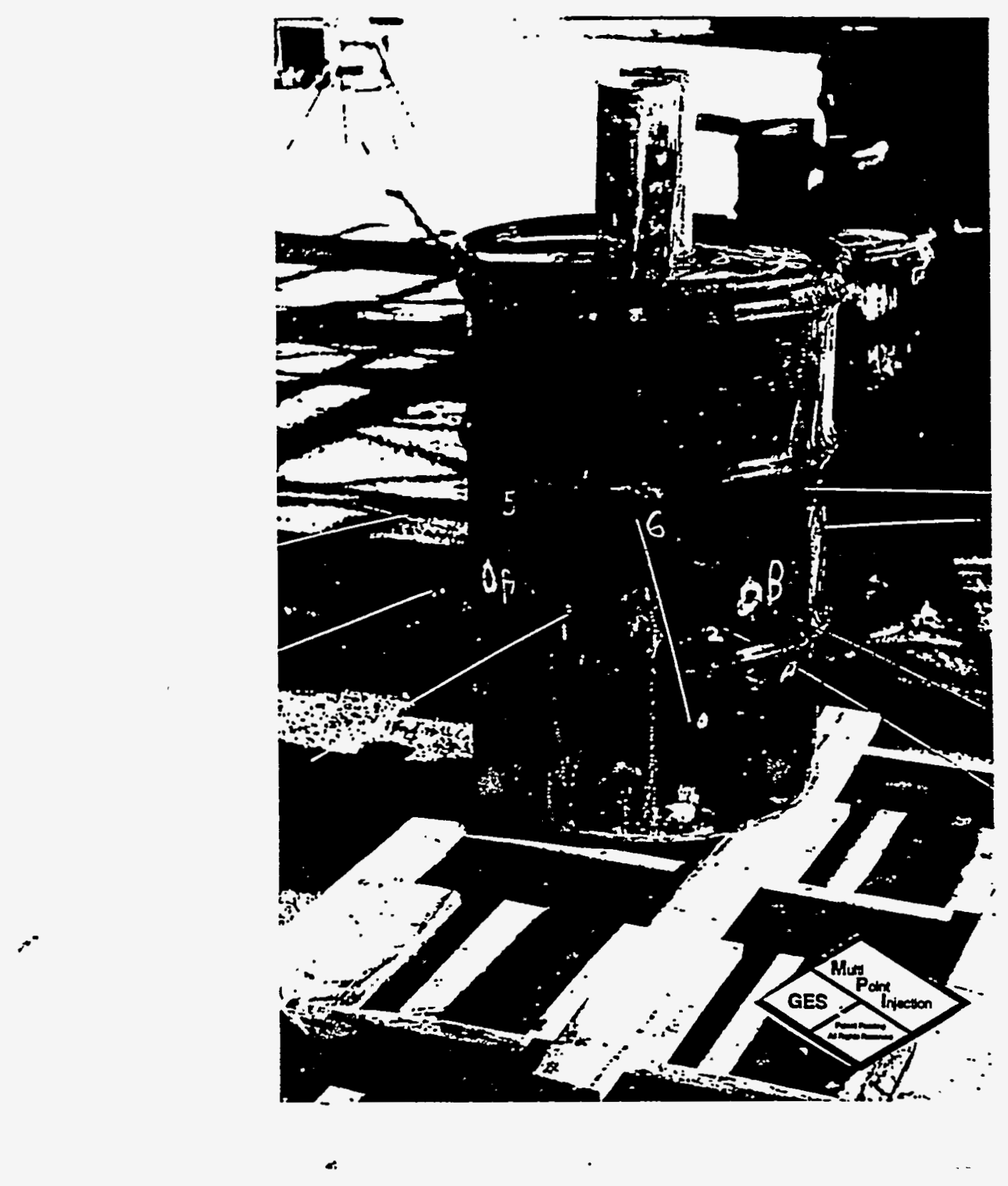

Figure 24 Close-up Photograph Depicting Barrel Cuts Created Using Jet Cutting Ability of MPI Process; MPI Demonstration Salt Lake City 


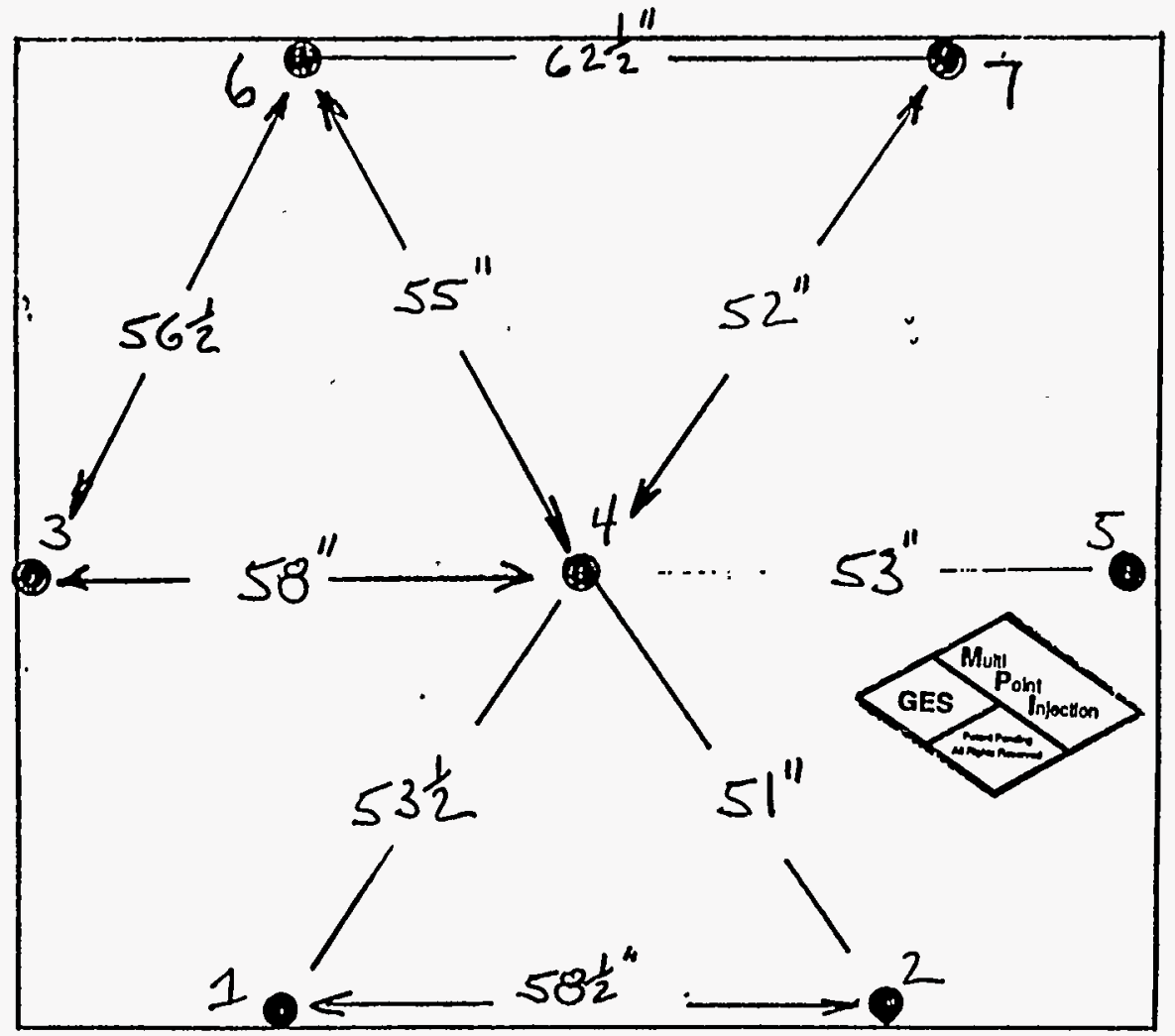

Figure 25. MPI Injection Hole Pattern Used to Solidify Waste in Pit 2 MPI Demonstration Salt Lake City 


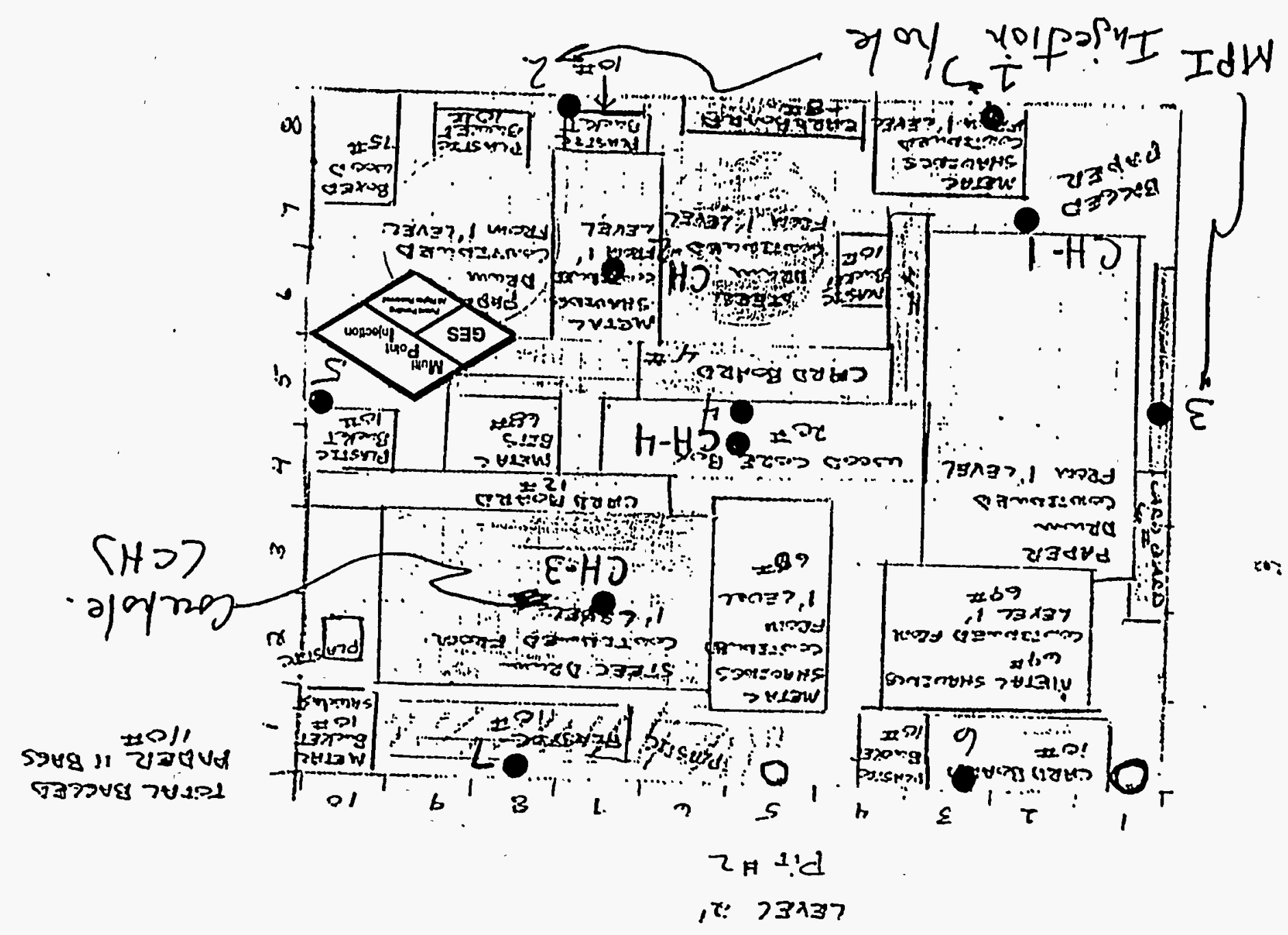

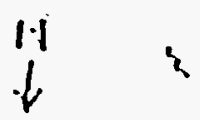



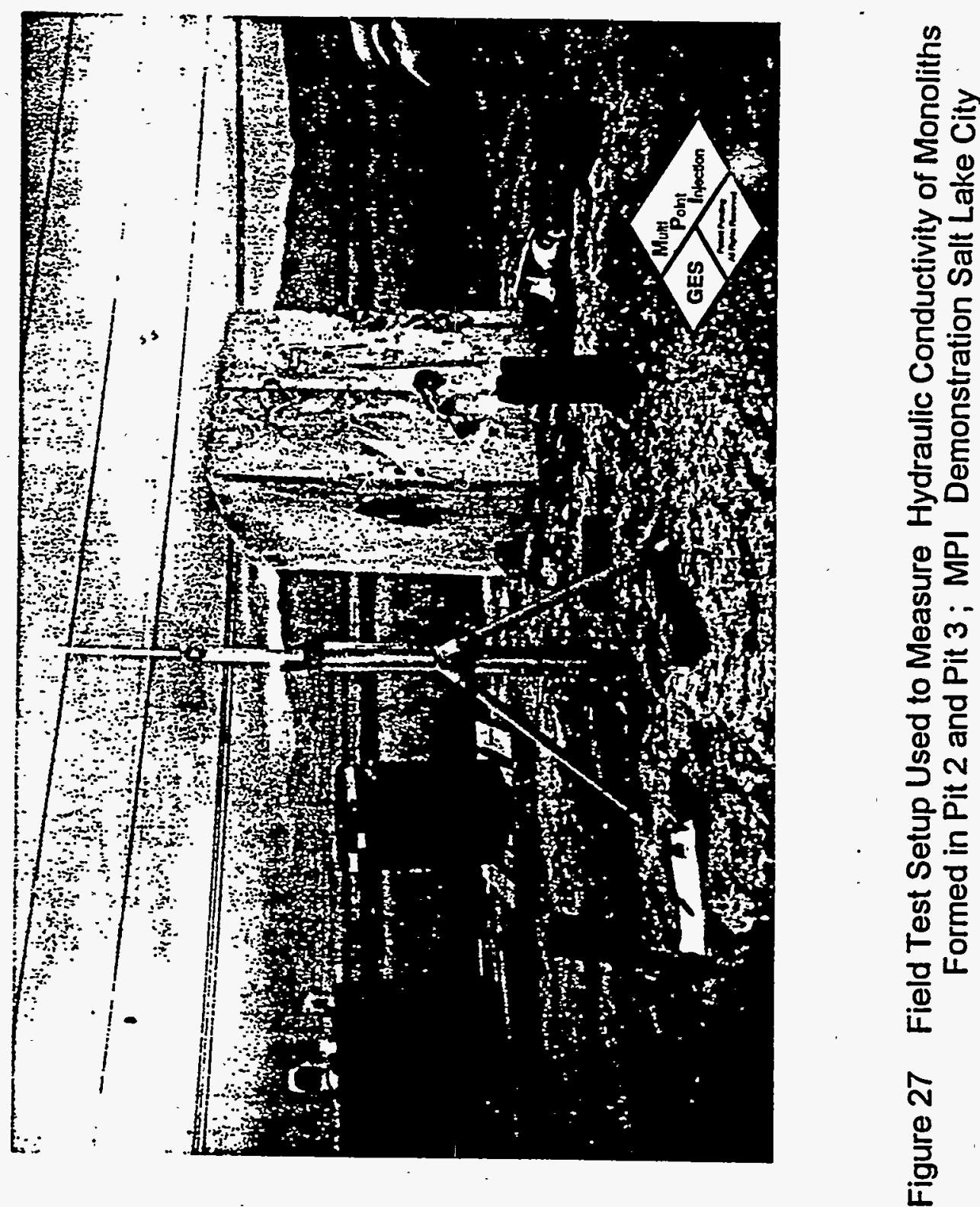


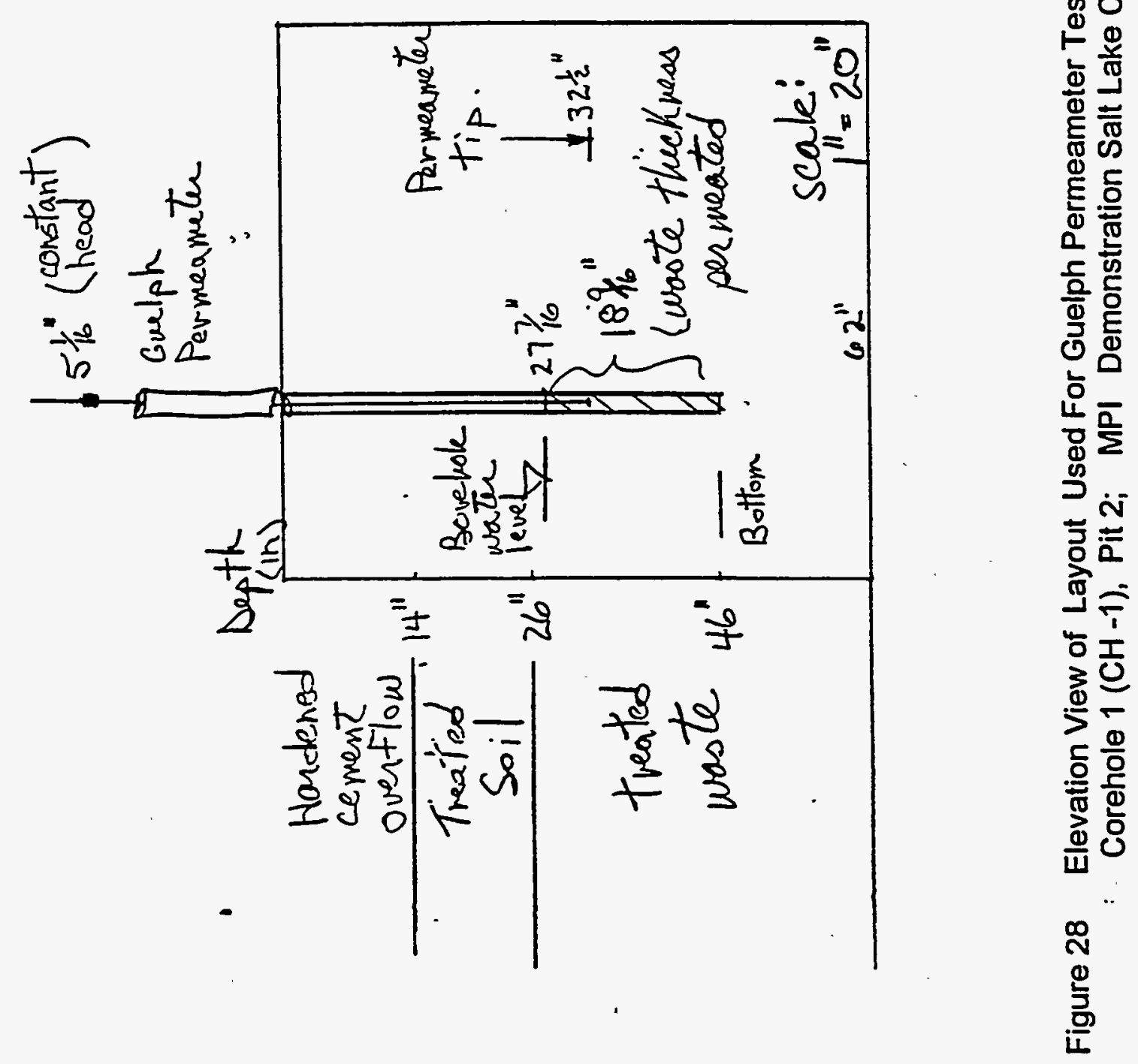




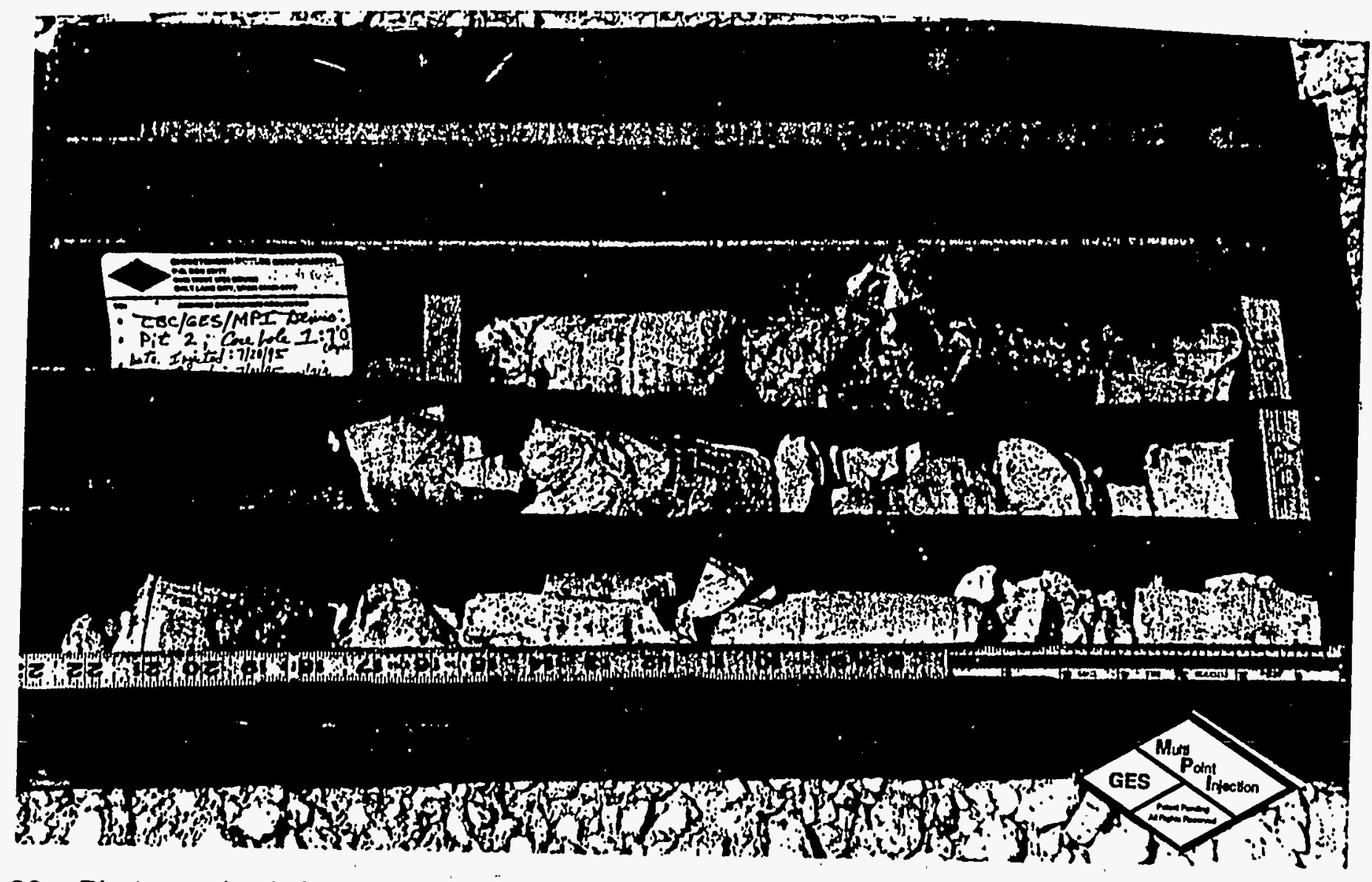

Figure 29 Photograph of Core From MPI Treated Solid Waste Solidified During Y-12/ORNL MPI Demonstration in Salt Lake City

Pit Number : 2

Core Hole:
$\mathrm{CH}-1$
Hydraulic Conductivity Data:

$$
\begin{array}{ll}
\text { Bottom Depth } & =46.0 \mathrm{in.} \\
\begin{array}{l}
\text { Top Depth } \\
\text { Thickness of Waste Tested }
\end{array} & 27.4 \mathrm{in.} \\
\text { Measured Conductivity } & 18.6 \mathrm{in} . \\
\text { Core Recovery } & 3.7 \times \mathrm{E}-07 \mathrm{~cm} / \mathrm{sec} \\
& =52.5 \mathrm{in.} \text { of } 63.6 \mathrm{in}(83 \%) .
\end{array}
$$




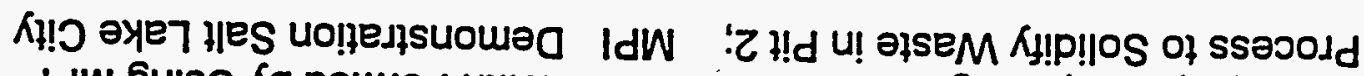

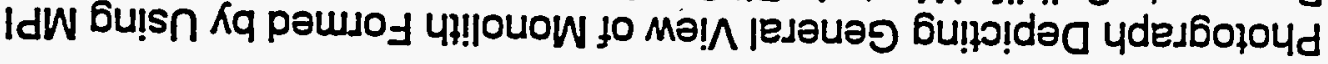

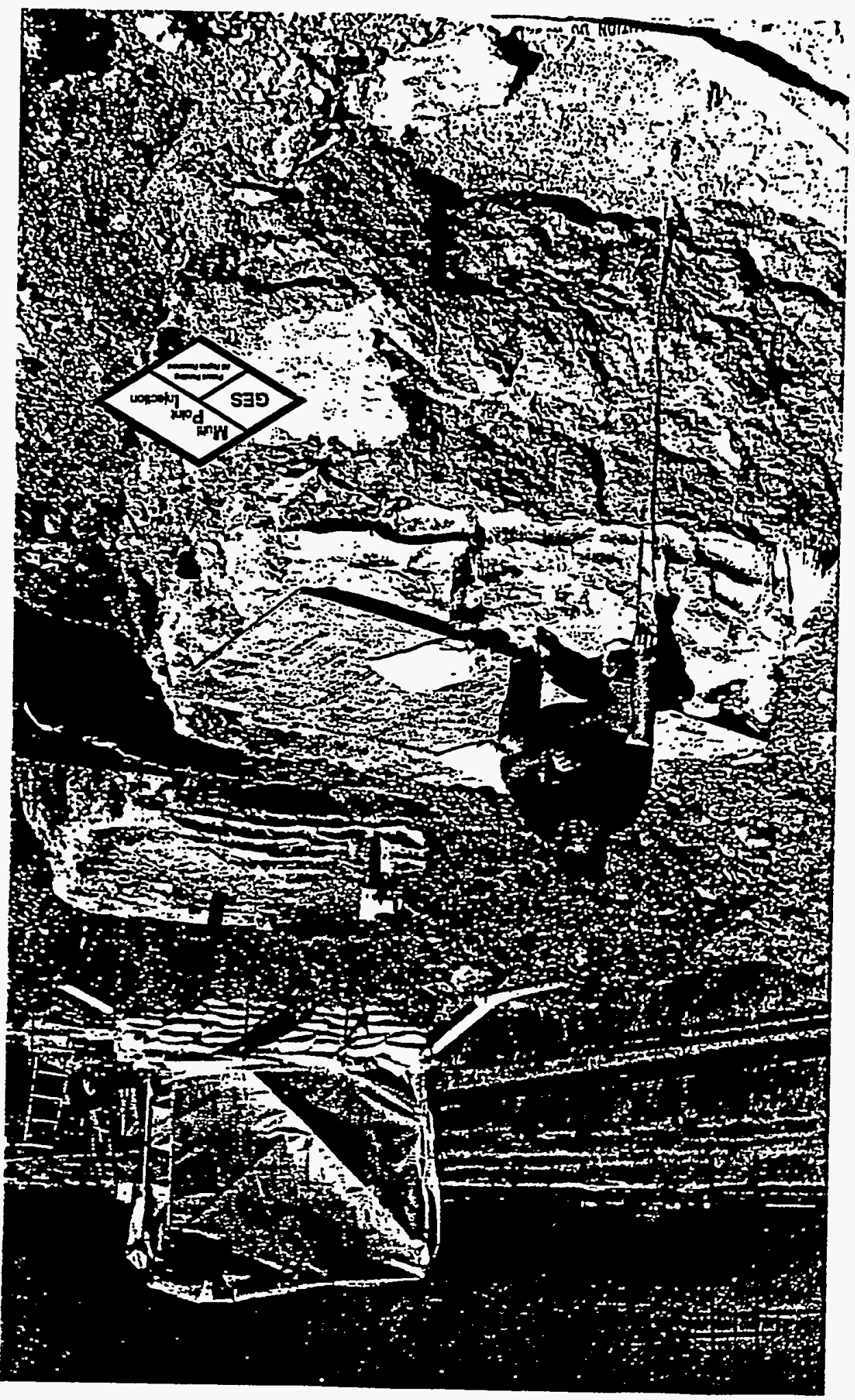




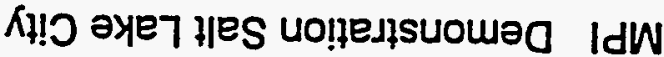

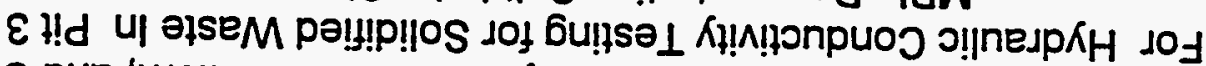

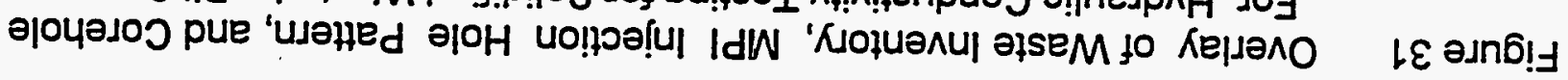

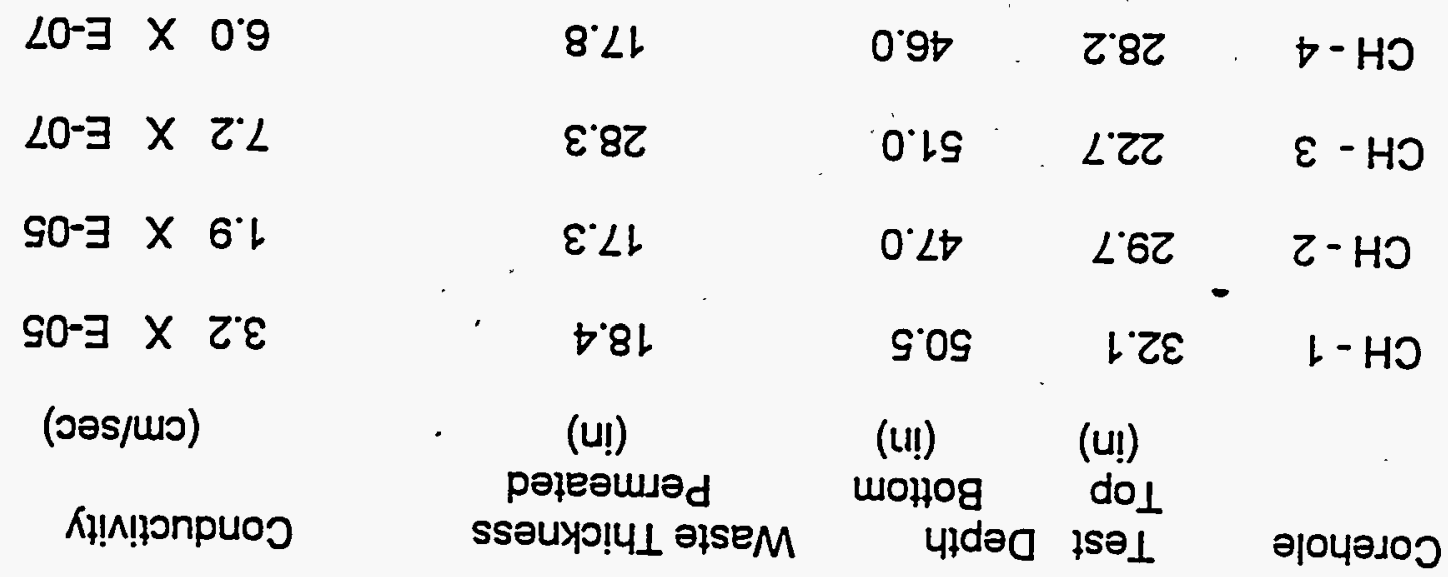

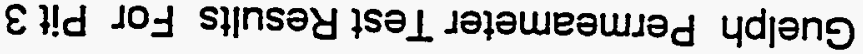

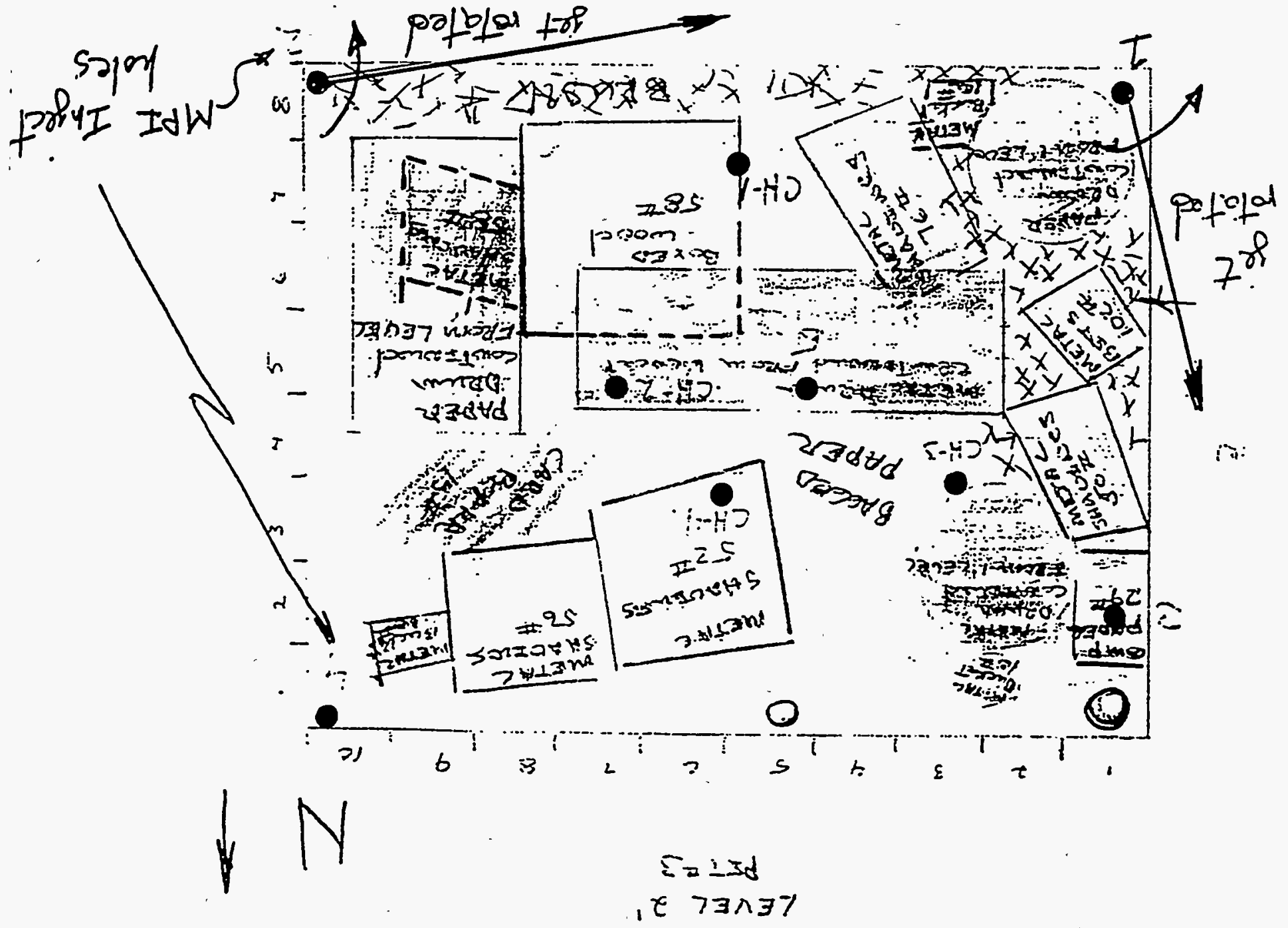




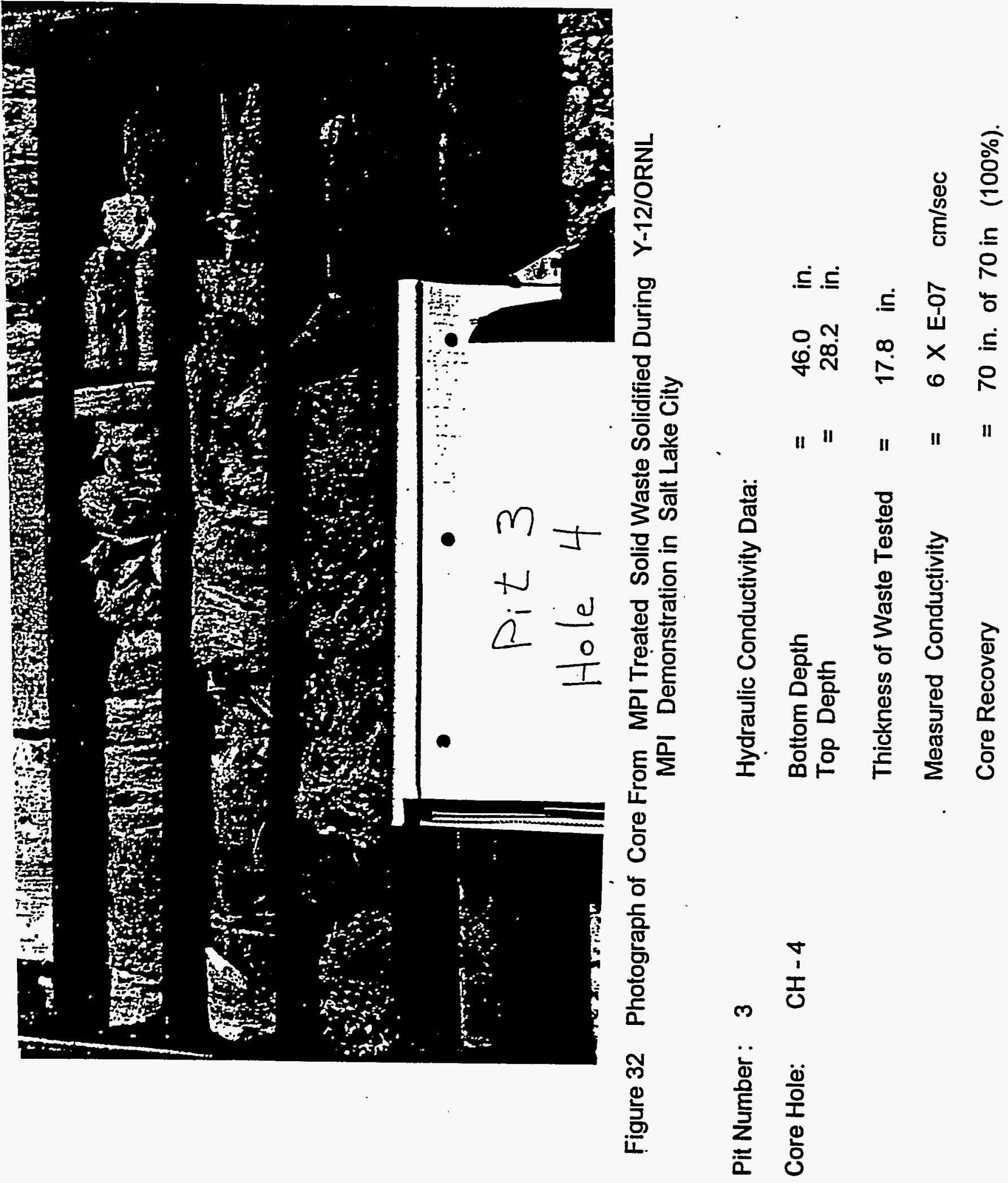




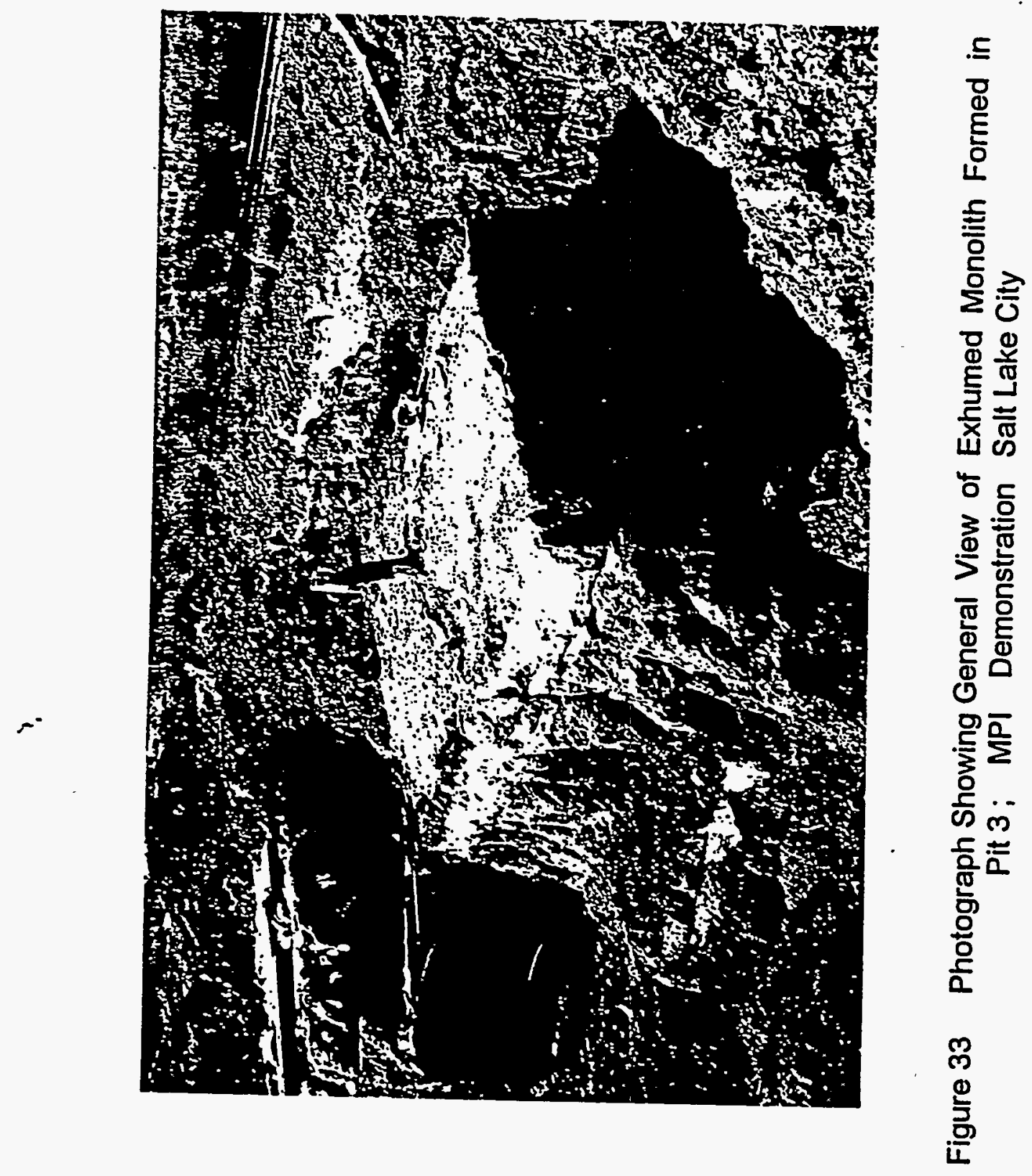




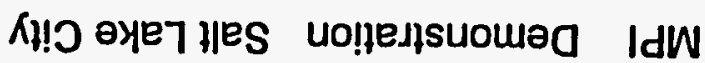

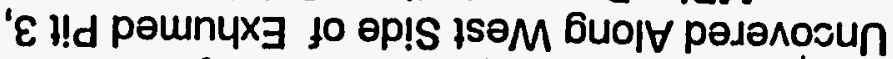

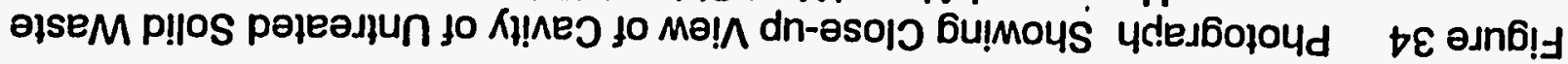

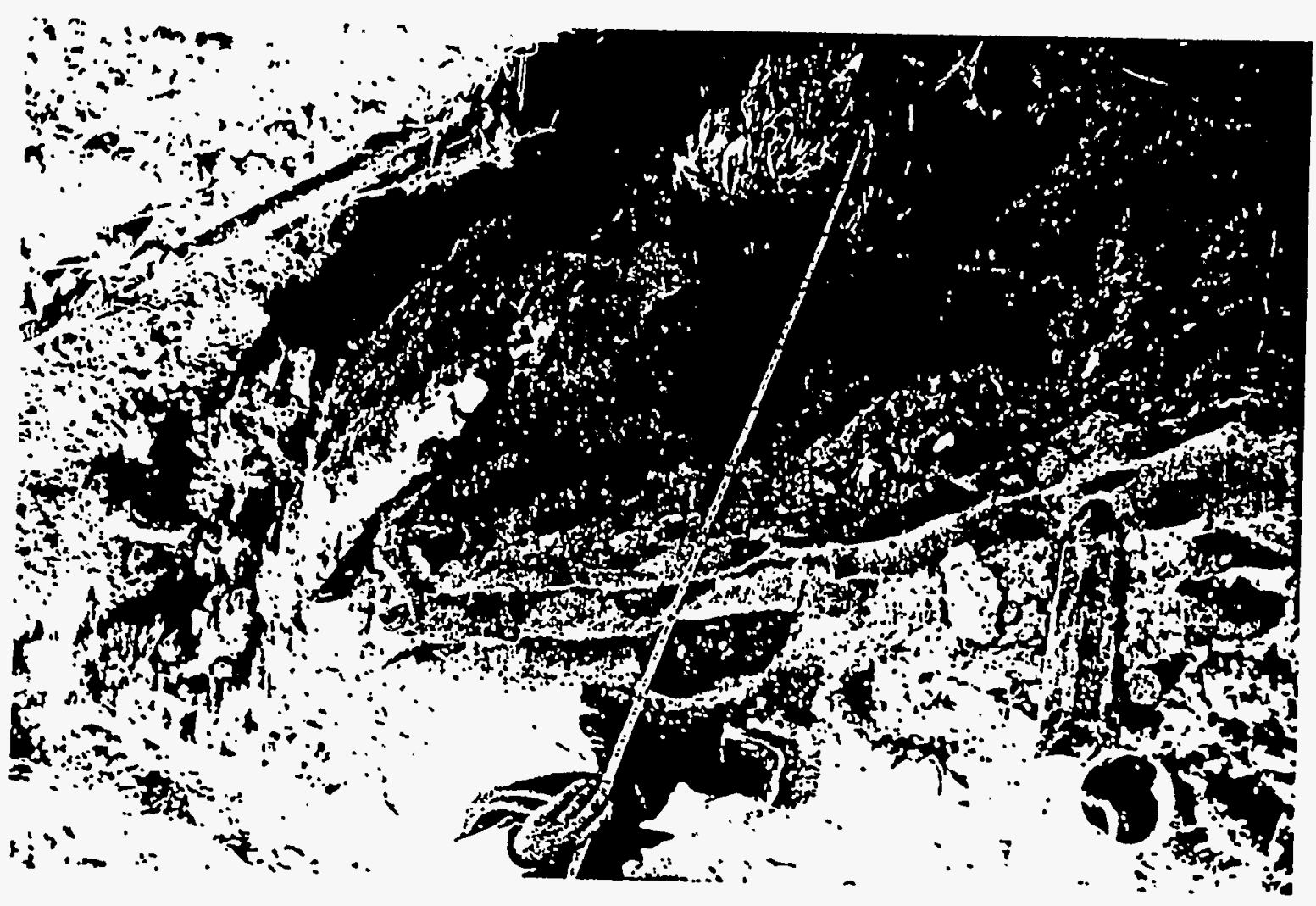




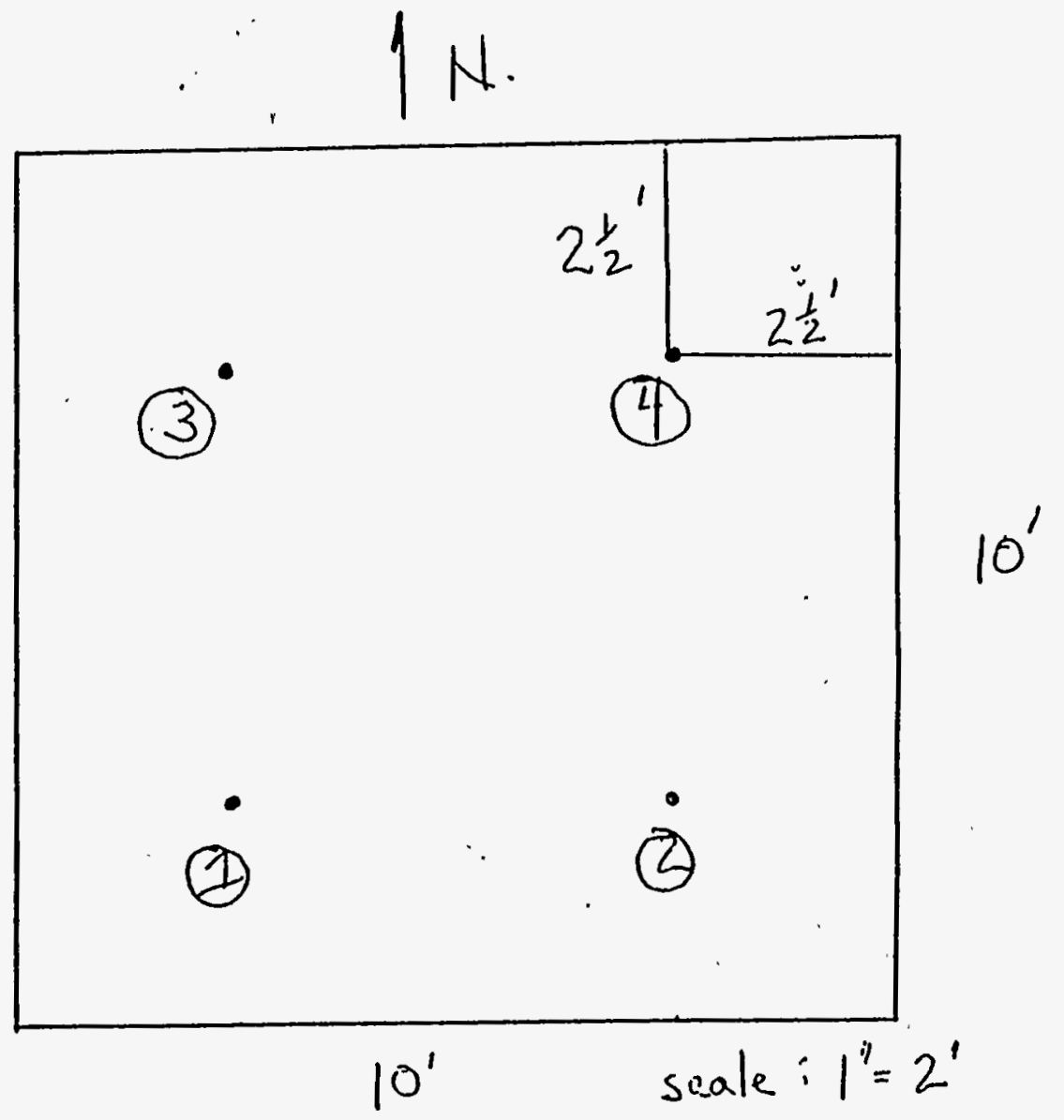

Figure 35 Schematic Illustrating MPI Injection Hole pattern Concrete Vault, MPI Demonstration Salt Lake City 


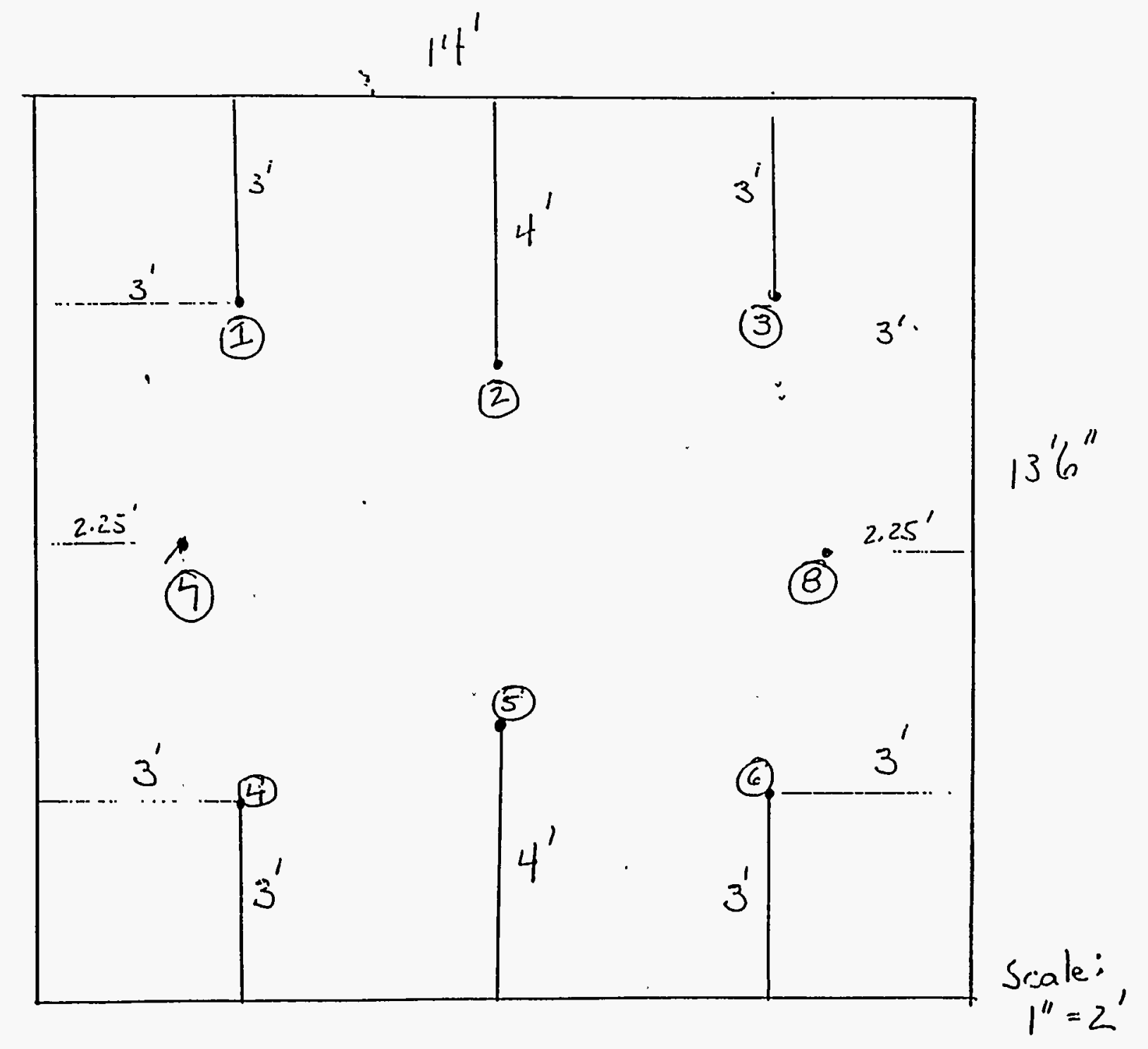

Figure 36 Schematic Illustrating MPI Injection Hole pattern Concrete Vault, MPI Demonstration Oak Ridge, Tennessee 

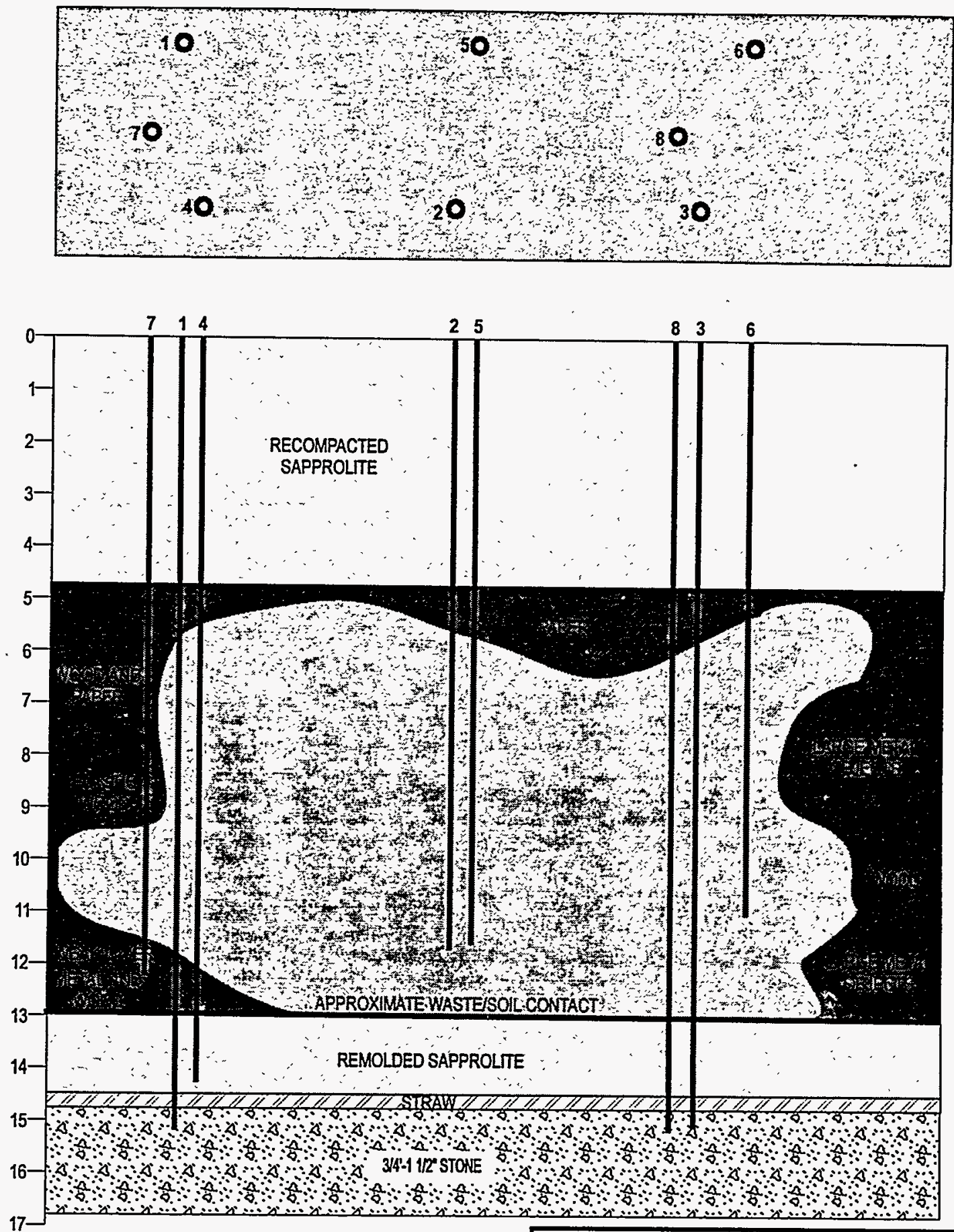

IJ Fig. 37

Plane and elevation view of MPI injection holes for SEG demonstration DOE - ORNL - Oak Ridge, Tennessee

\begin{tabular}{l|l|l}
\hline DOCAMENT 10:35H230 & DRAMANG ID: & DRAWNG DATE: \\
\hline
\end{tabular}




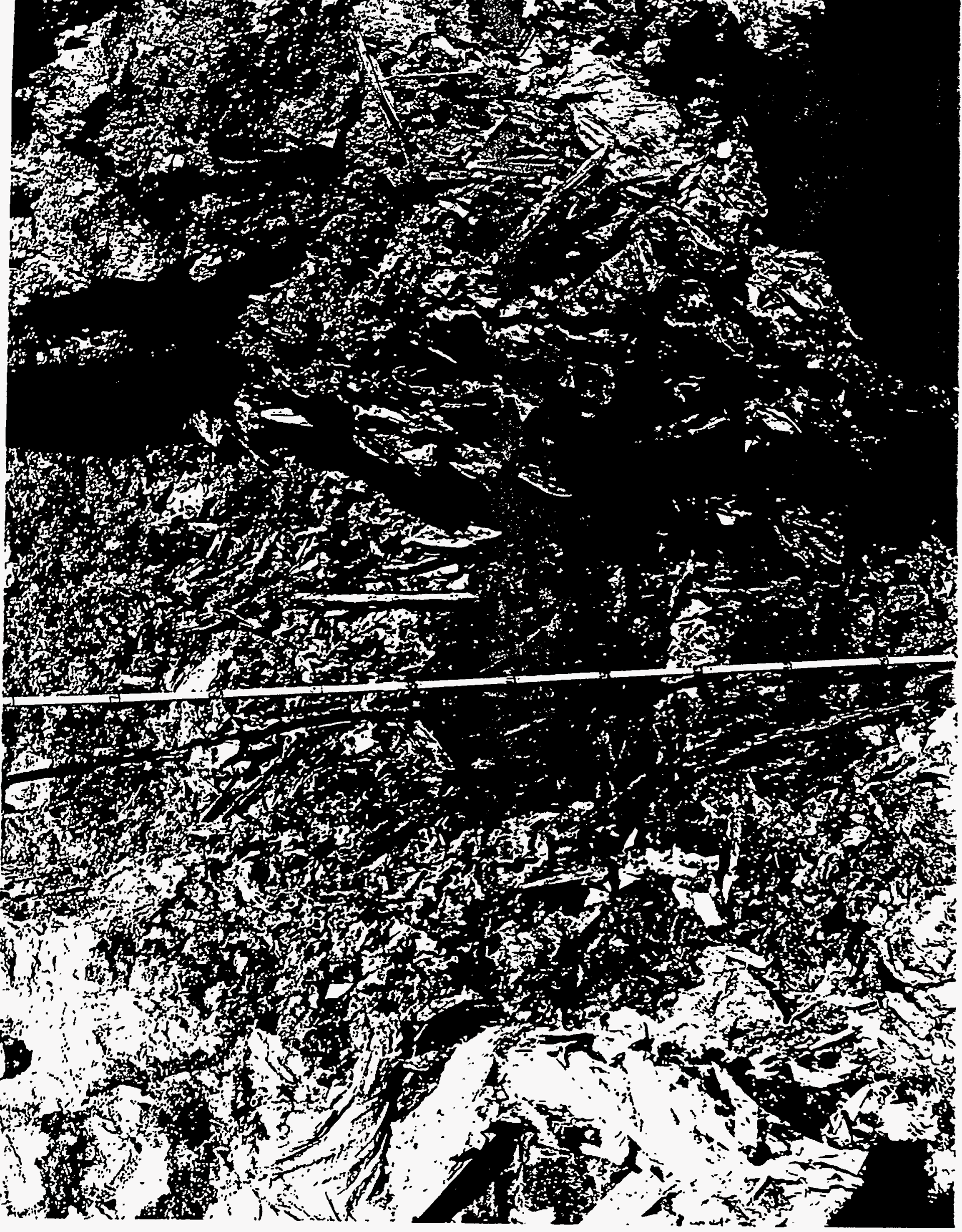

Figure 38

Buried Waste After MPI SEG Demonstration Site 


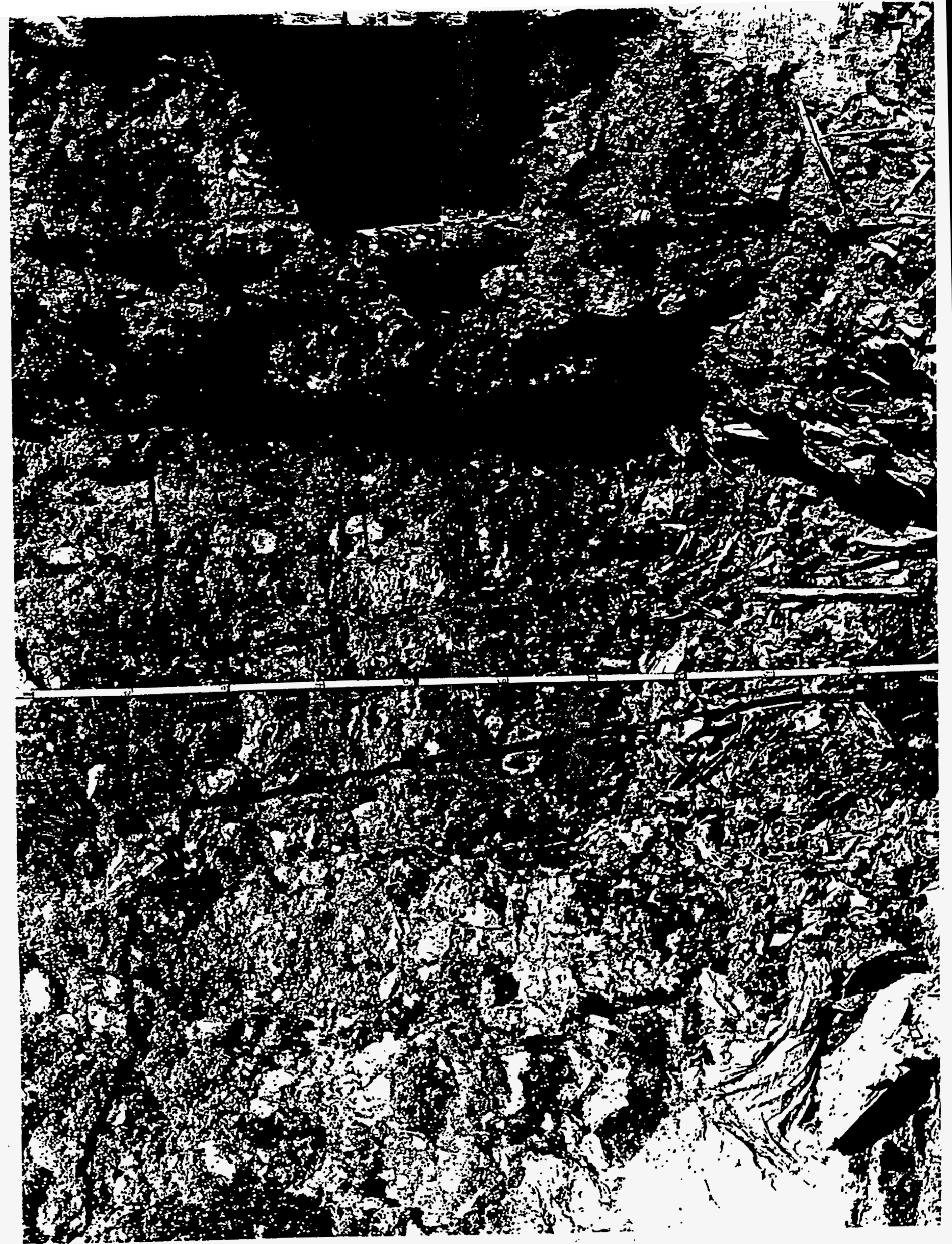

Figure $39 \quad$ MPI of Sapprolite Fill 


\section{DISTRIBUTION}

1. W. D. Brickeen

2. K. W. Cook

3. E. R. Cox, DOE/OS, Room 700N, 1301 Clay Street, Oakland, CA 94612-5208

4. B. Creighton, WETO, P. O. Box 3767, Butte, MT 59702

5. C. W. Francis

6. D. G. Garrett

7. G. Huffman, RFS, Building T116, P. O. Box 928, Golden, CO 80402-0928

8. J. L. Kauschinger, GES, 200 Berryglen Court, Alphabretta, GA 30202

9. C. M. Kendrick

10. J. W. Kubarewicz, Jacobs Engineering, 125 Broadway Avenue, Oak Ridge, TN 37830

11. A. J. Kuhaida

12. W. LaVeille, SRS, Building 703-A, P. O. Box A, Aiken, SC 29802

13. K. Lowe, RFS/ORNL, Building T124A, P. O. Box 928, Golden, CO 80402-0928

14-16. D. M. Matteo

17. S. McMullin, DOE/SRS, P. O. Box A, Building 703-A, Aiken, SC 29802

18. P. Moskowitz, Brookhaven National Lab, Building 830, Upton, NY 11973

19. D. Nickelson, INEL LITCO, P. O. Box 1625, Idaho Falls, ID 83415-3710

20. C. O'Laughlin, NTS, P. O. Box 93518, Las Vegas, NV 39193-3518

21. R. Peters, SEG, 1560 Bear Creek Road, Oak Ridge, TN 37830

22. E. Phillips, DOE/TD

23. D. Pflug, Chicago Site, EAD/900, 9700 South Cass Avenue, Argonne, Il 60439-4832

24. M. Serrato, SRTC

25. R. Shank, SRS/WSRC, Building 730-2B, Room 1035, P. O. Box 616, Aiken, SC 29808

26. R. C. Sleeman, DOE/ORO

27. C. Smith

28. R. Spence

29. S. D. VanHoesen

30. Central Research Laboratory

31. ER Document Management Center-RC

32-33. Office of Scientific and Technical Information, P. O. Box 62, Oak Ridge, TN 37831 